\title{
Flame retardancy of silicone-based materials
}

\author{
Siska Hamdani ${ }^{\mathrm{a}}$, Claire Longuet ${ }^{\mathrm{a}}$, Didier Perrin ${ }^{\mathrm{a}}$, José-Marie Lopez-cuesta ${ }^{\mathrm{a}}$, François Ganachaud ${ }^{\mathrm{b}, *}$ \\ ${ }^{a}$ Centre des Matériaux de Grande Diffusion, Ecole des Mines d'Alès, 6 avenue de Clavières 30319 ALES Cedex, France

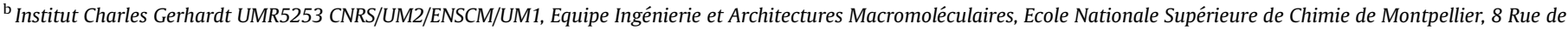 \\ l'Ecole Normale 34296 Montpellier Cedex, France
}

\section{A B S T R A C T}

This review describes some recent works related to the development of the flame retardation of silicone elastomers and/or applications of silicones as flame retardant agents in other polymers. First, the thermal degradation of silicones themselves is discussed, focussing on depolymerization mechanisms, effect of structure, heating conditions, and effect of additives (i.e. less than $5 \mathrm{wt} \%$ fillers) on thermal degradation of silicones. Then, the influence of several types of mineral fillers (of up to $80 \mathrm{wt} \%$ content) as ceramization agents of silicones is presented. Finally, the introduction of (functionalized) silicones as flame retardants into other polymers is described.

Keywords:

Flame retardancy

Silicone

Mineral fillers

Ceramization

\section{Introduction}

Synthetic polymers are a crucial part of today's life, they can be found nearly everywhere. Today, synthetic polymer materials are rapidly replacing more traditional materials such as metals, ceramics, and natural polymers such as wood, cotton, natural rubber etc. However, one weak aspect of synthetic polymer materials compared with other materials is that polymers are combustible. Thus, the majority of polymer-containing end-products (e.g., cables, carpets, furniture cabinets, etc.) must have a satisfactory degree of fire resistance to ensure public safety from fire. Silicone materials have been produced commercially since the beginning of the 1940s. Over the past 60 years, silicone materials have grown into a billion-dollar industry, and are used in many applications in civil engineering, construction building, electrical, transportation, aerospace, defence, textiles, and cosmetics industries [1]. The dominant polymer in the silicone industry is polydimethylsiloxane (PDMS). The main structural elements of polysiloxanes have direct or indirect influence on their stability at elevated temperatures, including: inherent strength of the siloxane ( $\mathrm{Si}-\mathrm{O})$ bond, pronounced flexibility of the $-[\mathrm{Si}-\mathrm{O}]_{x^{-}}$chain segments, and entropically higher stability of low molecular weight cyclic siloxanes compared to their high molecular weight linear counterparts

\footnotetext{
* Corresponding author. Tel.: +33 4671472 96; fax: +33 467147220 .

E-mail address: francois.ganachaud@enscm.fr (F. Ganachaud).
}

against thermal degradation [2]. Silicones have comparatively low heat release rates $(\mathrm{HRR})^{1}$, minimal sensitivity to external heat flux and low yields of carbon monoxide release. The HRR for most silicones falls within the range of $60-150 \mathrm{~kW} \mathrm{~m}^{-2}$ [3]. Silicones also show a slow burning rate without a flaming drip and when pure, no emissions of toxic smokes. Based on these fire properties, silicones offer significant advantages for flame retardant applications. It is not surprising that due to their properties against flames, PDMS has been put in the top list of polymers for applications at high temperature such as in electrical wires and cables. Unlike organic polymers, silicones exposed to elevated temperatures under oxygen leave behind an inorganic silica residue. The shielding effects provide some of the fundamentals for the development of silicone-based fire retardants. Silica residue serves as an "insulating blanket", which acts as a mass transport barrier delaying the volatilization of decomposition products. Therefore, it reduces the amount of volatiles available for burning in the gas phase and thus, the amount of heat that feeds back to the polymer surface. The silica residue also serves to insulate the underlying polymer surface from incoming external heat flux. It was reported by Hshieh [4] that the silica ash layer integrity governs the efficiency of the diffusion barrier that restricts the diffusion of fuels into the combustion zone and the access of oxygen to the unburned fuels. Even if the strength

\footnotetext{
${ }^{1}$ Readers not familiar with techniques applied to polymer to determine their flame retardancy are directed to Appendix, where their basics are briefly described.
} 
of the silica powder obtained by firing silicone polymer alone in air varies with the temperature ramp and final temperature, by no means however does it exhibit enough cohesion for any useful structural applications. Various methods have then been proposed for forming inorganic protective layers on the surface of burning polymers, since inorganic filler particles act through a dilution effect and reduce heat feedback due to large amount of ash [5]. The physical network formed by such additives of high surface area (e.g. aerosil) in the polymer melt also reduces dripping but, on the other hand, significantly restricts the processability of such systems. Similar problems occur when porous fillers like zeolites are used in high concentrations, especially if the average pore size ( $>10 \mathrm{~nm}$ ) allows the polymer chains to penetrate [6]. For instance, Mansouri et al. [7] improved the strength of PDMS residue by adding certain inorganic fillers into silicone-based polymers to generate ceramics with good integrity and shape retention after firing at temperatures up to $1050{ }^{\circ} \mathrm{C}$. More research described in this review addresses current efforts to improve flame retardant properties of silicone, including addition of fillers, modification of the structure of silicone by incorporation of flame retardant heteroatoms into siloxane backbone, or formulation issues. This review aims at describing most of the recent work related to the applications of silicones as flame retardant agents and/or development in the flame retardation of silicones themselves. Though trying to be as exhaustive as possible, all publications dealing with the flame retardancy of silicone, particularly patents, may not have been quoted here. This review is divided into three main parts. First, the thermal degradation of silicones is discussed, focusing on depolymerization mechanisms, effect of structure, heating conditions, and effect of additives (i.e. less than $5 \mathrm{wt} \%$ fillers) on the thermal degradation of silicone. Then, the influence of several types of mineral fillers (in contents up to $80 \mathrm{wt} \%$ ) as ceramization agents of PDMS is presented. Finally, the introduction of PDMS or functionalized PDMS as flame retardants into other polymers is described.

\section{Thermal degradation of silicones}

\subsection{Depolymerization}

Numerous studies have already established that the differences in degradation behaviour of polysiloxanes result from two main factors: (i) the type and concentration of polymer end-groups and (ii) the presence of catalytic amounts of impurities in the polymer. The depolymerization process is thus a conjunction of three different reaction mechanisms, named "unzipping", "random scission", and "externally catalyzed" mechanisms [2].

\subsubsection{Unzipping reaction}

Polysiloxanes containing silanol ( $\mathrm{Si}-\mathrm{OH}$ ) (and to a lower extent hydroxyalkyl $\mathrm{Si}-\mathrm{R}-\mathrm{OH}$ ) end-groups are principally depolymerized by the "unzipping" mechanism. As the polymer is heated, its viscosimetric molecular weight first sharply increases, which is typical of an intermolecular reaction between the polymer chainends through silanol condensation reactions. Further increasing the temperature leads to a decrease of the polymer molecular weight.
Indeed, silanol functions can 'back-bite' to promote intramolecular redistribution reactions which generate low molecular weight cyclic siloxanes, as shown in Scheme 1. Cyclic trimer and tetramer are the most prominent products of this fragmentation because of their thermodynamic stability at the temperatures of degradation. Their evaporation adds an additional driving force for the completion of the degradation process. The decrease in molar mass was found to be linear with the extent of volatilization, confirming the stepwise nature of the formation of volatiles characteristic of the unzipping reaction. The thermally weakest bond in PDMS is the $\mathrm{C}-\mathrm{Si}\left(326 \mathrm{~kJ} \mathrm{~mol}^{-1}\right)$ bond, however the cyclic oligomers formed by its decomposition suggest that the $\mathrm{Si}-\mathrm{O}$ bond $\left(451 \mathrm{~kJ} \mathrm{~mol}^{-1}\right)$ should break instead. This fact suggests that the depolymerization of PDMS could be governed mainly by the molecular structure and kinetic considerations, and not by bond energies. According to Camino et al. [8] the formation of an intramolecular, cyclic transition state is the rate-determining step. Silicon d-orbital participation was postulated with siloxane bond rearrangement leading to the elimination of cyclic oligomers and shortening of the chain.

\subsubsection{Random scission reaction}

Polysiloxanes end-capped with inert groups (most likely trimethylsilyl moieties) [2] are degraded either by inter- or intramolecular redistribution reactions that occur randomly between the siloxane bonds of the polymer backbone. The thermal degradation mechanism of PDMS results in the formation of the smallest cyclic product, hexamethylcyclotrisiloxane, as illustrated in Scheme 2. Random scission requires a sufficient flexibility of the polymer chain segments, high polarity of the siloxane bonds, and higher thermodynamic stability of the degradation products than that of the reagents (i.e. open chain macromolecules). This reaction is always possible when polymers are exposed to high enough temperatures. In a clear contrast to unzipping, the random scission mechanism results in a dramatic decrease of polymer molecular weight from the very onset of the degradation and in simultaneous broadening of the molecular weight distribution. Both effects are ascribed to the most probable location for the occurrence of random scission being towards the middle of the polymer chain. The transition state can be formed at any point of the polymer chain, and splitting of PDMS chains proceeds until the residual linear structure is too short to form new cycles and/or the evaporation of the shortened chain fragments favourably competes with cyclization. Thermal oxidation to $\mathrm{SiO}_{2}, \mathrm{H}_{2} \mathrm{O}, \mathrm{CO}_{2}$ mostly takes place by reaction in the gas phase between oxygen and volatile cyclic oligomers formed by thermal degradation, the latter increasing smoke opacity. In addition, holes form in the material, which leads to the loss of the integrity of the residue after combustion. Radhakrishnan [9] has evaluated the degradation of hydroxyl- and vinyl-terminated PDMS. Vinyl-terminated PDMS depolymerizes by random decomposition along the chain, whereas hydroxyl-terminated PDMS depolymerizes through its chain-ends as well as by random decomposition, making this latter less stable against thermal degradation. The relative contribution of each process to depolymerization depends on the temperature of degradation (random scission predominates at high temperatures), but also on

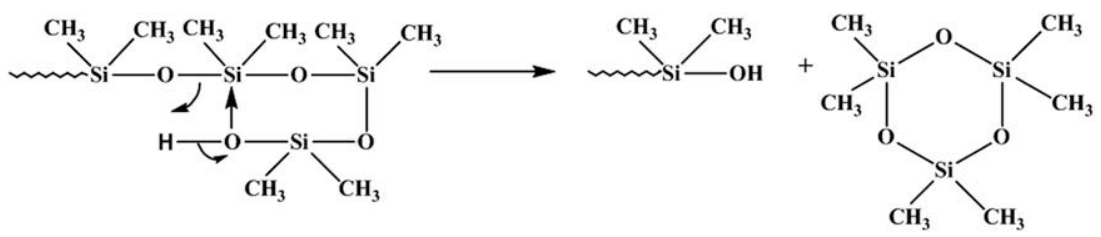

Scheme 1. Intramolecular mechanism of degradation of the hydroxyl-terminated PDMS by unzipping reaction. 

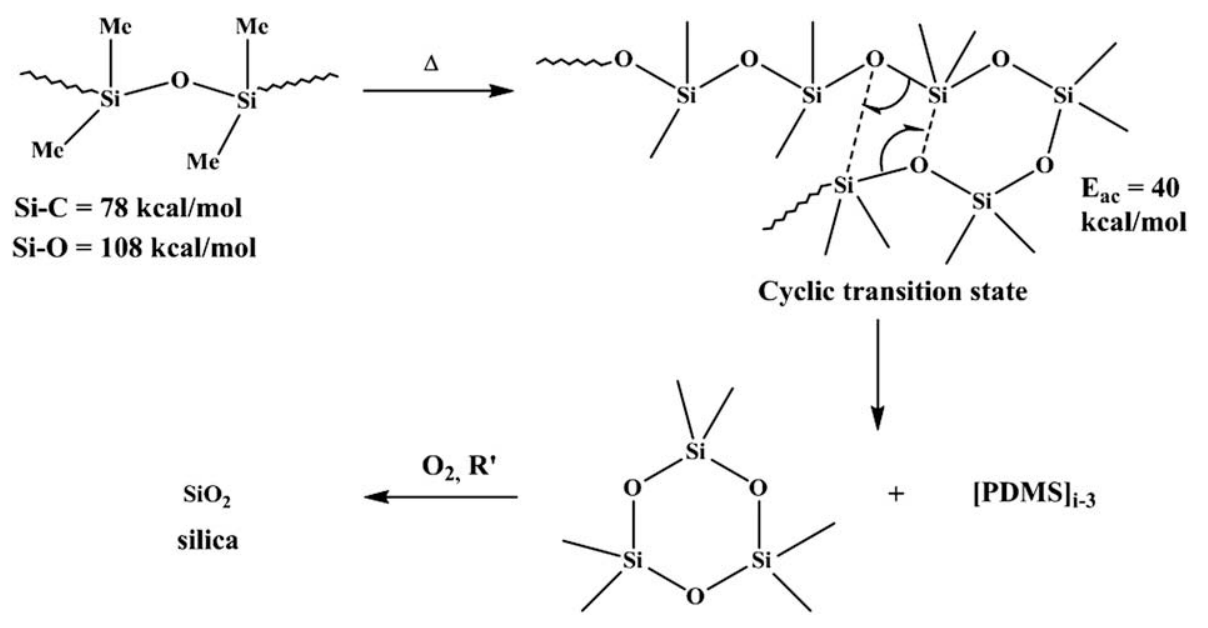

Scheme 2. Depolymerization mechanism of PDMS by random scission.

sample history and pyrolysis conditions. Decomposition products of silanol and vinyl-terminated PDMS at elevated temperatures and under inert atmosphere are principally some cyclic oligomers, with small amounts of methane and traces of linear oligomers (see also part 2.3.1 [9]).

\subsubsection{Externally catalyzed reaction}

Polysiloxanes which contain ionic, polar impurities or additives, even in very small amounts, are degraded by externally catalyzed mechanism [2]. In contrast to unzipping and random scission, this mechanism involves hydrolytic cleavage of the $\mathrm{Si}-\mathrm{O}$ backbone bonds by foreign species, which initiate the degradation process as shown in Scheme 3. Like random scission, the extent of the externally catalyzed reaction depends on the nature of polymer end-groups. Such degradation frequently yields unusual byproducts (such as methane), which results from reactions between two methyl groups (vide infra). In fact, the presence of ionic impurities in polysiloxanes may completely ruin the exceptional thermal properties of PDMS even at moderate temperatures [2]. For instance, Grassie and Macfarlane [10] showed that the presence of traces of $\mathrm{KOH}$ (a conventional catalyst of ring opening polymerization or polycondensation) caused an accelerated decomposition of the polymer by forming many short oligomers such as those presented in Scheme 3, accompanied by the formation of siloxy ion.

\subsection{Oxidative vs. inert degradation}

According to Camino et al. [11], the products of the thermal degradation of polydimethylsiloxane (PDMS) are determined by the heating conditions and the nature of the gaseous environment, where two thermal mechanisms of degradation, i.e. molecular and radical mechanisms, are competing.

\subsubsection{Molecular mechanism}

The molecular mechanism implies $\mathrm{Si}-\mathrm{O}$ bond scission that takes place at low temperature range and during slow heating, leading to the formation of cyclic oligomers. Camino et al. [8] studied the thermal degradation of PDMS end-blocked with trimethylsiloxy groups at different heating rates. At a slow heating rate of $1{ }^{\circ} \mathrm{C} \mathrm{min}^{-1}$, thermal oxidative degradation of PDMS is significantly different from degradation under a nitrogen flow (Fig. 1(a)). In the presence of nitrogen, one step of thermal degradation beginning at $514^{\circ} \mathrm{C}$ produces a mixture of oligomers, whereas in presence of air, at least two stages of degradation are observed, the first starting at $339^{\circ} \mathrm{C}$ and the second at $400{ }^{\circ} \mathrm{C}$. In both steps the major degradation products are similar to those produced in inert atmosphere, i.e. composed of various oligomers, but with additional $\mathrm{CO}_{2}$ and water. In this case as well, finely divided silica powder appears at $500{ }^{\circ} \mathrm{C}$ for a final residue around $60 \%$. The two-step process can be explained by assuming that oxygen catalyzes the depolymerization of PDMS to volatile cyclic oligomers, leading to a temperature of initial weight loss lower $\left(290^{\circ} \mathrm{C}\right)$ than that observed in nitrogen $\left(400^{\circ} \mathrm{C}\right)$. This process competes with oxidative crosslinking which stabilizes the material. Further decomposition to cyclic oligomers occurs above $400{ }^{\circ} \mathrm{C}$, as in nitrogen, although accelerated by competing oxidation. Interaction of oxygen with the degrading condensed phase depends on a complex competition between oxygen diffusion and solubility, on one hand, and degradation reaction and product evaporation on the other hand. At a higher heating rate of $50{ }^{\circ} \mathrm{C} \mathrm{min}^{-1}$, weight loss shifts to a higher temperature both in nitrogen and in air (Fig. 1(b)) and the final silica residue decreases to $10 \%$. At this rate, chemical reactions start to occur at higher temperatures than before, where the solubility of oxygen in the condensed phase decreases and the rate of thermal degradation reactions increases, making the heterogeneous phase reaction of active species with oxygen less probable. The first step of weight loss in air overlaps with the second, while stabilization<smiles>C[Si](C)(O)O[Si](C)(C)O[Mg]</smiles>

Scheme 3. Degradation of PDMS by externally catalyzed mechanism (here provoked by a hydroxyl anion). 

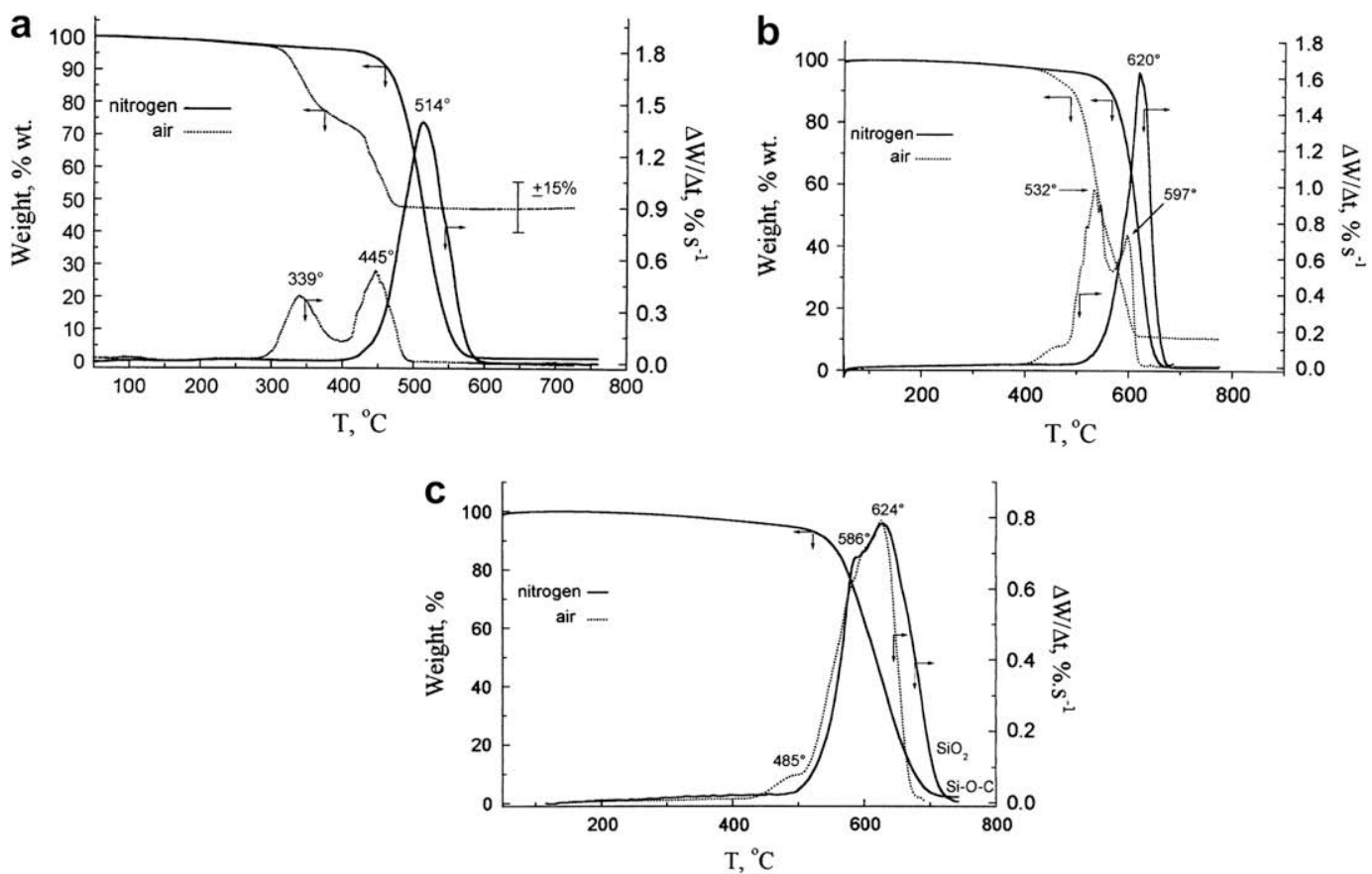

Fig. 1. TG and DTG curves of PDMS in nitrogen (solid line) and in air (dotted line) at a heating rate of (a) $1^{\circ} \mathrm{C} \mathrm{min}{ }^{-1}$, (b) $50{ }^{\circ} \mathrm{C} \mathrm{min}{ }^{-1}$, and (c) $100{ }^{\circ} \mathrm{C} \mathrm{min}{ }^{-1}[8]$.

induced by oxidative crosslinking takes place. Finally, at a heating rate of $100^{\circ} \mathrm{C} \mathrm{min}^{-1}$, thermal degradation behaviour of PDMS in nitrogen and in air tends to overlap. In nitrogen fluxed degradation, a small amount (4\%) of a black residue (e.g. silicon carbide or oxycarbide) was observed at $700-800{ }^{\circ} \mathrm{C}$ (Fig. 1(c)). In thermooxidative degradation, such black stable residue was difficult to detect in an overwhelming amount of white silica. Here, the thermal decomposition is strongly reduced due to the low rate of reaction between the material and oxygen, low oxygen solubility and high thermal degradation rate. The direct reaction of oxygen with the condensed phase either does not take place or at a limited extent. Another study by Camino et al. [11] showed that the heating rate influences the nature of volatile products formed during the thermal degradation of PDMS in helium or in air. At a slow heating rate of $10^{\circ} \mathrm{C} \mathrm{min}^{-1}$, cyclic oligomers, with trimer as primary product, were exclusively formed. Whereas at fast heating rate ( $80^{\circ} \mathrm{C} \mathrm{min}^{-1}$ up to $800^{\circ} \mathrm{C}$, also called "flash pyrolysis"), formation of cyclic oligomers, tetramer being the most abundant one, was accompanied by the generation of linear pentasiloxane or rearranged oligomeric siloxane compounds (e.g. tetrasiloxane, 3,5diethoxy-1,1,1,7,7,7-hexamethyl-3,5-bis(trimethylsiloxy)).

\subsubsection{Radical mechanism}

The radical mechanism occurs through homolytic $\mathrm{Si}-\mathrm{CH}_{3}$ bonds scission, which prevails at high temperatures and results in oligomers and methane release (Scheme 4). Cross-linking of the macroradicals by coupling of radicals I and II decreases the flexibility of the PDMS chain and hinders further splitting of cyclic oligomers. The thermal stability of this heavily crosslinked PDMS increases and reorganization of atomic bonds can take place with formation of black ceramic silicon-oxycarbide.

\subsection{Structure/degradation relationship}

From the different thermal degradation pathways presented above, it is anticipated that certain types of polysiloxanes will display higher thermal resistance than others. The chemical nature of polymer functional groups (either at the end or inside the chain) as well as their molecular weight has been shown to influence the degradation of PDMS significantly.

\subsubsection{Influence of end-groups}

As briefly depicted above, Grassie and Macfarlane [10] showed that hydroxyl end-groups lower the thermal stability of PDMS considerably compared to vinyl or methyl end-groups because of "back-biting" reactions. The product of degradation of pure hydroxyl-terminated PDMS is a mixture of cyclic oligomers with the trimer predominating and steadily decreasing amounts of tetramer, pentamer, etc. Grassie and Macfarlane [10] also reported that the replacement of hydroxyl end-groups by methyl enhances the thermal stability of PDMS considerably whereas no change in the distribution of by-products was observed. Jovanovic et al. [13] suggested that vinyl end-groups, as compared to methyl, change the degradation mechanism of the polysiloxanes. Introduction of vinyl end-groups decreases the thermal stability and thermooxidative stability of PDMS by reducing the amount of degradation residue in comparison with methyl end-groups. Later on, Radhakrishnan [9] reported that the decomposition products of

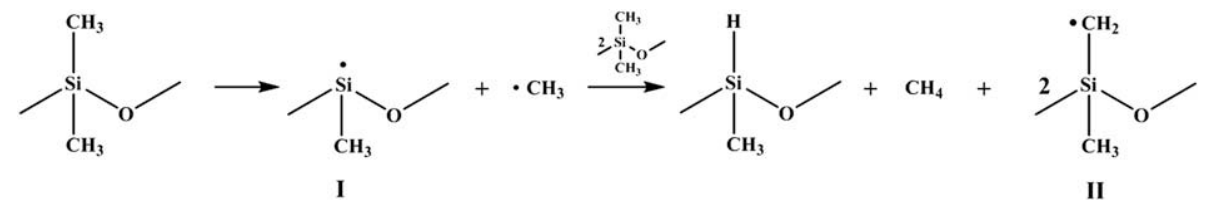

Scheme 4. Proposed radical mechanism in silicone thermal degradation. 
vinyl-terminated PDMS at elevated temperatures are principally cyclic oligomers, with small amounts of methane and traces of linear oligomers. This conclusion was also supported by Deshpande and Rezac [12] who reported that the decomposition products of vinyl-terminated PDMS at $364^{\circ} \mathrm{C}$ are principally the cyclic oligomers, hexamethyltrisiloxane (trimer) and octamethyltetrasiloxane (tetramer).

\subsubsection{Influence of side-groups}

Jovanovic et al. [13] found that the introduction of methylhydridosiloxy units in the polysiloxane backbone decreases their thermal stability in comparison to the dimethylsiloxy units. PDMS is thermo-oxidatively more stable than $\mathrm{Si}-\mathrm{H}$ based homo- or copolymers, i.e. degradation starts at lower temperatures for these latter. On the other hand, the final content of residue is always larger for the $\mathrm{SiH}$-based copolymers, presumably because crosslinking reactions occur both in air and under nitrogen. In contrast, substituting methyl by vinyl groups in the PDMS backbone decreases the weight loss after thermal degradation. Grassie and Macfarlane [10] studied the effect of incorporating phenyl groups into siloxane backbone. PDMS is naturally stable in vacuum until approximately $340^{\circ} \mathrm{C}$; the introduction of a small amount of methylphenylsiloxane or diphenylsiloxane into a PDMS skeleton can increase the onset temperature up to $400^{\circ} \mathrm{C}$ [14]. Grassie et al. [15] measured both the onset temperature of thermal degradation and residue content of PDMS containing phenyl groups, and showed a neat, direct correlation between increasing phenyl content and final weight of residue. The products of degradation of poly(dimethyl/diphenyl siloxane) are benzene and complex mixtures of cyclic oligomers. Deshpande and Rezac [12] confirmed that the degradation of poly(diphenyl-dimethyl)siloxane resulted in the release of benzene in the initial stages of the reaction whereas no cyclic oligomers were traced.

\subsubsection{Influence of molecular weight}

Connell et al. [16] found that as the length of the siloxane chain is increased, the time to ignition in a cone calorimetry test decreases because the amount of combustible hydrocarbon in the samples increases with increasing chain length. Grassie et al. [15] showed that the amount of residue is strictly proportional to the polymer molecular weight.

\subsection{Effects of additives}

We consider in this part all types of compounds that have been introduced in a silicone formulation at less than $5 \mathrm{wt} \%$.

\subsubsection{Platinum compounds}

Addition of a conventional hydrosilylation catalyst, i.e. platinum (0)-1,3-divinyl-1,1,3,3-tetramethyldisiloxane, into silicone rubber improves its fire retardancy uniquely [17]. Indeed, only a few ppm are a priori sufficient to dramatically modify the burning behaviour of silicone, in contrast to ordinary flame retardants whose contents are generally of about $10 \%$ or more. It has been found that crosslinking reactions of various polymer materials during their thermal degradation are closely related to their efficient flame retardancy. During the thermal treatment at around $400-500{ }^{\circ} \mathrm{C}$, the platinum compound induces the cleavage of methyl-silicon bonds in silicone rubber and radical coupling that leads to the formation of crosslinking points (Scheme 5). This radical mechanism is initiated by Ptcatalyzed homolytic breaking of $\mathrm{Si}-\mathrm{CH}_{3}$ bond to produce a methyl and a silyl radicals, the former which abstracts hydrogen from another methyl group to yield methane and a radical methylene grafted on the chain siloxane. Finally, this macroradical attacks an adjacent polymer chain inducing a meso-cross-linking of the
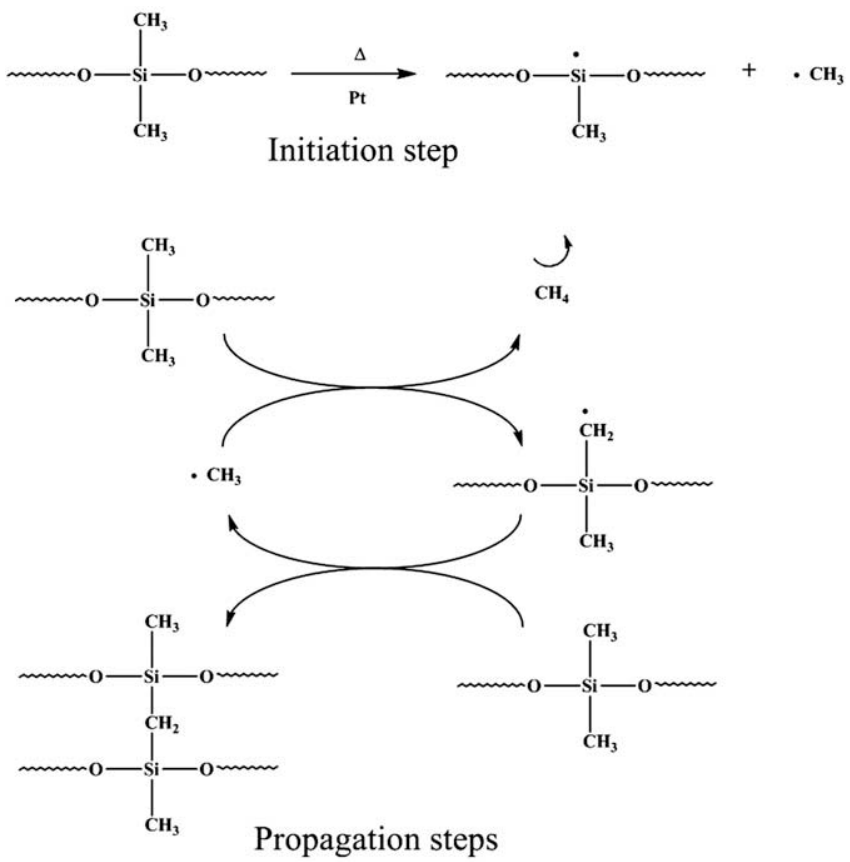

Scheme 5. Pathway for the methylene-bridge structure formation induced by platinum-catalysed radical chain-reaction.

matrix. According to Lagarde et al. [18], the action of Pt as flame retardant in PDMS occurs by preventing the formation of the complex of transition which supports the backbiting degradation of the polysiloxanes. Pt thus limits the quantity of condensates formed. Smith [19] used platinum or a platinum compound to improve flame retardancy of polyorganosiloxane foams used in coating applications or protective filling, wherein fire retarding is important. The flame retardancy can be further improved by addition of $0.2 \mathrm{wt} \%$ of carbon black: the foams are self-extinguishing in short times without releasing toxic fumes during combustion.

\subsubsection{Transition metal oxides}

Transition metal oxides such as $\mathrm{FeO}, \mathrm{Fe}_{2} \mathrm{O}_{3}, \mathrm{CeO}, \mathrm{TiO}_{2}$, etc or a mixture of two or more were used by Fujiki and Tanaka [20] to impart high-temperature resistance to silicone as coating and airbag-based material. A thickness of $5-20 \mu \mathrm{m}$ of this silicone was used for coating materials, such as polyamide fibres, polyester fibres, polyurethane sheets and so on. Silicone rubbers filled with titanium dioxide as heat resistant additive showed deteriorated mechanical and electrical properties when immersed in water. Even mixtures of platinum and fumed titanium compounds incorporated in silicone rubber did not improve their flame retardant properties when heated or exposed to moisture [21]. Therefore, Hatanaka et al. [21] proposed to use platinum and titanium dioxides treated with an organosilane or an organosiloxane in silicone rubber. The treated titanium dioxide imparted more efficient flame retardancy at smaller amount than the original untreated titanium dioxide. Even after a prolonged exposure to the atmosphere, the electrical and mechanical properties (including high elasticity) as well as the flame retardancy of the resulting silicone rubbers were not adversely affected. They suggested use of surface modified $\mathrm{TiO}_{2}$ having an average particle size of less than $0.1 \mu \mathrm{m}$ at composition of $1-20 \mathrm{phr}$ (parts per hundred) loading levels. Noteworthy, they reported that an excessive use of $\mathrm{TiO}_{2}$ decreased the mechanical properties, especially the tensile strength, of the resulting silicone rubber and increased its tendency 
to adhere to the compounding rolls, thus rendering it difficult to handle. A mixture of fumed $\mathrm{TiO}_{2}$ or zinc oxide $(\mathrm{ZnO})$ with aluminium trihydrate (vide infra) was used by Schroeder et al. [22] in order to get optimal smoke and fire resistant properties of sprayable silicone emulsions (based on silanol end-capped PDMS) for coating applications at a reasonable cost. Ota and Hirai [23] proposed to use heat stabilizers such as cerium silanolate or cerium salts of fatty acids together with some additives such as zinc carbonate, titanium dioxide, ferric oxide, carbon black, aluminium hydroxide, and calcium carbonate in the formulation of silicone for electrical wire and cable applications. The loading level of fumed titanium dioxide in silicone rubber was $5 \mathrm{phr}$, while carbon black was only 1 phr. Using this composition, they were able to obtain electrical cables without dripping during combustion according to UL758 test method. In addition, zirconia $\left(\mathrm{ZrO}_{2}\right)$ nanoparticles $(19 \mathrm{~nm})$ grafted onto fumed silica also showed the catalytic ability to diminish the temperature of thermal decomposition of PDMS and to increase the contribution of depolymerization against oxidation. Grafted zirconia changes the surface chemistry of particles and in turn affects the thermolysis of PDMS in both air and vacuum, since the peaks of elimination of the main products, such as methane and hexamethylcyclotrisiloxane, shifted toward lower temperatures and contribution of depolymerization increased against oxidation [24]. Rhône Poulenc claimed that addition of $\mathrm{TiO}_{2}$ and $\mathrm{CeO}$ shows different impacts on mechanical and flame resistances [25]. The $\mathrm{CeO}$ addition enhances the mechanical properties of the material preferentially whereas $\mathrm{TiO}_{2}$ improves its thermal resistance. They observed random mechanical properties for different compositions. Later on, Dubois et al. presented fire behaviour of formulations filled with cerium hydroxide $\left(\mathrm{Ce}(\mathrm{OH})_{2}\right)$, in place of cerium oxide $(\mathrm{CeO})$, together with $\mathrm{TiO}_{2}$ and blend of ferric oxide ( $\mathrm{FeO}$ and $\mathrm{Fe}_{2} \mathrm{O}_{3}$ ) [26]. UL-94 tests showed the same result $(\mathrm{V}-1)$ for compositions containing either $\mathrm{Ce}(\mathrm{OH})_{2}$ alone or $\mathrm{Ce}(\mathrm{OH})_{2}$ and $\mathrm{TiO}_{2}$, whereas the composition containing all metal oxide led to enhanced fire resistance $(\mathrm{V}-0)$. The latter improvement may be due to the synergy among $\mathrm{Ce}(\mathrm{OH})_{2}, \mathrm{TiO}_{2}$ and blend of ferric oxide ( $\mathrm{FeO}$ and $\mathrm{Fe}_{2} \mathrm{O}_{3}$ ) with platinum.

\subsubsection{Carbon nanotubes}

Alexandre et al. [27] proposed a flame retardant system containing crosslinked silicone and carbon nanotubes for coating materials especially useful in aeronautic applications. The advantage of this technique is the very low amount $(0.25-0.5 \mathrm{wt} \%)$ of carbon nanotubes needed, compared to other inorganic fillers (more than $10 \mathrm{wt} \%$ ). Among different types of carbon nanotubes, double walls nanotubes (DWNTs) showed the best flame retardant properties in silicone compared to multi-walls nanotubes (MWNTs) or thin MWNTs. Moreover, nanotubes without post-synthesis treatment showed better affinity to silicone matrix, thus better flame retardant properties. The flame retarding mechanism of carbon nanotubes in silicone was explained by heat dissipation of silicone by carbon nanotubes. Incorporation of $1 \mathrm{wt} \%$ of DWNTs was able to maintain matrix temperature at less than $350^{\circ} \mathrm{C}$ during up to 42 min while heating the material with a Bunsen burner between 950 and $1050{ }^{\circ} \mathrm{C}$ (French standard ISO2685).

\section{Flame retardancy of filled-silicone elastomers}

For many people, the word filler is associated with cost reduction, but in recent years it has become more widely recognized that fillers modify all properties of the material in which they are mixed. Most commonly, fillers are used to assist processing and to upgrade the mechanical properties of the host polymer [28]. The term fillers refer to solid additives, generally inorganic materials, classified according to their effect on the mechanical properties, as extender,
$\mathrm{Si}\left(\mathrm{OC}_{2} \mathrm{H}_{5}\right)_{4}+2 \mathrm{H}_{2} \mathrm{O} \longrightarrow \mathrm{SiO}_{2}+4 \mathrm{C}_{2} \mathrm{H}_{5} \mathrm{OH}$

Scheme 6. In situ preparation of silica in silicone matrix.

reinforcing and specific additive in the resulting mixture. Inert or extender fillers are added mainly to reduce the cost of the compound, although some inert particular fillers can also affect other properties of the compound besides cost. Examples of inert or extender fillers include china clay (kaolin), talc, and calcium carbonate. Reinforcing fillers are added in order to improve certain mechanical properties such as modulus or tensile strength, either by generating chemical bonds between the filler and the polymer, and/or by affecting the properties of the thermoplastic through the volume occupied by the filler. Silica is an example of reinforcing filler [29]. Among the properties of the fillers of particular importance are the particle shape, the particle size and distribution of sizes, and the surface chemistry of the particle. For example, platelike particles or fibrous particles may be oriented during processing in contrast to nanoparticles. The surface chemistry of the particle is important to promote interactions with the polymer and to allow for a good interfacial adhesion [29]. Flame retardant fillers function principally through endothermic decomposition, water release, and oxide residue formation, which inhibit thermal feedback. Combination with flame retardant synergists is indeed an attractive area of current research, so as to significantly reduce the overall fillers content in the formulation while achieving an acceptable level of performance [30]. As with other polymers, PDMS and its derivatives are also generally reinforced by filler loading to improve their mechanical properties. There are several fillers used in PDMS beside silica, namely calcium carbonate, mica, montmorillonite [31], and so on. The use of lamellar or plate-like phyllosilicate fillers such as mica, talc, montmorillonite, has been shown to improve the weight loss in pyrolysis by a barrier effect: they decrease mass transfers by creating a tortuosity for the volatiles. In addition, such a type of morphology would be capable to produce better reinforcement of the residual structure obtained after degradation [32]. The barrier formation depends on filler's morphology and it is particularly used to improve the fire resistance of the matrix. Besides, moist and hydroxylated fillers could initiate the thermal degradation of PDMS at lower temperature through surface catalyzed backbiting from hydroxyl group (case of silica or phyllosilicates), or by water released during thermal decomposition (case of flame retardant systems containing metal hydroxides), respectively

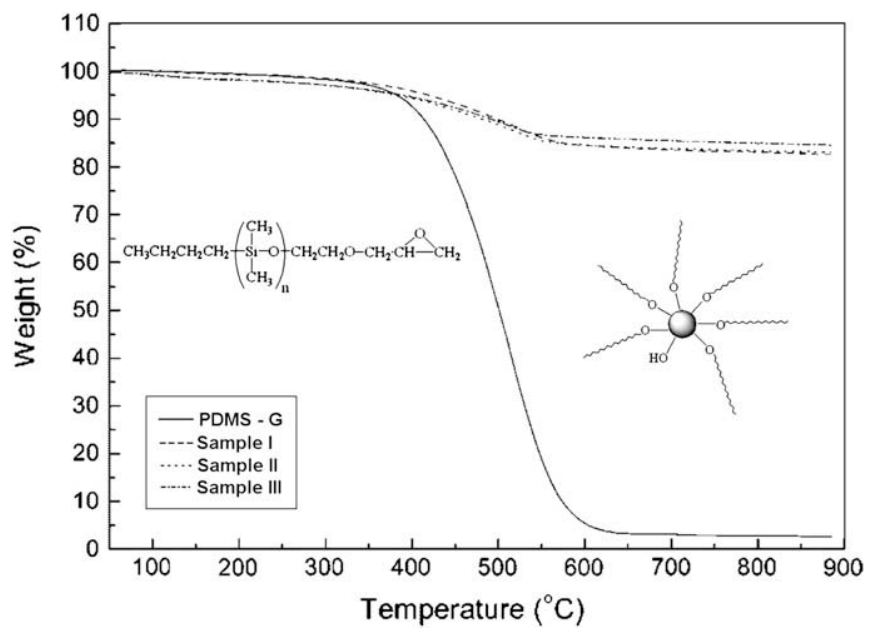

Fig. 2. TG thermograms of PDMS-G (monoglycidylether-terminated polydimethylsiloxane) and star polymers under nitrogen at heating rate of $10^{\circ} \mathrm{C} \mathrm{min}^{-1}$. Samples I, II and III differ by their silica content (30, 40 and 50 wt\% respectively) [40]. 

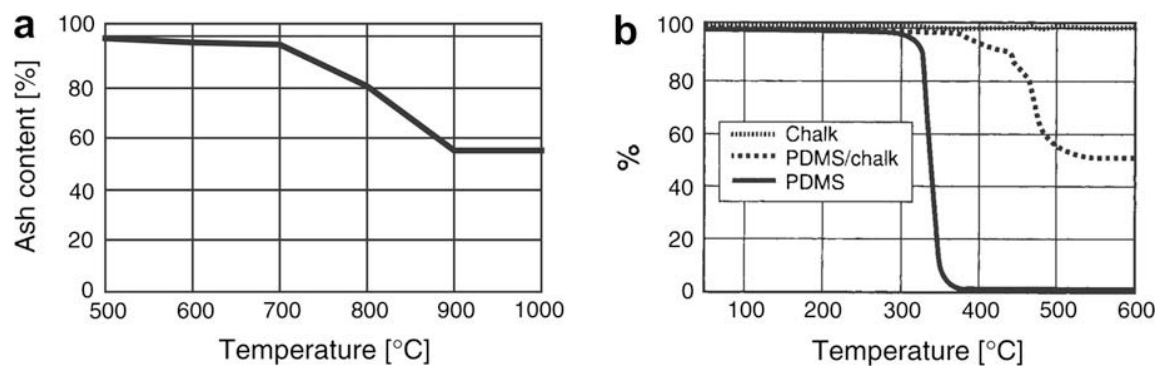

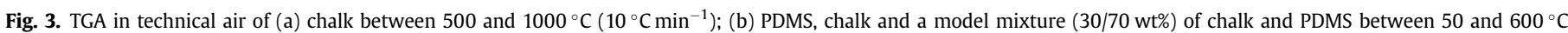
$\left(10{ }^{\circ} \mathrm{C} \mathrm{min}^{-1}\right)$ [44].

[33]. More details about flame retardancy of several inorganic fillers in PDMS are discussed in this part.

\subsection{Silica particles}

Silica is the most common filler introduced in PDMS because of its reinforcing effect $[34,35]$ induced by hydrogen bonding between oxygen of $\mathrm{Si}-\mathrm{O}-\mathrm{Si}$ in PDMS chain and hydrogen of silanol groups on the surface of silica [36]. As a component of flame retardant systems material, silica has been applied to several polymers such as polypropylene, poly(methyl methacrylate) (PMMA), epoxy resin, poly(ethylene-co-vinyl acetate) (EVA), butadiene-acrylonitrile rubbers, and of course, PDMS. The thermal decomposition of PDMS [37] is greatly enhanced by the physically absorbed and chemically combined water on the silica surface, whose release at high temperature catalyses the decomposition of PDMS by hydrolyzing the siloxane chain. This defect can be strongly reduced, even suppressed by surface treatment of silica before incorporating it into PDMS. The deposition of amorphous silica ash (a major combustion product of silicones) on the fuel surface is believed to play a significant role in mediating the fuel formation rate in silicone in fires. Some studies have reported some improved flame retardancy due to silica in PDMS with emphasis on techniques used to incorporate the silica, the effect of different sizes or different types of silica, etc. The flame retardant effectiveness and mechanism of silica is based on specific physical processes in the condensed phase rather than chemical reactions, as proven by Kashiwagi et al. [38]. The balance between the density and the surface area of the additive and polymer melt viscosity determines whether the additive accumulates near the sample surface or sinks through the polymer melt layer. From the synthesis point of view, elastomeric networks of poly(dimethyl siloxane) (PDMS) reinforced with silica particles can be prepared by different manners. Yuan and Mark [36] have reported that silica can be generated in situ through the hydrolysis and condensation of the precursor tetraethoxysilane (TEOS), as described in Scheme 6. They found that the in situ precipitation technique could control the size and size distribution and provides better dispersion of filler particles throughout polymer matrices and stronger polymer-filler interactions. Tanahashi et al. [39] made use of this new and simple method for the dispersion of ultrafine silica particles into thermoplastic resin by mechanical methods without any surface modification of dispersed fillers or any organic reactions. A clear advantage of this method is a good nanodispersion of silica particles in various polymer compositions regardless of the degree of chemical affinity between the dispersed silica and matrix resin and without complicated chemical reactions at the organic-inorganic interface. Later on, Liu and Li [40] prepared a hybrid material which silica core is surrounded by PDMS arms. Nanosilica-cored star polymers were prepared by grafting monoglycidylether-terminated polydimethylsiloxane (PDMS-G) onto nanosilica particles. The moderate grafting yield of 50-60\% was ascribed to steric hindrance from the growing shell of PDMS. The organic layer thus generated is able to separate the silica particles from each others and to prevent particle aggregation. They showed that this star PDMS/silica hybrid could effectively increase the thermal stability and char formation of the grafted PDMS arms in comparison to the starting PDMS arm (Fig. 2). The authors finally noted that the synthesis employed here could be applied to prepare other star polymers from nanosilica cores.

\subsection{Calcium carbonate}

Calcium carbonate has been extensively employed as a filler in polymer composites, because of its several remarkable benefits such as abundant raw material resource, low price, and stable properties. Several types of calcium carbonates, such as natural calcium carbonates or precipitated calcium carbonate, have been introduced in different proportions as fillers in PVC (65\%), polyester (20\%), polyolefins (5\%), etc [41]. Recently, Deodhar et al. [42] used calcium carbonate nanoparticles $(70 \mathrm{~nm})$ as flame retardant agent in PP. Calcium carbonate in the silicone industry was mainly used in sealant formulations [43]. Chalk is a natural calcium carbonate whose thermal stability and degradation were studied by Hermansson et al. [44]. Chalk action as flame retardant starts at high temperature by releasing $\mathrm{CO}_{2}$ gas and by providing an endothermic effect inside the matrix. The weight loss starts slowly from $500{ }^{\circ} \mathrm{C}$ and remains constant above $900{ }^{\circ} \mathrm{C}$, finally providing a residue of $56 \mathrm{wt} \%$. The content of residue correlates well with the theoretical value when all $\mathrm{CaCO}_{3}$ has been transformed into $\mathrm{CaO}$ (Fig. 3(a)). According to Hermansson et al. [44], chalk has a positive effect on silicone elastomers, because it neutralizes acidic residues remaining from polymerization processes, which are otherwise destructive for the elastomer. TG curves typically show enhancement of thermal stability of silicone by addition of chalk (Fig. 3(b)). PDMS degrades around $300^{\circ} \mathrm{C}$, whereas when mixed with chalk, some residue remains in samples treated at $500{ }^{\circ} \mathrm{C}$. The silicone elastomer stabilized by chalk thus survives at higher temperatures in addition to taking an active part in the formation of the intumescent structure. After treatment at $500{ }^{\circ} \mathrm{C}$, the intumescent structure consists of calcium carbonate and silicon oxides. At higher

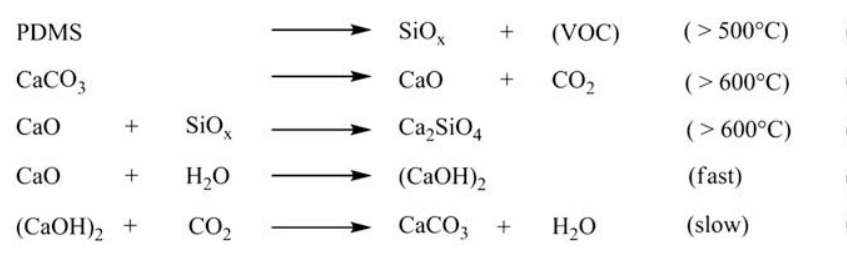

1) 

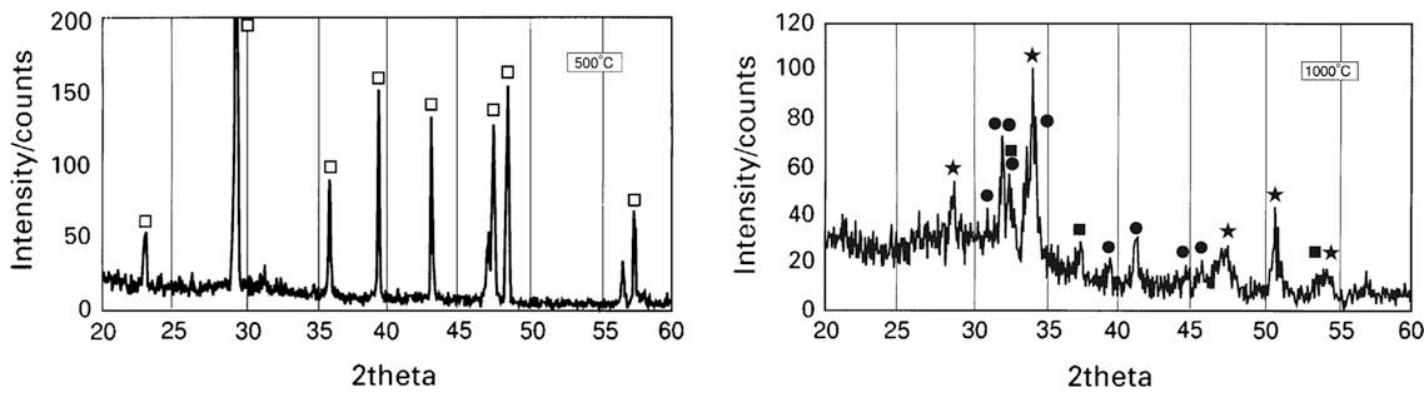

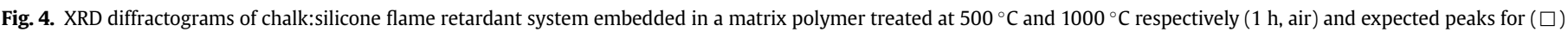
$\mathrm{CaCO}_{3} ;(\bullet) \mathrm{Ca}_{2} \mathrm{SiO}_{4} ;(\star) \mathrm{Ca}(\mathrm{OH})_{2} ;(\boldsymbol{\square}) \mathrm{CaO}[44]$.

temperatures, calcium silicate $\left(\mathrm{Ca}_{2} \mathrm{SiO}_{4}\right)$ forms through a sintering reaction between calcium oxide $(\mathrm{CaO})$, formed from the degradation of chalk, and silicon oxides as shown in Scheme 7. The formation of $\mathrm{CaO}, \mathrm{Ca}(\mathrm{OH})_{2}$ and $\mathrm{Ca}_{2} \mathrm{SiO}_{4}$ explains the presence of calcium, oxygen and silicon in the fired sample treated at $1000^{\circ} \mathrm{C}$ as shown by XRD analysis (Fig. 4). Therefore, flame retarding action of calcium carbonate seems identical to those of metal hydroxides with a decomposition temperature range shifted toward higher temperatures. In a silicone matrix, calcium carbonate releases $\mathrm{CO}_{2}$ and $\mathrm{H}_{2} \mathrm{O}$ gases during combustion that cool the polymer substrate and in the same time dilute flammable gases available for burning in the vapour phase. Therefore the heat feedback to the polymer substrate is reduced and in turn the emission of flammable gases decreases. Moreover, calcium carbonate contributes to the constitution of a mineral or ceramic-like calcium silicate residue after degradation which acts as flame retardant by barrier effect [44].

\subsection{Wollastonite}

Wollastonite, also known as calcium metasilicate, is a naturally occurring mineral. It consists of pure white, non-hydrous needleshaped crystals. The particle lengths are typically larger than the widths by a factor of between one and two, but the aspect ratio (diameter divided by thickness) can be much higher, up to 15 . Consequently, wollastonite reinforcing property can compete with or partially replace other reinforcing fillers and fibres as its cost is competitive [45]. Wollastonite is used in composites to increase mechanical properties such as tensile, flexural, and impact strengths, as well as to increase dimensional stability and minimize distortion at elevated temperatures. Park [46] reported the use of non-treated wollastonite and surface-treated wollastonite with 3aminopropyl triethoxysilane (APTS) or allyltrimethoxysilane (ATMS) to improve mechanical properties of silicone rubber. Incorporation of $10 \mathrm{wt} \%$ of wollastonite into compression-moulded silicone rubber decreased tensile strength, increased tear strength, and decreased elongation at break. Lower values of tensile strength and elongation at break are a consequence of weaker adhesion. An increase in weight percentage of filler reduced the deformability of the matrix, and, in turn, reduced also the ductility in the skin area so that the composite tended to form a weak structure. In contrast, the silane treated wollastonite composites developed higher tensile strength than untreated composites and a significant improvement in tear strength. Silane coupling agents are predominately used as mediators, binding organic materials to inorganic materials. These react with the silanols on the filler surface through a covalent bond, whereas the allyl functional group bonds to the rubber during vulcanization; the case of aminosilanes may however be more complex and its action is not fully understood yet. Filler-polymer bonding helps to increase tensile strength and to improve other compound properties such as higher strength and abrasion resistance. Application of wollastonite as flame retardants in PDMS has also been patented by several authors. Nicholson et al. [47] from Dow Corning Corporation incorporated $21.1 \mathrm{wt} \%$ of wollastonite into $66.4 \mathrm{wt} \%$ of dimethylvinylsiloxy terminated dimethyl siloxane to obtain a cured silicone foam exhibiting high flame resistance and forming hard ceramized char with few cracks on burning. The form of wollastonite used was a needle-like shape with particle size from about $5-15 \mu \mathrm{m}$ and aspect ratio 15:1. Compositions with $<1 \mathrm{wt} \%$ wollastonite did not exhibit char formation or low heat release rate, but if wollastonite content $>60 \mathrm{wt} \%$, uncured compositions were too stiff, and therefore difficult to process, and did not blow into uniform foams. Moreover, for wire and cable coating applications, Shephard [48] from Dow Corning proposed a curable silicone composition, made by mixing ingredients comprising: 30-90 wt\% of a heat-curable non-halogenated organosiloxane polymer, containing at least 2 alkenyl groups per molecule, $1-65 \mathrm{wt} \%$ of a reinforcing silica filler, 5-70 wt\% of wollastonite having an average particle size of $2-30 \mu \mathrm{m}$ and aspect ratio of at least $3: 1$, and curing component sufficient to cure the composition (a peroxide catalyst). Addition of $38.7 \mathrm{wt} \%$ wollastonite into silicone resulted in a tough resinous char with few surface cracks and high surface integrity while sample containing $8 \mathrm{wt} \%$ amorphous silica and $60 \mathrm{wt} \%$ wollastonite resulted in hard and resinous char structure with no vertical expansion; in the latter case, the weight loss was only $6 \mathrm{wt} \%$ and the fire did not penetrate through the $1 / 4^{\prime \prime}$ thick sample. Substitution of a part of wollastonite with diatomaceous earth $(5 \mu \mathrm{m})$ resulted in a self-extinguishing material with a hard and resinous char structure and a weight loss of only $8 \mathrm{wt} \%$. High consistency rubbers were systematically formulated for plenum

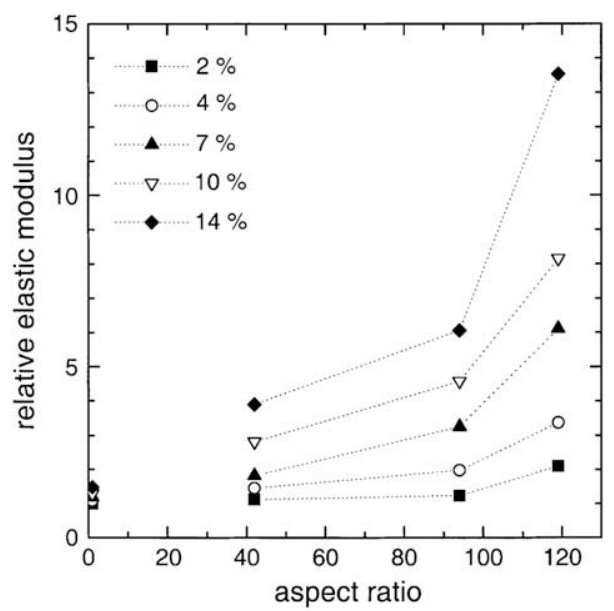

Fig. 5. Dependence of the relative elastic modulus on the aspect ratio (diameter divided by thickness) of the filler particles at different loading levels (vol\%) [51] 

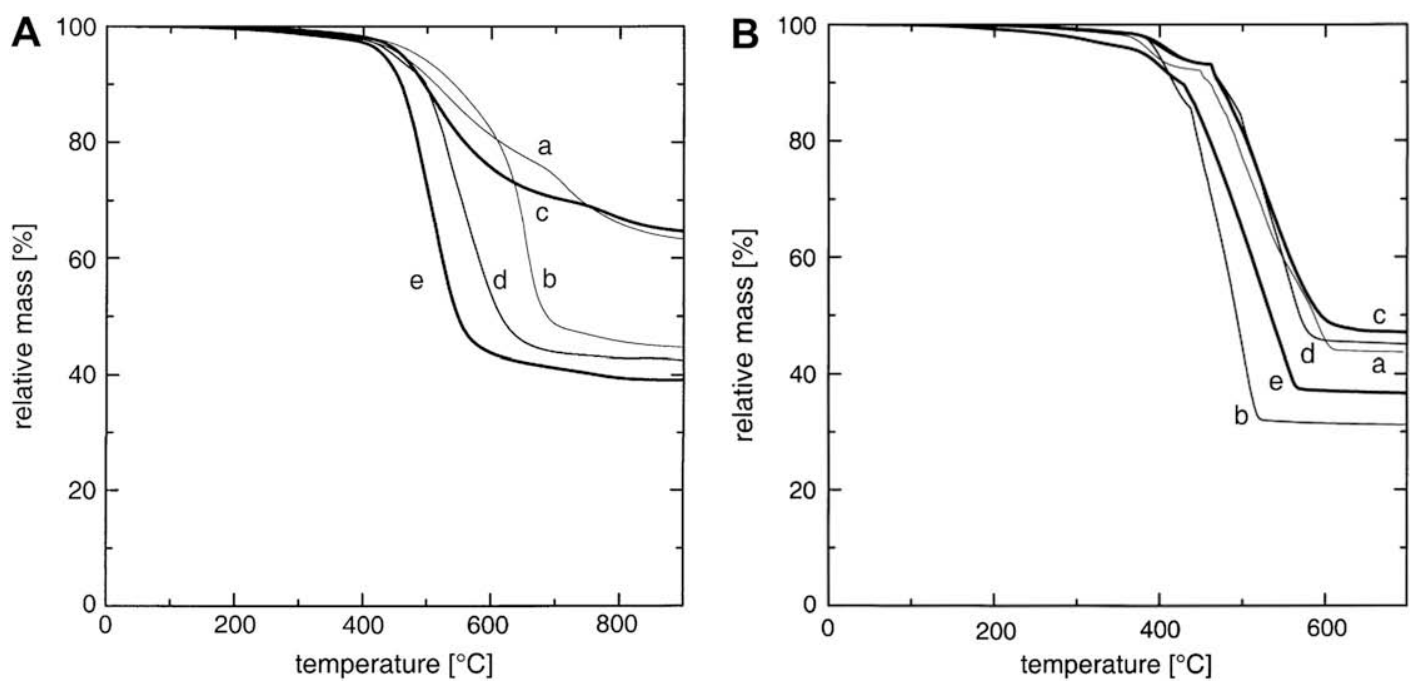

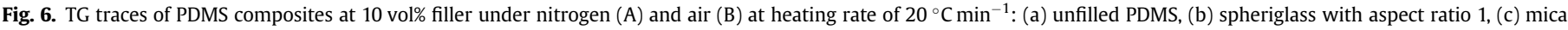
with aspect ratio 42, (d) mica with aspect ratio 94, and (e) mica fines with aspect ratio 119 [51].

cable coatings with different sizes of wollastonite. A sample containing wollastonite with an average particle size of $12 \mu \mathrm{m}$ and a particle size range of $1-393 \mu \mathrm{m}$ was compared with a sample containing wollastonite with an average particle size of $10 \mu \mathrm{m}$, and a particle size range of $1-119 \mu \mathrm{m}$. Both samples showed very similar HRR peaks without significant difference in the char structures of the two materials [48]. Compositions with less than about $5 \mathrm{wt} \%$ of wollastonite did not exhibit the char formation and low heat release rate of the present invention. The upper limit of wollastonite that is useful would depend on the properties desired in the uncured and cured compositions. Generally, wollastonite present at greater quantity than about $70 \mathrm{wt} \%$ resulted in uncured compositions that are too stiff and therefore difficult to process, and in cured compositions that have reduced tensile strength and elongation. George et al. [49] used modified wollastonite (with functional alkoxysilanes) to improve flame retardant of PDMS by adding $3.5 \mathrm{wt} \%$ of wollastonite into $65 \mathrm{wt} \%$ of dimethylvinylsiloxy terminated dimethyl siloxane. The matrix also contained other fillers such as silica, mica, $\mathrm{TiO}_{2}$ and other additives. This formulation resulted in a ceramized char with good cohesivity that is required for cable application.

\subsection{Mica}

\subsubsection{Structure and reinforcing effect of mica}

Mica [50] corresponds to a group of aluminosilicate minerals characterized by a layered structure which can be cleaved to give thin, flexible sheets. The two most common classes of commercially available mica are muscovite and phlogopite. Muscovite mica is a 2:1 layered aluminosilicate (ideal formula $\mathrm{KAl}_{2}\left(\mathrm{Si}_{3} \mathrm{Al}\right) \mathrm{O}_{10}(\mathrm{OH})_{2}$ ). Each 2:1 layer consists of two tetrahedral silica sheets sandwiching an alumina octahedral sheet of about $1 \mathrm{~nm}$ thick. Since on average, one $\mathrm{Si}$ atom out of four in the tetrahedral sheets is replaced by $\mathrm{Al}$, the layers are negatively charged. These charges are compensated by interlayer cations, mostly potassium, and the layers are held together in stacks by electrostatic and Van der Waals forces. Phlogopite mica is a trioctahedral alkali aluminium silicate $\left(\mathrm{KMg}_{3}\left(\mathrm{Si}_{3} \mathrm{Al}\right) \mathrm{O}_{10}(\mathrm{OH})_{2}\right)$. Phlogopite has a layered structure of magnesium aluminium silicate sheets weakly bonded together by layers of potassium ions. Both mica types are typically present in the form of thin plates or flakes with sharply defined edges. Mica is chemically inert and is stable to about $600^{\circ} \mathrm{C}$ where dehydroxylation takes place. The key characteristic of mica as a filler for plastics is its ability to be processed to give thin and plate-shaped particles, with aspect ratios higher than for any other minerals. The aspect ratio of the final flakes depends upon the origin of the mica and the processing method, designed to achieve a high aspect ratio while keeping undamaged flat flakes. This ideal becomes increasingly difficult with decreasing particle size. For certain applications, mica needs surface treatment, among which silane coating is the most popular technique. Indeed, hydroxyl groups on the mica surface are well suited to react with the silanol groups of hydrolyzed silanes. It should be noted here that uncoated mica gives adequate interaction with polar resins such as thermoplastic polyesters and polyamides, so that the additional benefits of silane coating are rarely worth the extra cost, and even in non-polar resins, most applications do not justify the additional expense of silane surface treatment. Taking into account compounding costs, mica filled compounds are generally more expensive than the unfilled resin. Consequently, mica is not viewed as a cost-saving filler, but rather as a means to modify mechanical properties. Mica affects some properties such as stiffness, dimensional stability, flexural, tensile, and impact strengths. Only glass fibre rivals on the high aspect ratio of mica as a tool in stiffening polymer compounds. Osman et al. [51] reported the reinforcing effect of mica to silicone network. The elastic modulus of PDMS networks was dramatically increased by the incorporation of plate-like particles such as mica. The modulus enhancement depends on the aspect ratio and volume fraction of the particles (agglomerates or primary particles), as well as on their distribution in the matrix. They showed that at the same loading level, mica with higher aspect ratio increased dramatically the reinforcing effect on PDMS composite (Fig. 5). At all loading levels, mica is uniformly distributed in the PDMS matrix, except in the $14 \mathrm{vol} \%$ of high aspect ratio (119) mica composite. This is probably due to the attractions between the platelets which seem to increase with increasing interfacial area and decreasing inter-particle distance, so that the fine mica particles tend to agglomerate above $10 \mathrm{vol} \%$.

\subsubsection{Thermal degradation of mica/silicone elastomers}

Mica is one of the most popular flame retardant fillers in silicone polymer especially for electric cable applications, both from the electrical and the mechanical points of view. Osman et al. [51] reported that the thermal degradation of PDMS composites was 

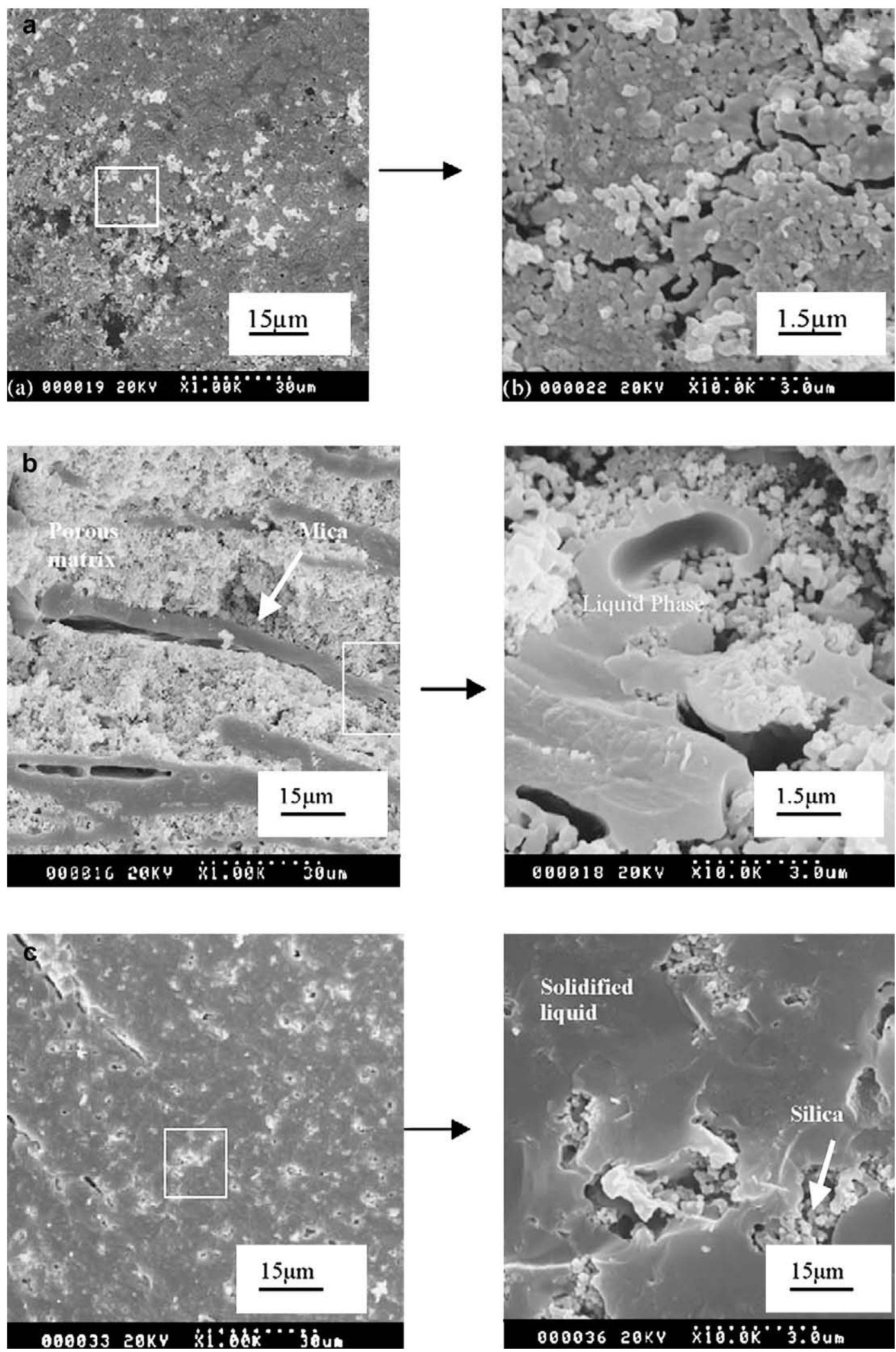

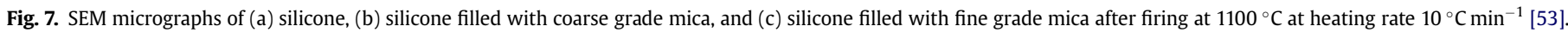

increased by increasing the aspect ratio of mica (Fig. 6). The weight loss of the 10 vol\% composites under nitrogen atmosphere showed that mica with high aspect ratio strongly enhanced the amount of residue, while mica with small aspect ratio did not. The oxidative degradation of the same composites showed that only the mica with high aspect ratio enhanced the oxidation of PDMS. Note that the unfilled PDMS was extraordinary stable under these thermal conditions, a result which let us think that other fire retardant 
additives are present in the sample. Also, mica is able to form a ceramized residue in silicone composite after pyrolysis at high temperature. Hanu et al. [52] reported that addition of $20 \mathrm{wt} \%$ of mica with average particle size $110 \mu \mathrm{m}$ into silicone increased residue yield from $54 \%$ to $63 \%$ in comparison to pristine PDMS, while smaller mica $(20 \mu \mathrm{m})$ increased residue yield to $60 \%$. This residue showed a ceramized structure as sought in electrical cable application. They suggested that the formation of this ceramized residue was due to the reaction between inorganic fillers and the silica issued from the decomposed polymer matrix, which formed a eutectic liquid phase at the edges of the fillers able to penetrate into matrix region. The extent of eutectic formation was shown to be influenced by factors such as particle size and chemical composition of the fillers. The size of muscovite particles in silicone-based composites was shown to have significant effects on the orientation of the particles, on the tensile properties of polymer composites and on the strength of resultant ceramics. Therefore, Hanu et al. [53] used coarse and fine grade muscovite mica as fillers in PDMS, with average particle sizes $95 \mu \mathrm{m}$ and $7 \mu \mathrm{m}$ respectively. They found that, at $20 \mathrm{wt} \%$ loading levels of mica in silicone, the strength of ceramic formed through high temperature pyrolysis of polymer composites was improved with increased amount of eutectic liquid and particle size, as observed in SEM studies with an improvement in the ultimate strength of the ceramic residue (Fig. 7). The residue of fired silicone polymer is highly porous and contains micro-cracks (Fig. 7(a)). There is some evidence of solidification of silica particles, but the amount of liquid is too low to produce a strong char after firing at $1100^{\circ} \mathrm{C}$. Addition of coarse muscovite to silicone polymer resulted in a stronger residue after firing and a higher resistance to heat distortion with shrinkage reduction (around 50\%, Fig. 7 (b)). On firing at $1100{ }^{\circ} \mathrm{C}$, a eutectic reaction took place between the coarse muscovite and the silica matrix, but the temperature was not high enough to melt the entire muscovite particle. Instead, it produced a liquid phase around the surface of the muscovite particles. Overall, in sample containing coarse mica, the preferential orientation and the low surface area of the muscovite particles left many silica regions poorly infiltrated by the liquid phase and thus weakly bonded. Hanu et al. schematized the effect of filler particle size on the strength of the samples after firing (Fig. 8). With a reduction in filler particle size and the same volume percentage of filler, reduced inter-particle distance and higher surface area of filler resulted in an increased amount of reactivity of the filler particles and a greater amount of eutectic liquid being formed. The increased amount of liquid led to a higher strength ceramic material and greater observed shrinkage after firing (Fig. 7(c)). Mansouri et al. [7] have studied the mechanism of ceramization structure of mica-PDMS composite after firing at $1050{ }^{\circ} \mathrm{C}$. $20 \mathrm{wt} \%$ mica flake (muscovite) with particle size $114 \mu \mathrm{m}$ was added into a silicone gum containing $40 \mathrm{wt} \%$ silica with particle sizes between 20 and $40 \mathrm{~nm}$ and $1.44 \mathrm{~g}$ dicumyl peroxide

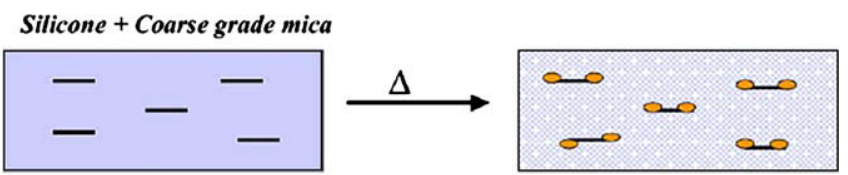

Silicone +Fine grade mica

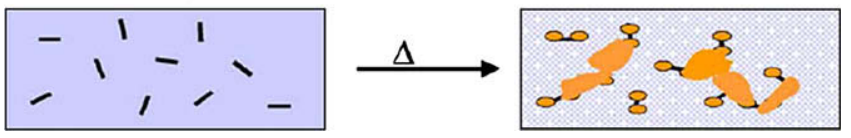

Fig. 8. Influence of muscovite particle size and preferential orientation within the polymer matrix on the sintering and solidification of ceramic composites [53].
(DCP) for cable formulation. This cable was fired in air to $1050{ }^{\circ} \mathrm{C}$ for $30 \mathrm{~min}$, then sprayed with a water jet (fire test conditions for cables according to Australian Standard, AS/NZS3013:1995). Upon firing, the cable formed a coherent and strong ceramic with no visible cracks, thus able to withstand small mechanical shocks from the water spray applied at the end of firing. The inner and outer surfaces of cable were observed by SEM: on the outside, the shape of mica plates at the edges was clearly altered after heating to $1050^{\circ} \mathrm{C}$ (Fig. 9(a,b)) whereas the inner surface in contact with the copper conductor, has formed a more liquid phase and micro-bridges
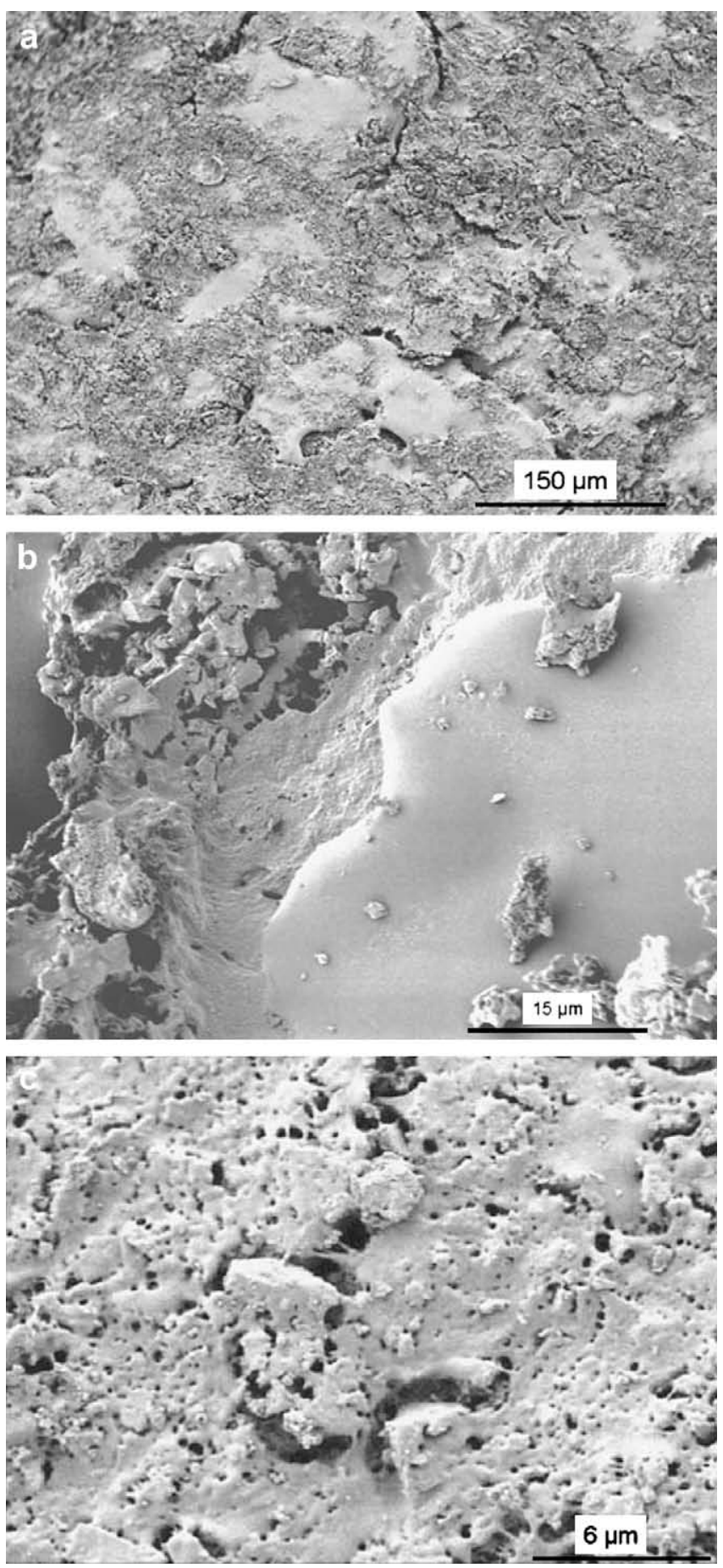

Fig. 9. Scanning electron micrographs of $(a, b)$ the outer surface of the cable at different magnifications, (c) the inner side of the cable after fire test [7]. 
responsible for the strength of the residue (Fig. 9(c)). They showed that edge melting and joining of mica plates after firing at $1050{ }^{\circ} \mathrm{C}$ result from eutectic reactions at the interfaces between the mica particles and silica formed from decomposition of the silicone polymer matrix. Ordinarily, silicon dioxide and mica each have melting points well above $1050^{\circ} \mathrm{C}$. However, when mica decomposes and reacts with silica on heating, an eutectic can form at the interface around $900{ }^{\circ} \mathrm{C}$. This eutectic liquid is believed to infiltrate the silica matrix and so acts as a bridge between the silicone dioxide particles and the mica particles, giving a coherent structure at the firing temperature. The presence of micro-bridge filling pores with regions up to $5-10 \mu \mathrm{m}$ thick is believed to improve ash strength. The weight loss of mica occurred when temperature rose from 600 to $900{ }^{\circ} \mathrm{C}$ due to dehydration and decomposition of mica. As a result, muscovitefilled silicone offers some improvement in fire performance in terms of both time to ignition and rate of heat release when compared to muscovite-unfilled silicone. Upon addition of muscovite, the TTI is increased from 75 to $92 \mathrm{~s}$ and the peak rate of heat release is decreased from 144 to $98 \mathrm{~kW} \mathrm{~m}^{-2}$. Latter on, Mansouri et al. [54] studied the pyrolysis behaviour of silicone-mica composites. They observed the presence of skin formation and preferential positioning of silica on the surface. These effects were more pronounced at higher temperatures. Either silica has diffused into the surface upon firing and has formed a skin layer upon cooling, as suggested by the authors, and/or silica formed preferentially at the surface where oxygen is present. Silica from silicone decomposition (mainly fumed silica) has a large surface area (high pore volume) and low density, tending to accumulate near the surface without sinking through the polymer melt layer during the burning process. Samples fired at $1000{ }^{\circ} \mathrm{C}$ showed continuous skin formation richer in silicon (30-40 wt\%) than that for the sample fired at $600{ }^{\circ} \mathrm{C}(20-25 \mathrm{wt} \%)$. At lower firing temperature $\left(600^{\circ} \mathrm{C}\right)$, eutectic reaction occurred between the product of pyrolysis (silica) and filler to form a compact powder with no or limited binding whereas at higher firing temperature $\left(1000^{\circ} \mathrm{C}\right)$, mica flakes melted at the edges and diffused into the matrix, and pyrolysis products acted as a binder to join the mica plates together.

\subsubsection{Effect of additives + mica on ceramization}

Mansouri et al. [54] suggested that the addition of certain inorganic materials to the mica-silicone composite could produce a liquid phase at lower temperature to facilitate the formation of a strong ceramic. Among inorganic materials that are commonly used to improve the ceramization of the residue resulting from silicone-mica composite fire burning, one finds glass frits, zinc oxide, ferric oxide, and zinc borate. Ariagno et al. [55] have proposed the formulation of a heat-vulcanisable silicone elastomer which is well adapted for conversion into mechanically strong flame-retardant protective sheathings/coatings for, e.g., electrical wires and cables. This formulation comprises at least one polydiorganosiloxane polymer containing a fireproofing and mechanical strength-enhancing amount of mica and $\mathrm{ZnO}$. They found that mica has synergistic effect with zinc oxide in obtaining silicone elastomers with good mechanical properties, mainly elongation at break (at least 180\%) and better ceramized residue. They observed that the composite containing only $\mathrm{ZnO}$ has fragile residue and cracks. Therefore, they proposed to use the composition containing about $1.5-15 \mathrm{wt} \%$ mica and $0.5-5 \mathrm{wt} \%$ of $\mathrm{ZnO}$ in order to obtain a good ceramized residue. They noted that incorporation of both fillers may not exceed $40 \mathrm{wt} \%$. Branlard et al. [56] from Rhodia disclosed mica in the silicone elastomer composition for making electric wires or cables displaying an enhanced reaction to fire. These silicone elastomers contained $8-30 \mathrm{wt} \%$ of mica and about 6 $20 \mathrm{wt} \%$ of $\mathrm{ZnO}$. For cable application, they suggested to use $6.26 \mathrm{wt} \%$ of mica and $3.48 \mathrm{wt} \%$ of $\mathrm{ZnO}$ among other fillers in their silicone composition to obtain ceramized residue after firing at high temperature according to NFC 32070 CR1 standard. On the contrary, another patent by Rhodia suggested using lower mica content but higher $\mathrm{ZnO}$ content in the silicone formulation for wire and cable application. George et al. [49] disclosed that silicone containing $0.74 \mathrm{wt} \%$ of mica and $2.05 \mathrm{wt} \%$ of $\mathrm{ZnO}$ produced ceramized residue after firing at $940{ }^{\circ} \mathrm{C}$ thus satisfying the cable standard test NFC 32070 CR. The mica used does not need a special particle size if smaller than $100 \mu \mathrm{m}$, as long as it gives a good dispersion in polymer matrix. The variation in mica's content in silicone formulation is probably due to the existence of other fillers that promote ceramization residue. Alexander et al. [57] proposed to use a composition consisting essentially of the silicone polymer, mica, glass additive and crosslinking agent for cable application. A composition containing $5-30 \mathrm{wt} \%$ of mica and $0.3-8 \mathrm{wt} \%$ of glass frits in silicone polymer formed a strong ceramized residue at elevated temperature $\left(1050^{\circ} \mathrm{C}\right)$ of substantially the same shape and volume as the pristine material. For cable application, where the electrical resistivity of the composition is important, the levels of mica and/or glass additive must be selected carefully. For a given composition, if the level of mica is too high, electrical integrity problems arise due to an unacceptable reduction in electrical resistivity of the composition and/or from dielectric breakdown. The preferred level of mica is from $15 \%$ to $30 \%$ by weight and more preferably from $20 \mathrm{wt} \%$ to $30 \mathrm{wt} \%$, the mean particle size being of $50-200 \mu \mathrm{m}$. Muscovite mica is the type generally preferred for those applications because compositions containing phlogopite mica display greater mechanical strength when heated to about $1000^{\circ} \mathrm{C}$ to form ceramics, but on the opposite greater shrinkage than that containing muscovite mica. Typically, mica with a mean particle size from $15 \mu \mathrm{m}$ to $250 \mu \mathrm{m}$ was selected. Micas at the lower end of this range (e.g. less than $50 \mu \mathrm{m}$ mean particle size) result in ceramics that are mechanically stronger but display greater shrinkage that can result in cracking. Micas at the middle and upper end of the range are preferable for use in cable applications or other applications where shape retention is particularly important. If the mean particle size of the mica is too large or the amount of mica present is too high, the resultant composition tends to be difficult to process, for instance by extrusion. In addition, the mechanical properties of crosslinked silicone polymers containing coarser particle size grades of mica or high mica levels are poorer. In another study, Alexander et al. [57] reported that replacement of the low-melting glass with zinc borate was undertaken to improve the fire resistance of the ceramizable system, while maintaining high stiffness and good shape retention. Decreasing weight loss from $32 \%$ to $25 \%$ and cohesive residue were observed by addition of zinc borate. Hanu et al. [58] used two types of mica (muscovite and phlogopite) in addition with glass frit or ferric oxide as flame retardant fillers in silicone rubber. Incorporation of $20 \mathrm{wt} \%$ of mica or mica mixture containing $15 \mathrm{wt} \%$ of mica and $5 \%$ glass frit or ferric oxide has found to have a stabilizing effect on the thermal stability of silicone polymer. It was found that this composition improved silicone thermal stability through several ways: (i) adsorption of

Table 1

Flammability of silicone-mica composites using different additives [58].

\begin{tabular}{lllcc}
\hline Sample & Filler & $\begin{array}{l}\text { TTI } \\
(\mathrm{s})\end{array}$ & $\begin{array}{l}\text { Average HRR } \\
\left(\mathrm{kW} \mathrm{m}^{-2}\right)\end{array}$ & $\begin{array}{l}\text { Peak HRR } \\
\left(\mathrm{kW} \mathrm{m}^{-2}\right)\end{array}$ \\
\hline HTVSi & None & 67 & 117 & 144 \\
SiEAPI & Glass frit & 62 & 117 & 130 \\
SiMO & Ferric oxide & 55 & 102 & 117 \\
SiGAI & Muscovite & 87 & 93 & 98 \\
SiGAEAPI & Muscovite + glass frit & 66 & 121 & 134 \\
SiGAMO & Muscovite + ferric oxide & 69 & 87 & 95 \\
\hline
\end{tabular}


polymer chains onto the mica surface resulting in restriction of segmental mobility and thus suppressing redistribution and chain transfer reactions; (ii) shielding effects which reduce mass transport rates (i.e. a reduction in diffusion of fuel products into the gas phase due to an increase in the polymer melt viscosity); (iii) crosslinking promotion and hence lower segmental mobility to suppress redistribution reactions resulting in an overall improvement in residue yield. Cone calorimeter test at incident heat flux of $50 \mathrm{~kW} \mathrm{~m}^{-2}$ showed that both ferric oxide and glass frit effectively reduce the time to ignition, an undesirable effect in the field of passive fire protection. However, ferric oxide was considered better than glass frit because, unlike glass frit, it actually lowered the heat release rate of silicone polymer (Table 1 ). The adsorption of polymer chains onto the surface of mica and ferric oxide particles reduced segmental mobility and suppressed redistribution and chain transfer reactions (typical of silicone depolymerization), which explain the observed delay in the onset of degradation. Ferric oxide was also found to delay the onset of degradation, but resulted in residual yield lower than that of neat silicone. The differences in the residual yields of silicone-mica composites compared to the silicone-ferric oxide composites is explained by the fact that mica addition has a diluting effect on yield, whereas Fe ion in ferric oxide catalyses hydroperoxide decomposition during oxidation, which ultimately catalyzes depolymerization and degradation. Glass frits were found to reduce the thermal stability of silicone polymer due to the increased concentration of metal ions present in these fillers. As mentioned above, glass frits react with fillers and the silica matrix to form a liquid phase which bonds the fillers and silica matrix together, conferring strength to the char. Thus, low temperature ceramization has important role in ceramization residue. The requirement for low temperature ceramization would be insufficient if it relied purely on the mica-silica eutectic reaction, which takes place above $800^{\circ} \mathrm{C}$. The addition of glass frits is a useful technique for lowering the temperatures. These glass frits melt at temperatures below the mica-silica eutectic temperature and combine with the inorganic fillers and pyrolysis products of silicone rubber to assist the formation of a ceramic. Typically, Mansouri et al. [59] studied the influence of various glass frits on the ceramization residue and thus dimensional changes at different temperature. They used two different sizes of muscovite mica, coarse muscovite mica A with particle sizes between 63 and $150 \mu \mathrm{m}$, and dry-ground fine muscovite mica B with particle sizes between 38 and $75 \mu \mathrm{m}$. Muscovite mica was chosen as it is expected that its alkali component would promote the formation of

Table 2

Dimensional changes of different silicone compositions at different temperatures ${ }^{a}$ [59].

\begin{tabular}{lccc}
\hline Compositions & \multicolumn{3}{c}{ Shrinkage (-)/expansion (+) (\%) } \\
\cline { 2 - 4 } & $600{ }^{\circ} \mathrm{C}$ & $800{ }^{\circ} \mathrm{C}$ & $1000{ }^{\circ} \mathrm{C}$ \\
\hline $\begin{array}{l}\text { Silicone/mica A/peroxide } \\
\quad(78: 20: 2)\end{array}$ & 1.5 & 0.57 & -0.73 \\
$\begin{array}{l}\text { Silicone/mica A/peroxide/glass frit E } \\
\quad(75.5: 20: 2: 2.5) \text { (composition H) }\end{array}$ & 0.64 & 0.59 & -3.5 \\
$\begin{array}{l}\text { Silicone/mica A/peroxide/glass frit D } \\
\quad(76.75: 20: 2: 1.25)\end{array}$ & -0.37 & -1.2 & -5.7 \\
$\begin{array}{l}\text { Silicone/mica A/peroxide/glass frit D } \\
\quad(75.5: 20: 2: 2.5)\end{array}$ & -0.8 & -1.96 & -5.4 \\
$\begin{array}{l}\text { Silicone/mica A/peroxide/glass } \\
\quad \text { frit D/glass frit E } \\
\quad(75.5: 20: 2: 1.25: 1.25)\end{array}$ & 0.26 & -0.17 & -5.9 \\
$\begin{array}{l}\text { Silicone/mica A/mica B/peroxide } \\
\quad(68: 20: 10: 2) \text { (composition F) }\end{array}$ & & & \\
$\begin{array}{l}\text { Silicone/mica A/mica B/peroxide/glass } \\
\quad \text { frit C(65.5:20:10:2:2.5) (composition G) }\end{array}$ & 0.92 & 0.2 & -6.3 \\
\hline
\end{tabular}

\footnotetext{
${ }^{a}$ Numbers in brackets are weight percent of each component in the composition. Peroxide: dicumyl peroxide.
}

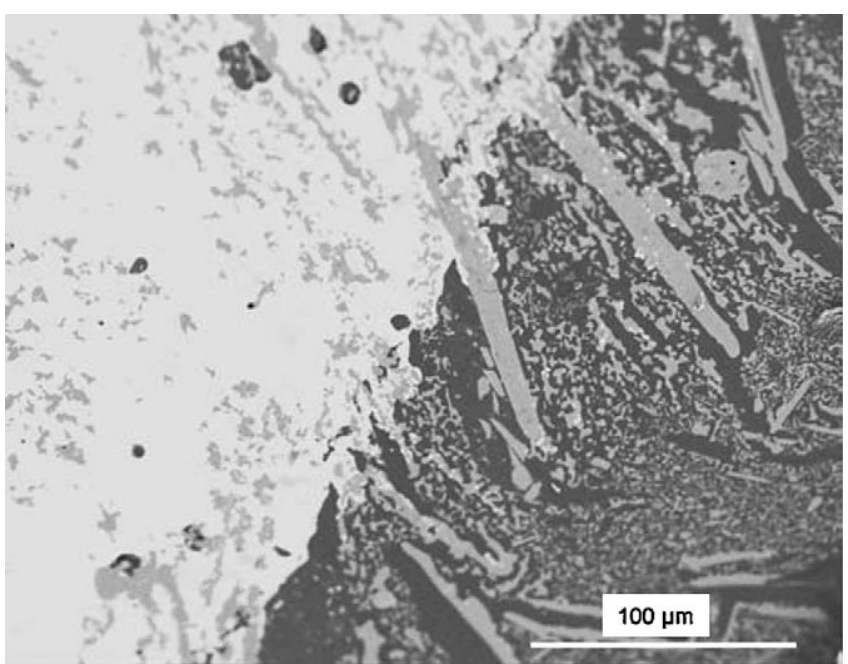

Fig. 10. Scanning electron micrograph of a cross-section of cable showing the interaction between mica particles and copper. Bright area is conductor and grey area is ceramized insulation [59].

a liquid phase during heating at elevated temperatures. Three types of glass frits with softening point of $525^{\circ} \mathrm{C}$ (glass frits $\mathrm{C}$ and $\mathrm{D}$ ) and $800{ }^{\circ} \mathrm{C}$ (glass frit E) with different compositions were selected [59]. The dimensional changes of ceramized samples were measured and showed that shrinkage at $1000^{\circ} \mathrm{C}$ (Table 2) increased when low temperature glass frits ( $C$ and $D$ ) were added, compared with the high temperature glass frit $\mathrm{E}$. This is expected if liquid phase sintering occurs via the densification mechanism, as a greater volume of liquid phase would allow for more rapid particle rearrangement. Compositions made with glass frits $\mathrm{C}$ and $\mathrm{D}$ showed limited shrinkage at 600 and $800{ }^{\circ} \mathrm{C}$, which contrasts with other compositions, expanding at these temperatures. When high softening point glass frit $\mathrm{E}$ was added to the base composition, no significant dimensional changes occurred up to $800{ }^{\circ} \mathrm{C}$. In contrast to the results for the lower temperature, heating at $1000^{\circ} \mathrm{C}$ caused significant shrinkage, due to the formation of a liquid phase that allows densification via liquid phase sintering. This mechanism was not observed at lower temperatures, because insignificant amounts of low viscosity liquid phase were produced. However, at high temperatures, alkali metal ions, from either the mica or the glass additives, tend to provide conductive pathways in the liquid phase. It is thus appropriate either to limit the level of mica and/or the level of glass additive or to select a glass additive having a low alkali metal oxide content (e.g. preferably less than $30 \%$ alkali metal oxide content) and/or a fine particle size to reduce the overall level of the additive required to achieve the desired mechanical properties [57]. Finally, Mansouri et al. [59] have unexpectedly observed the interaction between copper of the electric cable and ceramic at the interface (Fig. 10). The XRD spectrum for the residue remaining after the fire test showed the presence of cuprite $\left(\mathrm{Cu}_{2} \mathrm{O}\right)$. The diffusion of copper oxides towards the insulation layer has previously been observed by Henrist et al. [60] for a cable sheathed with a zinc-borate filled composition.

\subsection{Kaolin}

Kaolin is also called china clay or porcelain earth. Kaolin is a dioctahedral 1:1 layered clay mineral and its structural formula is $\mathrm{Al}_{2} \mathrm{Si}_{2} \mathrm{O}_{5}(\mathrm{OH})_{4}$. Each layer consists of two sheets: a tetrahedral sheet in which silicon atoms are tetrahedrally coordinated by oxygen atoms; and an octahedral sheet where aluminium atoms are octahedrally coordinated to hydroxyl groups and share apical 
Table 3

Composition, thermal and modulus properties of kaolin/PDMS composites [61].

\begin{tabular}{|c|c|c|c|c|c|c|c|}
\hline \multirow[t]{2}{*}{ Composition (wt\%) } & \multicolumn{2}{|c|}{ Thermogravimetric mass loss step: $T\left({ }^{\circ} \mathrm{C}\right),\left(\right.$ rate $\left.\left(\% \mathrm{~min}^{-1}\right)\right)$} & \multirow{2}{*}{$\begin{array}{l}\text { Mass loss at } 900^{\circ} \mathrm{C} \\
(\%)\end{array}$} & \multirow{2}{*}{$\begin{array}{l}\text { TTI } \\
(s)\end{array}$} & \multirow{2}{*}{$\begin{array}{l}\text { Peak HRR } \\
\left(\mathrm{kW} \mathrm{m}^{-2}\right)^{\mathrm{a}}\end{array}$} & \multirow{2}{*}{$\begin{array}{l}\text { Density } \\
\left(\mathrm{g} \mathrm{cm}^{-3}\right)\end{array}$} & \multirow{2}{*}{$\begin{array}{l}\text { Modulus } \\
\text { (MPa) }\end{array}$} \\
\hline & Step 2 & Step 3 & & & & & \\
\hline$\overline{\text { PDMS }}$ & $510(1.6)$ & $730(1.2)$ & 28.1 & 123 & $74 / 72$ & $0.48 \pm 0.02$ & $6.2 \pm 0.7$ \\
\hline PDMS:kaolin (72:28) & $529(3.6)$ & $726(0.7)$ & 31.5 & 148 & $80 / 71$ & $0.62 \pm 0.02$ & $12.3 \pm 0.6$ \\
\hline
\end{tabular}

${ }^{\mathrm{a}}$ Composites display two peaks, the higher HRR peak is indicated in italics.
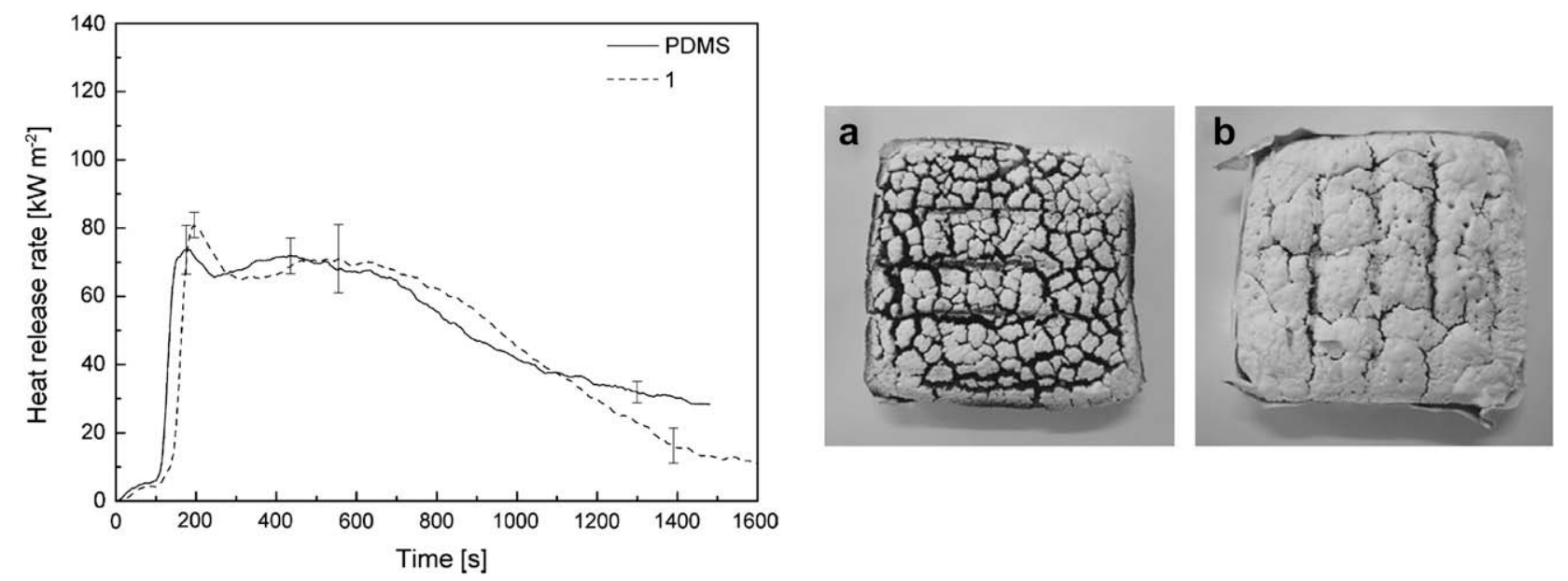

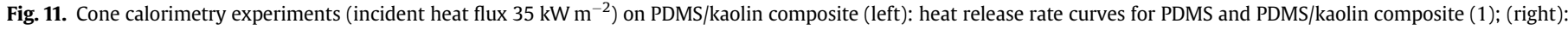
residues of (a) PDMS foam, (b) composite PDMS containing calcinated kaolin [61].

oxygen from the silica tetrahedral sheet. Such typical structure of clay in kaolin crystal foreshows that kaolin could have the potential flame retardancy that montmorillonite has (vide infra). Kaolin is a hydrous aluminosilicate of two varieties, i.e. naturally occurring (hydrous form) and calcined kaolin (anhydrous form). Calcined kaolin is obtained when the clay is heated at more than $600{ }^{\circ} \mathrm{C}$, therefore this variety is harder than the hydrous one, i.e. 6-8 on the Mohs scale ${ }^{2}$, against 2 for the former [45]. Addition of calcined kaolin $(\sim 28 \mathrm{wt} \%)$ into PDMS has improved its fire retardancy properties and strength residual [61]. Composite PDMS containing kaolin exhibits a greater mass loss at lower temperature compared to PDMS alone. The incorporation of kaolin was expected to provide an increased torturous pathway for the pyrolysis gases to diffuse through and to reinforce the polymer matrix; however this was not the case. Such increase in mass loss cannot be ascribed to calcined kaolin, which exhibits a very small amount of mass loss $(<1 \%$ by TGA). Rather, the aluminosilicate mineral $\left(\mathrm{Al}_{2} \mathrm{SiO}_{5}(\mathrm{OH})_{4}\right)$ entails dehydroxylation during calcination process which increased the catalytic activity of the particle surfaces. The mass loss of this composite at $900{ }^{\circ} \mathrm{C}$ was greater (32\%) than theoretically calculated based on the mass loss of PDMS (21\%). The structural change may be described by the observation of greater mass loss rate at $529^{\circ} \mathrm{C}$. Detail information about composition, thermal and modulus properties of PDMS composites are shown in Table 3. Test by cone calorimeter at a constant incident heat flux of $35 \mathrm{~kW} \mathrm{~m}^{-2}$ has shown an increasing TTI from 123 to $148 \mathrm{~s}$ because of the retarding effect of the mineral in degrading the polymer. The formation of an insulating char on the surface resulted in decreasing the HRR to a minimum of about $66 \mathrm{~kW} \mathrm{~m}^{-2}$ before reaching a similar HRR to the PDMS at later time (Fig. 11). All composites exhibited two peak

\footnotetext{
2 The Mohs scale is a qualitative and somewhat arbitrary hardness indexing scheme, based on scratch tests of natural minerals on a softer material. The Mohs scale ranges from 1 for talc to 10 for diamond.
}

HRRs, the first similar to PDMS but the second peak being shifted to higher HRR. This behaviour is ascribed to the disruption and breakdown of the PDMS foam structure during the combustion test due to filler addition which increases stiffness of PDMS foam. Fig. 11 also shows that the composites reveal crack formation that occurred during the test resulting in opening foamed structure. The increased surface area exposed to the heat implies that an increase in fuel for fire is available for combustion. Addition of kaolin into PDMS increased the mass loss at $900{ }^{\circ} \mathrm{C}$, which suggests that kaolin promotes the decomposition of PDMS. Adding to the formulation a combination with magnesium hydroxide and zinc borate decreased the mass loss of PDMS at $900{ }^{\circ} \mathrm{C}$ while maintaining char density. The residual char surface exhibited a thicker silica ash deposit and less cracks compared to another composites containing magnesium hydroxide and zinc borate. In conclusion, addition of kaolin into PDMS matrix does not change significantly the fire property of PDMS according to cone calorimeter test but nonetheless, induces a better ceramization residue after firing.

\subsection{Metal hydrates}

Among the metallic hydroxide flame retardants, aluminium trihydrate $\left(\mathrm{Al}(\mathrm{OH})_{3}\right.$ abbreviated $\left.\mathrm{ATH}\right)$ or magnesium dihydroxides $\left(\mathrm{Mg}(\mathrm{OH})_{2}\right.$ or $\left.\mathrm{MDH}\right)$ are popular flame retardants and smoke suppressants. ATH offers numerous benefits since it is cheap, safe and easily incorporated into many plastics/polymers. It is also halogen-free and produces nontoxic fume, which makes it a valuable competitive fire retardant [62]. The flame retarding property of ATH in polymers is based on its thermal decomposition, in the temperature range from 180 to $200^{\circ} \mathrm{C}$, where it is converted into aluminium oxide in an endothermic reaction with release of water vapour (Scheme 8) [63]. ATH typically loses $34.6 \%$ of its mass as water vapour after heating to temperatures above $350{ }^{\circ} \mathrm{C}$ [64]. Flame retardants containing $\mathrm{MDH}$ act similarly to those containing 
$2 \mathrm{Al}_{2}(\mathrm{OH})_{3}$

$$
\mathrm{Al}_{2} \mathrm{O}_{3}
$$$$
3 \mathrm{H}_{2} \mathrm{O}
$$

$298 \mathrm{~kJ} \mathrm{~mol}^{-1}$

Scheme 8. Thermal decomposition of ATH.

ATH, but start to decompose at a higher temperature range of 250$300{ }^{\circ} \mathrm{C}$. The exothermic breakdown of the ATH, the formation of aluminium oxide, the liberation of water vapour, effect the combustion by physical ways including [65]: (i) diluting the polymer in the condensed phase, (ii) decreasing the amount of available fuel, (iii) increasing the amount of thermal energy needed to raise the temperature of the composition to the pyrolysis level, due to the high heat capacity of the fillers, (iv) increasing the enthalpy of decomposition - emission of water vapour, ( $v$ ) diluting gaseous phase by water vapour which decreases the amount of fuel and oxygen in the flame, (vi) possibly generating endothermic interactions between the water and decomposition products in the flame, (vii) decreasing feedback energy to the pyrolysing polymer, and finally (viii) creating an insulating effect by the oxides remaining in the char. Besides, due to the high specific surface area of the oxide layer, absorption of smoke and other toxic or decomposed carbonaceous gaseous products takes place, making ATH a very effective smoke suppressant as well [66]. To date, most application of ATH is as flame retardant fillers in electrical/electronic cables used in critical environments such as subways, airports, ships and nuclear power stations, whereas cables containing $\mathrm{MDH}$ are generally reserved for automotive and special applications. ATH or MDH also can be used in combination with coadditives such as organomodified clays, zinc borate, red phosphorus or nitrogen/phosphorous compounds. Some studies related to improving residue properties after/during combustion have also been reported. Specific effects of transition metals, when coprecipitated with magnesium hydroxide as solid solutions, included [67]: (i) facilitating and lowering the temperature of the dehydration of the additive; (ii) catalyzing the dehydrogenation of the polymer; (iii) promoting carbonization; and (iv) improving acid resistance. However, the use of ATH in polymers does present some disadvantages, for example loadings as high as $60 \mathrm{wt} \%$ are required to impart significant flame retardancy, which affects the physical properties of the composites. In addition, ATH is less ideal for use as flame retardant agent in polymer such as PDMS for security cable application because of its relatively low decomposition temperature and cracks generation which is of inconvenience in terms of residual cohesivity. Nicholson et al. [47] reported that incorporation of $13.8 \mathrm{wt} \%$ of ATH into silicone formulation for electric wires or cables gave a significantly poorer fire performance. The char structure of residue after combustion was cracked and friable. Genevose and Shanks [61] reported that the combination of zinc borate (ZB) and MDH improves fire performance and increases the strength of the residual char of PDMS. The hydrated fire retardants reject water that cools on the substrate. MDH and ZB were incorporated into PDMS matrix in the presence of kaolin (Table 4). The fire performance behaviour measured by cone calorimetry showed
Table 4

Composition, thermal and modulus properties of composites PDMS containing MDH [61].

\begin{tabular}{|c|c|c|c|c|c|c|}
\hline Sample & $\begin{array}{l}\text { Composition } \\
(\mathrm{wt} \%)\end{array}$ & $\begin{array}{l}\text { Mass loss at } \\
900^{\circ} \mathrm{C}(\%)\end{array}$ & $\begin{array}{l}\text { TTI } \\
(s)\end{array}$ & $\begin{array}{l}\text { Peak HRR } \\
\left.(\mathrm{kW} \mathrm{m})^{-2}\right)^{\mathrm{a}}\end{array}$ & $\begin{array}{l}\text { Density } \\
\left(\mathrm{g} \mathrm{cm}^{-3}\right)\end{array}$ & $\begin{array}{l}\text { Modulus } \\
\text { (MPa) }\end{array}$ \\
\hline$\overline{1}$ & PDMS & 28.1 & 123 & $74 / 72$ & $0.48 \pm 0.02$ & $6.2 \pm 0.7$ \\
\hline 2 & $\begin{array}{l}\text { PDMS:kaolin: } \\
\text { MDH (73:16:11) }\end{array}$ & 23.5 & 144 & $78 / 118$ & $0.66 \pm 0.01$ & $11.6 \pm 0.8$ \\
\hline 3 & $\begin{array}{l}\text { PDMS:kaolin: } \\
\text { MDH:ZB (73: 16:10:1) }\end{array}$ & 22.3 & 155 & $82 / 116$ & $0.71 \pm 0.03$ & $8.2 \pm 0.9$ \\
\hline 4 & $\begin{array}{l}\text { PDMS:kaolin: } \\
\text { MDH:ZB (73:16:6:5) }\end{array}$ & 24.1 & 109 & $84 / 108$ & $0.65 \pm 0.02$ & $13.6 \pm 0.9$ \\
\hline
\end{tabular}

a Composites display two peaks, the higher HRR peak is indicated in italics.

decreasing of both TTI and peak HRR compared to unfilled PDMS. Magnesium oxide is retained in the composite thus insulating and limiting the diffusion of combustible volatiles. However, addition of fillers increased the density and stiffness of the PDMS foam (Tables 3 and 4). The loss of water and volatiles caused the PDMS to lose its flexibility and to become rigid and brittle (ceramic precursor). The pressure of gases through the structure, accompanied by changes in internal stresses (shrinkage) caused formation of cracks in the composites during the test at $900{ }^{\circ} \mathrm{C}$ and therefore resulting in open foam structure (Fig. 12). The increased surface area exposed to the heat implies that an increase in fuel for fire is available for combustion. Reduction of MDH content in PDMS matrix (substituted by $\mathrm{ZB}$ ) resulted in less cracks in the residue due to less water release from hydrothermal degradation of $\mathrm{MDH}$.

\subsection{Talc}

Talc [45] is a naturally occurring hydrated magnesium sheet silicate, $3 \mathrm{MgO} \cdot 4 \mathrm{SiO}_{2} \cdot \mathrm{H}_{2} \mathrm{O}$. The elementary sheet is composed of a layer of magnesium-oxygen/hydroxyl octahedral, sandwiched between two layers of silicon-oxygen tetrahedral. The main or basal surfaces of this elementary sheet do not contain hydroxyl groups or active ions, which explains its hydrophobic nature and inertness. Most of talcs are lamellar in nature, they are chemically inert, organophilic and water-repellent to a great extent. Above $900{ }^{\circ} \mathrm{C}$, talc progressively loses its hydroxyl groups and above $1050^{\circ} \mathrm{C}$, it re-crystallizes into different forms of enstatite (anhydrous magnesium silicate). Similarly to clays, talc belongs to the phyllosilicate group, but in contrast to montmorillonite, hectorite or saponite, talc cannot be exfoliated by using cationic surfactant due to the absence of metallic cations between the layers. Therefore, lamellar talc particles may have effects similar to those of clay platelets in the material. Optionally, talc has been used as nonreinforcing filler in silicone elastomer useful as insulation for electrical equipment, as encapsulants and as sealants where flame retardancy is necessary [68]. Tkaczyk et al. [69] from General Electric used $20 \mathrm{wt} \%$ of talc, chosen among ground silicate minerals,
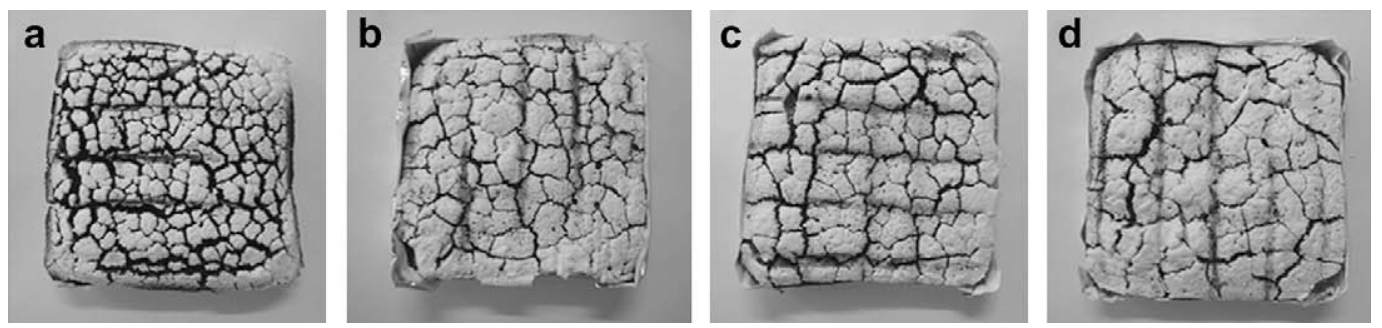

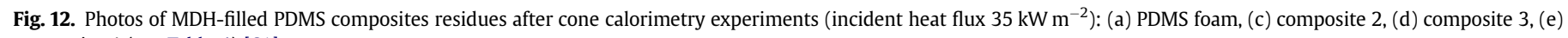
composite 4 (see Table 4) [61]. 

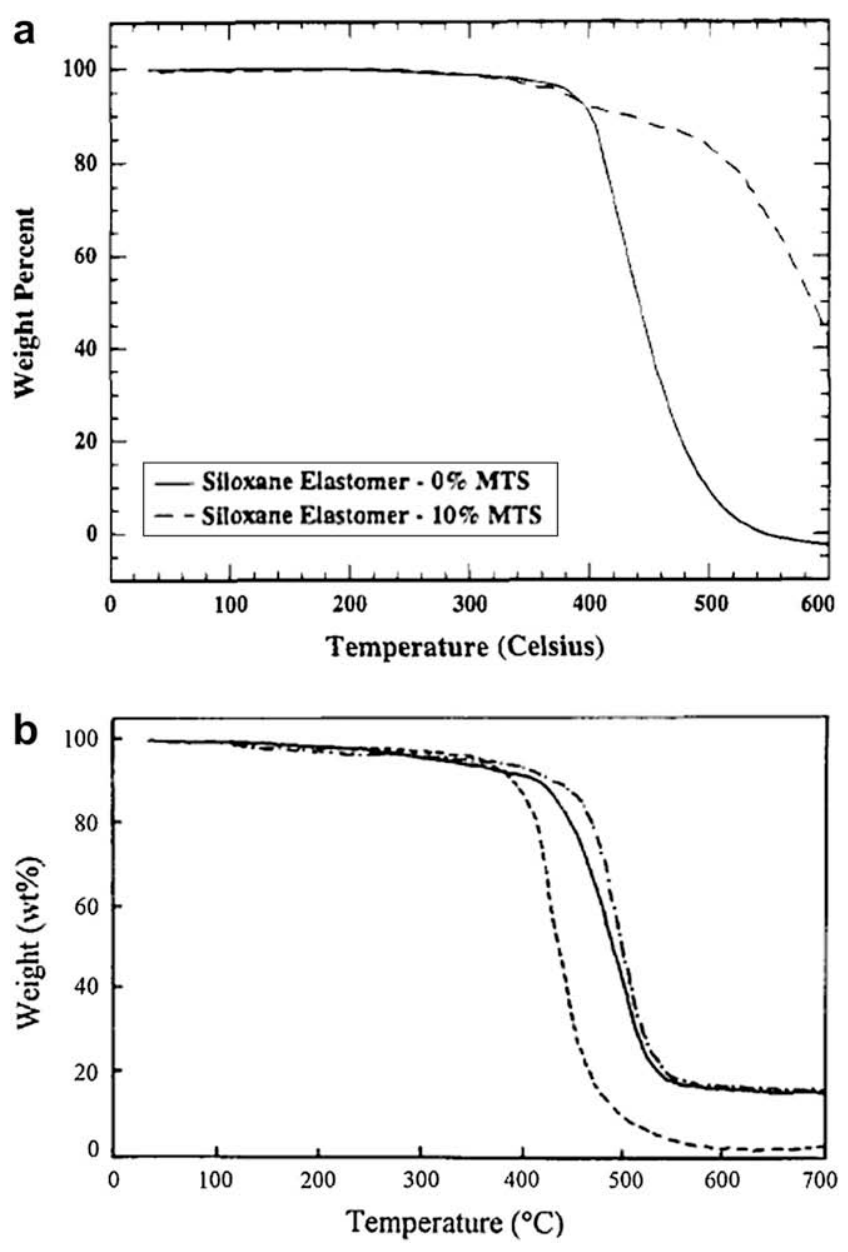

Fig. 13. Two different TGA studies on MMT/silicone composites: (a) PDMS (solid line) and PDMS nanocomposite (dashed line) containing $10 \mathrm{wt} \%$ of S04682 silicate [73]; (b) silicone rubber without filler (-); silicone rubber/oMMT hybrid (-_); silicone rubber/ aerosilica $(-\bullet-)$ [76].

to make silicone composite useful in insulating electrical wires. They found that talc which surface was treated with a silane provided a lower conductivity than untreated talc, a better compatibility with silicone and improved mechanical properties of silicone composite. Talc-filled silicone composite also exhibited a lower conductivity at higher temperatures compared to mica or wollastonite, making these very resistant to electrical breakdown during fire. Sweet and Gallmeyer from Dow Corning Corp. [70] and George et al. from Rhodia [49] used talc as filler in preparation of silicone rubber. The invention of Dow Corning Corp. deals with flame retardant silicone rubbers useful as marine deck coatings, firewall construction and fire-blanket applications. Rhodia's one deals with organopolysiloxane-based compositions vulcanizable by hot process into silicone elastomers, useful in particular for making electric wires or cables. Rhodia used talc alone or in combination with calcinated kaolin or calcium carbonate as semi-reinforcing filler.

\subsection{Montmorillonite (MMT)}

According to Gilman et al. [71], the general flame retardant mechanism of clay based nanocomposites is a build-up of a highperformance carbonaceous silicate char on the surface during burning. This layer insulates the underlying material and slows the mass loss rate of decomposition products. Recently Leszczyńska et al. [72] studied in detail the factors and mechanism that controls thermal stability of polymer/MMT nanocomposites. According to these authors, there are several factors that influence thermal stability of polymer/MMT nanocomposites, among which : (i) a labyrinth effect induced by intercalated or exfoliated structure of MMT, which limits oxygen diffusion inside the nanocomposite sample; (ii) a steric effect, in that MMT layers strongly interact with polymer matrix thus limiting the polymer chain motion; (iii) a mass barrier effect, which protects the bulk of sample from heat, decreases the rate of mass loss during thermal degradation of polymer nanocomposite and generates more intensive char formation on the surface; (iv) a heat barrier effect, that could also provide superheated conditions inside the polymer melt thus leading to extensive random scission of polymer chain and to the release of numerous chemicals. These degradation products trapped between clay layers have more opportunity to undergo secondary reactions; ( $v$ ) a catalytic effect of the nanodispersed clay effectively promoting char-forming reactions. It was also suggested that the more effective char production during thermal decomposition of polymer/clay nanocomposites may be favoured by chemical interactions between the polymer matrix and the clay layer surface during thermal degradation. Nanodispersed MMT layers were also found to interact with polymer chains in a way that forces the arrangement of macro-chains and restricts the thermal motions of polymer domains. Generally, the thermal stability of polymeric nanocomposites containing MMT is related to the organoclay content and the dispersion. Burnside and Giannelis [73] reported the synthesis of PDMS/organo-montmorillonite nanocomposites using melt intercalation. The organosilicate was prepared by ionexchanging $\mathrm{Na}^{+}$-MMT with dimethyl ditallow ammonium bromide and the hybrids were prepared by a sonication method. Fig. 13(a) shows the TG curves for both the unfilled PDMS and the PDMS nanocomposite containing $10 \mathrm{wt} \%$ of S04682 (a commercial organosilicate). The nanocomposite shows delayed decomposition compared to the unfilled polymer. Whereas PDMS decomposes into volatile cyclic materials, the permeability of the MMT/PDMS nanocomposite is dramatically decreased thus hindering volatile decomposition products. Besides, Burnside and Giannelis [74] observed an increase and a broadening of the glass-transition

Table 5

TGA analysis and corresponding flammability performances of fire-retardant MMT-filled silicone rubbers ${ }^{\mathrm{a}}$ [77].

\begin{tabular}{|c|c|c|c|c|c|c|c|c|c|}
\hline Sample & oMMT & $\mathrm{SiO}_{2}$ & $\mathrm{MDH}$ & $\mathrm{RP}$ & LOI (\%) & UL-94 test & $T_{-5 \%}\left({ }^{\circ} \mathrm{C}\right)$ & $T_{-50 \%}\left({ }^{\circ} \mathrm{C}\right)$ & Residue at $750^{\circ} \mathrm{C}(\%)$ \\
\hline MVMQ0 & 0 & 0 & 0 & 0 & 27.1 & $\mathrm{~V}-1$ & & & \\
\hline MVMQ1 & 0 & 20 & 20 & 5 & 29.0 & V-0 & 229.4 & 545.5 & 29.9 \\
\hline FSNCO & 1 & 0 & 0 & 0 & 29.4 & V-0 & 336.8 & 556.8 & 32.53 \\
\hline FSNC1 & 1 & 20 & 20 & 5 & 31.1 & V-0 & 358.7 & 594.7 & 33.50 \\
\hline FSNC2 & 3 & 20 & 20 & 5 & 29.5 & $\mathrm{~V}-0$ & 327.8 & 548.3 & 31.37 \\
\hline FSNC3 & 5 & 20 & 20 & 5 & 29.8 & V-0 & 311.2 & 553.2 & 34.21 \\
\hline FSNC4 & 7 & 20 & 20 & 5 & 30.2 & V-0 & 299.6 & 549.8 & 35.28 \\
\hline
\end{tabular}

\footnotetext{
${ }^{\text {a }}$ Each sample contain 100 parts of MVMQ and 2.8 parts of bis(2,4-dichlorobenzoyl) peroxide. Heating rate for TGA is $10^{\circ} \mathrm{C}$ min ${ }^{-1}$. For abbreviations, see text.
} 


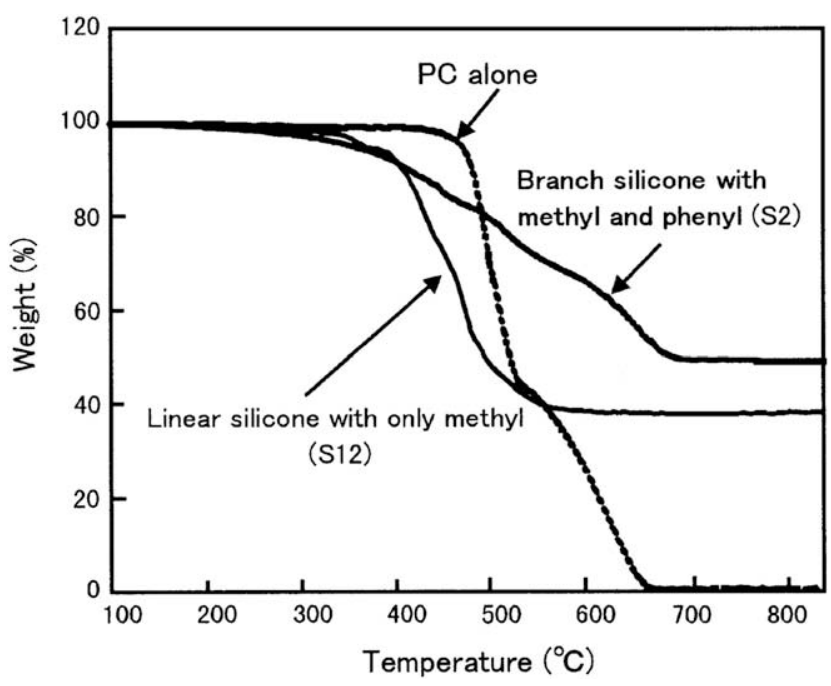

Fig. 14. Thermogravimetric analysis of PC/silicone derivative blends [79].

temperature and loss of the crystallization transition of the bound polymer chains of PDMS nanocomposites. Ma et al. [75] prepared exfoliated/intercalated polydimethylsiloxane (PDMS) nanocomposites by two steps, i.e. preparation of treated MMT solution and solution blending with PDMS. Incorporation of $10 \mathrm{wt} \% \mathrm{Na}^{+}-$ a

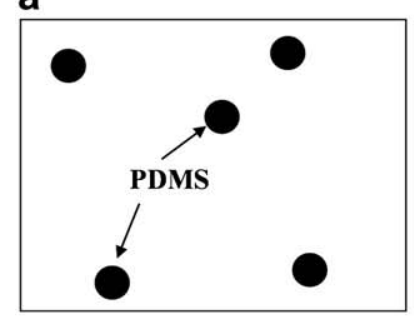

No silica b

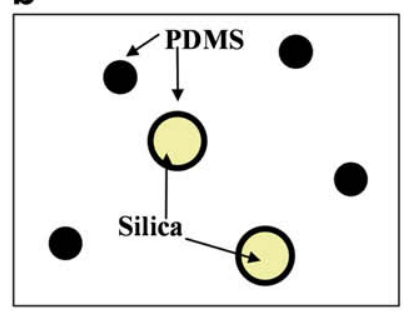

PDMS $>$ silica
C

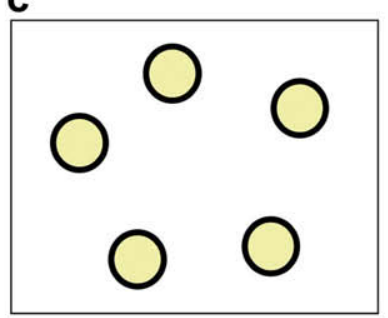

PDMS $=$ silica d

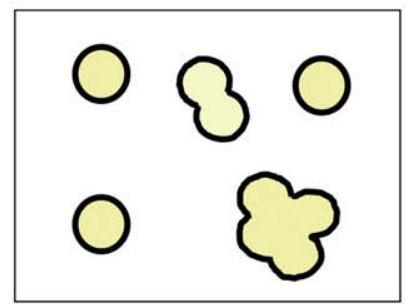

PDMS $<$ silica e

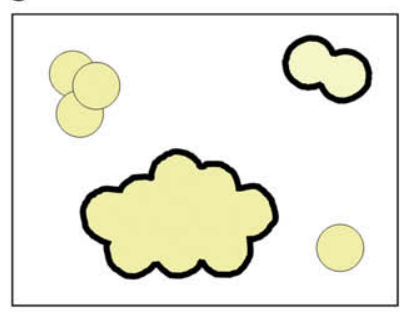

PDMS $<<$ silica
Fig. 15. Schematic distribution of PDMS in the PC-PDMS block copolymers containing nanosized silica [81].
MMT into the PDMS matrix shifted decomposition temperature of PDMS nanocomposite from 395 to $463^{\circ} \mathrm{C}$. The nanocomposites displayed delayed decomposition temperature compared to the pristine polymers again because of hindered diffusion of the volatile decomposition products. They found that PDMS was grafted onto MMT layer surface via condensation of hydroxyl groups of PDMS and those on MMT layer surface, then preventing nanolayers of MMT to re-aggregate. Wang et al. [76] synthesized silicone rubber/oMMT hybrid nanocomposites via melt-intercalation process. oMMT (organo-modified montmorillonite) was synthesized by dissolving $5 \mathrm{wt} \%$ of $\mathrm{Na}^{+}$-MMT in an excess of hexadecyltrimethylammonium bromide. This process advantageously does not need any solvent, so it is easy to apply in industry. oMMT particles were exfoliated into nano-scale layers of about $50 \mathrm{~nm}$ thickness from their original $40 \mu \mathrm{m}$ particle size and uniformly dispersed in silicone rubber matrix (hydroxyl-terminated polydimethylsiloxane). The mechanical properties and thermal stability of the hybrids were very close to those of aerosilica-filled silicone rubber. In terms of thermal properties, silicone rubber/oMMT hybrid nanocomposites showed the enhancement of thermal stability of PDMS. Fig. 13(b) shows the TG traces of unfilled silicone rubber and filled silicone rubber with 8.1 vol\% of filler (oMMT or aerosilica). Decomposition temperatures of the filled silicone rubber were $433^{\circ} \mathrm{C}$ for the hybrid and $440{ }^{\circ} \mathrm{C}$ for the aerosilicafilled silicone rubber, both higher than that of the unfilled silicone rubber $\left(381^{\circ} \mathrm{C}\right)$. Yang et al. [77] prepared flame-retardant methyl vinyl silicone rubber (MVMQ)/montmorillonite nanocomposites by solution intercalation method, using magnesium hydroxide (MDH) and red phosphorus (RP) as synergistic flame retardant additives, and aerosilica $\left(\mathrm{SiO}_{2}\right)$ as synergistic reinforcement filler (Table 5). The oMMT used was montmorillonite modified by hexadecyl trimethyl ammonium bromide with average particle size $5 \mu \mathrm{m}$. In this report, they showed that the nano-dispersed lamellae of oMMT (exfoliation or intercalation) in MVMQ rubber matrix have the main flame-retardant effect and this nanocomposite have a good flame retardant synergistic effect with MDH and RP. The nanocomposites show higher thermal stabilities, flame-retardant properties, and excellent mechanical properties. The nanocomposite containing $1 \mathrm{wt} \%$ of oMMT enhanced LOI of MVMQ/oMMT from 27.1 to $29 \%$, while the MVMQ/oMMT/MH/RP/SiO 2 hybrids had LOI of $31.1 \%$ and achieved V-0 rating on the UL-94 test. The synergistic flame retardant mechanism by using MVMQ/oMMT nanocomposites is mainly ascribed to the physical process occurring in condensed phase. A silicate layers may protrude on the surface of a burning nanocomposite, creating a physical protective barrier on the surface of the material. These layers act as a protective barrier and can limit the oxygen diffusion to the substrate.

\section{Silicone and modified silicone as flame retardants in other polymer matrices}

In a number of studies, silicones have been used as flame retardant synergists to modify the manner in which more conventional plastics burn. Silicones can be used as flame retardant agents through direct blending within the polymer matrix, incorporation into porous fillers, or by synthesizing block/graft

Table 6

LOI of different particles size silica in PC-PDMS block copolymers (1 wt\% PDMS) [81].

\begin{tabular}{llll}
\hline Silica types & Average particle sizes & Silica content (wt\%) & LOI (\%) \\
\hline Colloidal silica & $50 \mathrm{~nm}$ & 0.5 & 38 \\
& $20 \mathrm{~nm}$ & 0.5 & 40 \\
Microsilica & $16 \mu \mathrm{m}$ & 0.5 & 27 \\
Nanosized-silica & $50 \mathrm{~nm}$ & 0.5 & 40 \\
& $50 \mathrm{~nm}$ & 2 & 34 \\
\hline
\end{tabular}


a<smiles>[2H]P1(=O)Oc2ccccc2-c2ccccc21</smiles>

DOPO

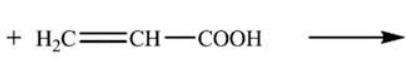

AA<smiles>O=C(O)CP1(=O)Oc2ccccc2-c2ccccc21</smiles>

b<smiles>CO[As](C)(C)CCCNCCN</smiles><smiles>CC(C)[Si](C)(C)O[Si](C)(C)C</smiles>

PDMS

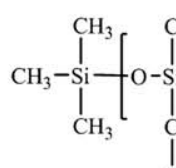

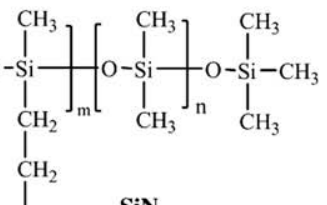

C

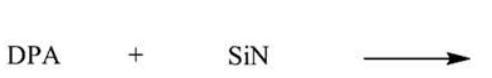

Scheme 9. The synthesis route of DPA-SiN flame retardant.

copolymers including silicone segments. Cone calorimeter evaluations reported by Pape and Romenesko [78] showed that the silicone powder additives give improved fire retardant properties such as reduced peak and heat release rate, reduced levels of carbon monoxide generation and reduced levels of smoke evolution in a variety of polymer systems including polyolefins, polycarbonate, polystyrene, PPO, polyamide, even at addition levels of $1-5 \mathrm{wt} \%$. Silicone powder additive is a combination of polydimethylsiloxane and fumed silica. This combination is necessary to give a free flowing powder, as well as to affect burning characteristics. This powder has been modified with organofunctional reactivity (amino, epoxy, or methacrylate) to enhance the compatibility in various polymer systems. Combination with conventional fire retardant systems, such as halogen/antimony, ammonium polyphosphate, and water evolving fire retardant products such as magnesium hydroxide also gave improvements in flame retardancy.

\subsection{Polycarbonate (PC)-PDMS block copolymer}

Iji and Serizawa [79] used several types of silicone polymers as flame retardant in polycarbonate (PC). Silicones tested varied in their chain structure (linear or branched type), the nature of functional groups in the chain (methyl, phenyl, mixture of them) and the type of end-groups (methyl, phenyl, hydroxyl, methoxy, vinyl). Branched silicone polymers containing a mixture of methyl and phenyl groups along the chain and end-capped by methyl groups proved the most effective in enhancing LOI values and final residue (Fig. 14). According to the authors, the superior flameretardant effect of the silicone derivatives (branched silicone with methyl and phenyl) is due to their excellent dispersion and migration on the surface of PC during combustion, where they form a uniform and highly flame resistant barrier. The formation of a highly flame-resistant char resulted from combination of polysiloxane and condensed aromatic compounds onto the PC surface. Furthermore, the efficiency of the branched silicones was observed to increase with decreasing molecular weight due to accelerated migration to PC surface as a result of its lower viscosity. Nodera and Kanai [80] reported the different flame retardancy effects between nano-sized and micro-sized silica in PC-PDMS block copolymer. They found that the thermal stability and the amount of residue for PC-PDMS block copolymer were slightly enhanced by adding the nano-sized silica. It is thought that the maximum loss rate decreases with increasing nano-sized silica content because the residue has a good sealing efficiency. Meanwhile, micro-sized silica or silica aggregated at more than $1.0 \mathrm{wt} \%$ of silica in PC-PDMS block copolymer has little effect on the sealing efficiency of residue because micro-sized silica cannot cover on enough of the surface of the residue. Furthermore, when the nano-sized PDMS domains ( $\sim 50 \mathrm{~nm}$, which has high flame retardancy) move to surface of the 

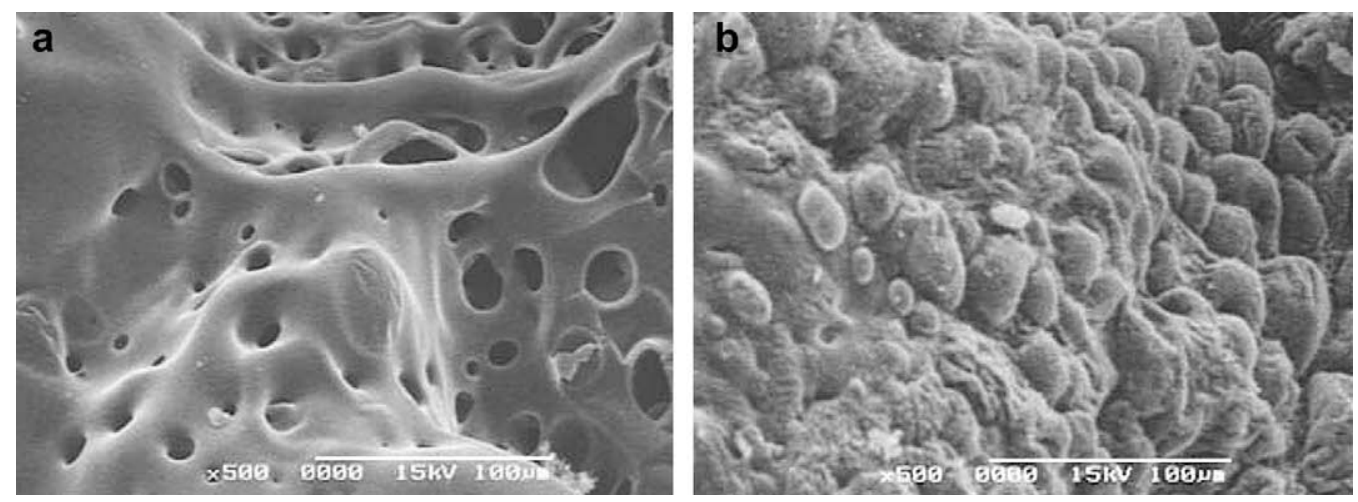

Fig. 16. SEM micrographs of (a) the inner surface and (b) the outer surface of the char layer [85].

micro-sized silica particles, the interaction between PC and PDMS decreases and so the flame retardancy of PC-PDMS block copolymer decreases. Further works by Nodera and Kanai [81] showed that monodisperse nano-sized silica ( $50 \mathrm{~nm}$, in powder form) had a positive effect on the flame retardant mechanism of PCD-PDMS, whereas colloidal silica (nano-sized silica dispersed in liquid polyethyleneglycol) with a median particle size of $20 \mathrm{~nm}$ has higher flame retardancy as compared with this of $50 \mathrm{~nm}$. The enhancement of the flame retardancy was ascribed to the fact that the PCPDMS block copolymer is mainly distributed on the surface of the nano-sized silica through physical interactions. Indeed, the size of silica is almost the same as the size of PDMS domains effective in flame retardancy (domain size $\sim 50 \mathrm{~nm}$ ). Furthermore, micro-sized silica has a little effect on the sealing efficiency of residue because micro-sized silica cannot cover enough on the surface of the residue. It is supposed that the PDMS on the surface of micro-sized silica has a behaviour similar to large PDMS domain ineffective in flame retardancy. Therefore, polymers with micro-sized silica or a lot of aggregated nano-sized silica have lower LOI values (Table 6). Based on such results, Nodera and Kanai [81] proposed a conceptual model of silica distributions in PDMS which influence the flame retardancy efficiency of PDMS (Fig. 15). When the nanosized silica content is less than the PDMS content (Fig. 15(b)), silica is perfectly dispersed in the matrix and fully covered with PDMS. The monodisperse silica is effective in the flame retardant enhancement of matrix polymer. In that case, it is thought that PDMS located on the surface of nano-sized silica particle exhibits higher thermal stability than PDMS alone and generates high sealing residue covered with more nano-sized silica particles in combustion. As the nano-sized silica content increases, a part of the silica particles aggregates but still the aggregated silica surface is covered with PDMS (Fig. 15(d)). At large silica content, the content of uncovered aggregated silica particles and single silica particle increased (Fig. 15(e)). Since the flame retardancy of PDMS is low, the thermal degradation behaviour of the polymer composite is decreased. Yasuhiro and Kazuhiko [82] used both PDMS and $\mathrm{TiO}_{2}$ which surfaces were treated with siloxane to provide remarkable flame retardancy to PC resin composition. In this composition, PC resin achieved V-0 rate in flammability test according to UL-94 standard. In other work to improve flame retardancy of PC, Barren

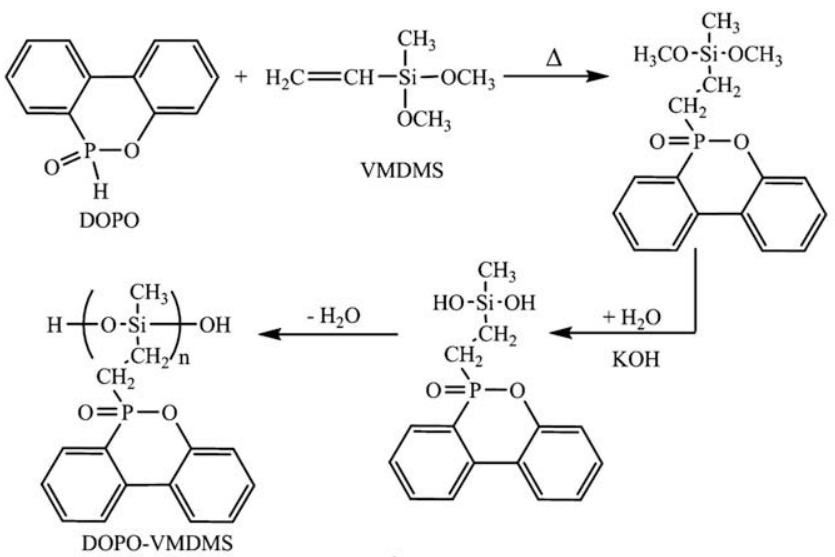

Reaction I

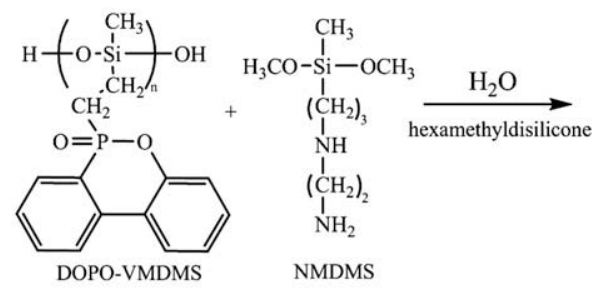

Reaction II

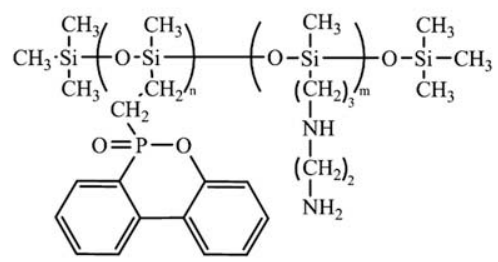

DOPO-VMDMS-NMDMS

Scheme 10. The synthesis route for DOPO-VMDMS-NMDMS (DVN). 
et al. [83] used $\mathrm{TiO}_{2}$ surface treated with PDMS as pigment and flame retardant agent in PC. Lupinski and Howkins [84] also used up to $9 \mathrm{wt} \%$ of PDMS-treated fillers such as $\mathrm{TiO}_{2}$, clay or carbon black in PC resin order to improve flame retardancy of resin by achieving V-0 rate for UL-94 test.

\subsection{PC/poly(acrylonitrile-butadiene-styrene) (ABS)}

Silicone additives can be modified by introduction of heteroatom-containing molecules that may have synergistic effect in flame retardant action. Zhong et al. [85] used flame retardant containing phosphorous, nitrogen and silicon elements simultaneously in a PC/ABS alloy. This type of flame retardant was synthesized through a simple method depicted scheme 9. 9-(9,10-Dihydro-9-oxa-10-phosphaphenanthrene-10-oxide)-propanoic acid (DPA) was synthesized through direct addition reaction of 9,10-dihydro-9-oxa-10-phosphaphenanthrene-10-oxide (DOPO) and acrylic acid (AA). DOPO has high thermal stability, oxidation resistance, and good water resistance. DPA was introduced into $\mathrm{N}$ $b$-(aminoethyl)-c-aminopropyl methyl dimethoxy silane/dimethyl siloxane copolymer ( $\mathrm{SiN}$ ) to form the flame retardant called DPASiN. Incorporation of $30 \mathrm{wt} \%$ of DPA-SiN into PC/ABS improved the LOI value from 21 to 27 with 2.2 wt\% of P, 2.4 wt\% of Si and 1.2 wt\% of $\mathrm{N}$. At this loading level, the HRR, THR and EHC are reduced to about half of unmodified $\mathrm{PC} / \mathrm{ABS}$. It was reported that the addition of DPA-SiN changed the thermal behaviour of PC/ABS by forming more stable char layer during thermal decomposition. Unfortunately, this type of flame retardant could not increase TTI as expected, because it decomposed earlier than the polymer. The morphological structure of char formed by DPA-SiN modified PC/ABS blends indicates that a smooth and compact char layer was obtained at $800^{\circ} \mathrm{C}$ whereas char layer could swell well to form a barrier to resist the transfer of heat and mass during a fire (Fig. 16). Another type of flame retardant containing Si, P and $\mathrm{N}$ for PC/ABS alloys has also been developed by Zhong et al. [86]. This type of flame retardant called DVN was synthesized from the reaction of DOPO, vinylmethyldimethoxy silane (VMDMS) and $\mathrm{N}-\beta$ (aminoethyl)- $\gamma$-aminopropyl methyl dimethoxy silane (NMDMS) (Scheme 10). In PC/ABS, DVN has activity in both condensed phase and gas phase. Incorporation of up to $30 \mathrm{wt} \%$ DVN into PC/ABS alloys has improved thermal stability and flame retardancy by enhancing LOI of PC/ABS alloys from 21.2 to 27.2. The highest LOI was obtained if DVN contain $2.8 \mathrm{wt} \% \mathrm{P}, 3 \mathrm{wt} \% \mathrm{Si}$ and $0.5 \mathrm{wt} \% \mathrm{~N}$. At the same loading level of flame retardant DVN (typically $30 \mathrm{wt} \%$ ), Zhong et al. [87] observed a decrease in LOI by decreasing $\mathrm{P}$ and increasing $\mathrm{Si}$ and $\mathrm{N}$ contents. The morphological structures of the chars obtained after the LOI test were observed by SEM (Fig. 17) [86]. The outer surface is smooth and plain while the internal surface exhibits cell structure. The swollen internal structure, dense and smooth outer surface provide a good barrier to the transfer of heat and mass during the fire. The char retards the overflow of the flammable volatiles at high temperature. The thermal decomposition performance of PC/ABS/DVN occurs through decomposition of phosphorus-containing groups to hydrate the char source-containing groups in a fire or during heating. Then, they form a continuous and protective carbon-silica layer. The gases generated by the nitrogen-containing groups form the carbon-silica layer. $\mathrm{SiO}_{2}$ reacts easily with phosphate to yield silicophosphate which is known to stabilize phosphorus species.

\subsection{Ethylene butyl acrylate (EBA)}

In the early 1990s, Davidson and Wilkinson [88] reported the improvement of flame retardancy of acrylate-based copolymers in wire and cable applications by addition of chalk and silicone. $5 \mathrm{wt} \%$ of trimethylsilyl chain-ended PDMS gum containing nominally $0.2 \mathrm{~mol} \%$ vinyl groups and $30 \mathrm{wt} \%$ of stearate coated calcium carbonate having an average particle size of 1.5 microns were added into $65 \mathrm{wt} \%$ of EBA copolymer (noted CaSiEBA in the following). This formulation successfully increased the LOI value of EBA copolymer from 18 to 34. Later on, the flame retardancy of EBA copolymer containing silicone and chalk has been investigated in detail by two groups in Sweden, namely the group of researchers from Borelys Technology Oy (Hermansson, Sultan, or Huhtala), and Krämer et al. [89]. Beside the development of flame retardancy of CaSiEBA type, they also studied CaSiEBA application as flame retardant in polyolefin polymers. Both of these groups used EBA, chalk and silicone from the same supplier i.e. Borealis AB (Sweden). Table 7 compares the results gained on the cone calorimeter and LOI tests using two slightly different CaSiEBA formulations. Increasing silicone content in CaSiEBA slightly increased flame retardancy in term of cone calorimeter test results. This is probably due to the role of silicone in the formation of heat barrier layer (i.e. $\mathrm{CaSiO}_{4}$ ) through its reaction with chalk at high temperature. Hermansson's team observed that at $1000^{\circ} \mathrm{C}$ the char of CaEBA collapsed during burning while CaSiEBA formed an intumescent structure with a compact and flat char, even though LOI test did not show much differences between CaEBA and SiEBA (Table 8). According to Hermansson et al. [44], ester pyrolysis of ethyl butyl acrylate (EBA) which occurs at $300^{\circ} \mathrm{C}$, results in a reaction between the chalk and the carboxylic acid, leading to formation of gases and ionomers. The volatile species dilute and reduce the combustible gases transported to the flame front and cause the melt to effervesce hence generating an intumescent structure. The intumescent structure acts as a heat insulating layer protecting the material underneath from burning and preventing new combustible gases to reach the flame front. The intumescent structure is reinforced by the ionomers creating crosslinks in the melt. In addition, crosslinked points through the reaction between carboxylic acid (after ester pyrolysis of EBA) and calcium ions in chalk increases the melt viscosity and thus the stability of the (initial) melt. Hermansson et al. [90] also showed that the reinforcement of intumescent structure through an insulation effect is triggered by temperature. At high temperature (above $700{ }^{\circ} \mathrm{C}$ ) intumescent structure was stabilized by the presence of some calcium silicate. The fact that some calcium silicate is present in the surface layer shows that chalk to a small extent has been converted to calcium oxide, although the conversion rate is slow below $700^{\circ} \mathrm{C}$. The final ash residue consists of cavities of different sizes due to insulation effect of outer layer. Two layers can be seen, where the bulk layer consists mainly of chalk and the protective surface layer consists of chalk and traces of amorphous silica. The flame retardancy of composites is known to be strongly affected by the dispersibility of flame retardant agents in the matrix, enhanced by a good adhesion at the filler-matrix interface [91]. Hermansson et al. [92] thus studied the effect of chalk and silicone distributions to flame retardant efficiency. A homogeneous distribution of chalk particles in the polymer matrix leads to a larger contact area between the chalk particles and polymer matrix, which is positive for the interactions and the chemical mechanisms occurring between the solid phase and the melt phase. Homogeneous dispersion of silicone elastomer is also important, as it facilitates the formation a uniform thickness of $\mathrm{SiO}_{2}$ at the surface that withstands the pressure of volatile gases formed in the bulk, and the initial crack propagation that occurs at the weakest spots (lowest thickness) can most likely be reduced or perhaps entirely avoided. Indeed, more extensive mixing provided a better dispersion of chalk particles and silicone elastomer, as well as improved flame retardant properties as shown by cone calorimeter test at incident heat flux of $35 \mathrm{~kW} \mathrm{~m}^{-2}$ (Table 9). CaSiEBA manufactured in a full scale extruder (i.e. a $300 \mathrm{~mm} / 7 \mathrm{D}$ 

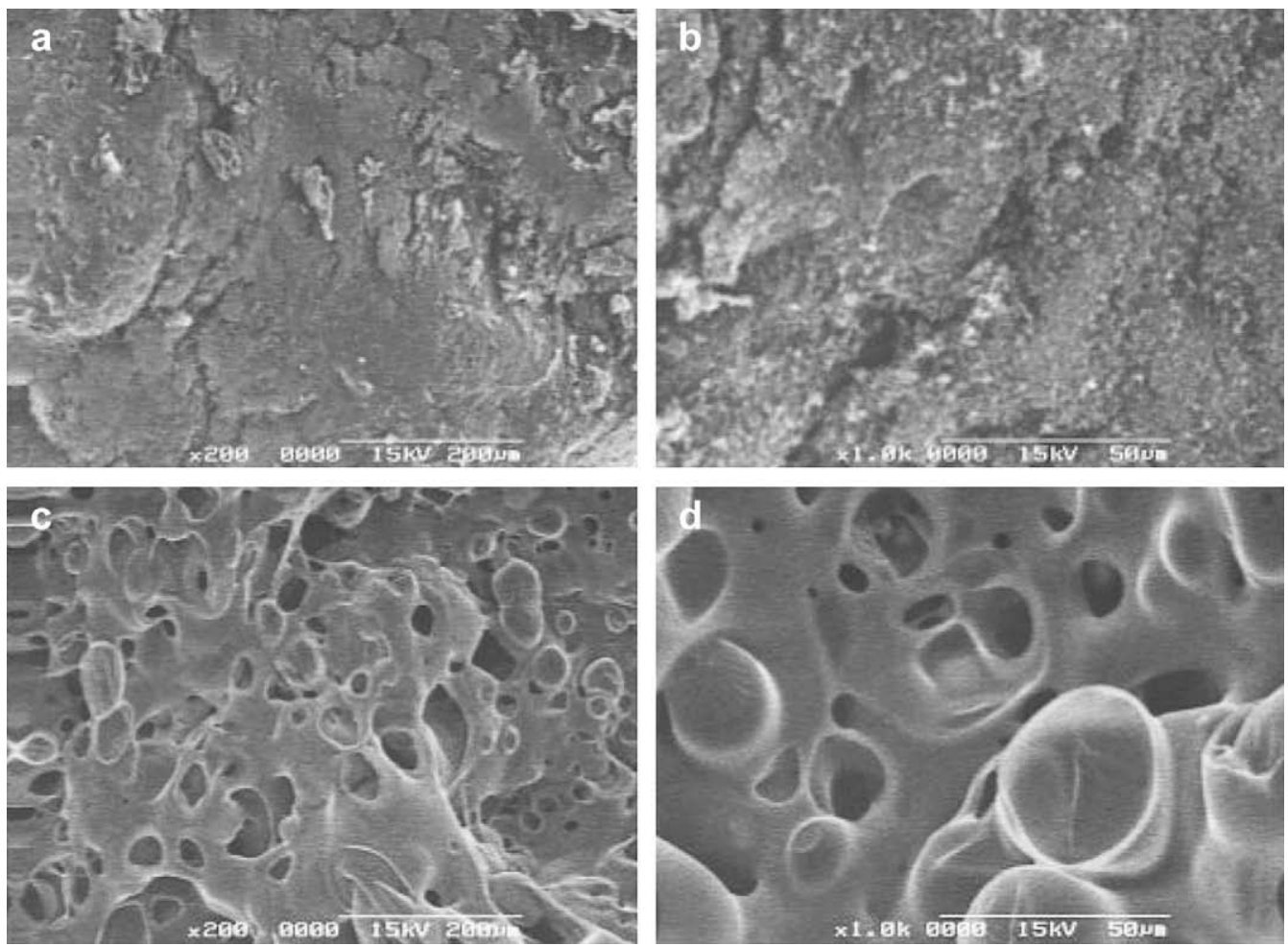

Fig. 17. The outer $(a, b)$ and internal $(c, d)$ surfaces of $P C / A B S / D V N-30$ after LOI test [86].

Buss-co-kneader, FSE in Table 9) has higher oxygen index (LOI) value than that of produced on a laboratory two-roll mill (TRM$4 \mathrm{~min}, \mathrm{TRM}-10 \mathrm{~min}$, etc. in Table 9). The two-roll mill was run at a rotation speed of $5 \mathrm{rpm}$ during addition of fillers and, thereafter, of $22 \mathrm{rpm}$, on both rolls. According to author, the oxygen index of materials produced on the two-roll mill is optimal at a mixing time of $20 \mathrm{~min}$. The flame retardancy of CaSiEBA can be further improved by introduction of some additives such as metal oxides. For cable and wire applications, Sultan et al. [93] from Borealis Technology Oy added $2 \mathrm{wt} \%$ of metal oxide such as $\mathrm{Al}_{2} \mathrm{O}_{3}(110 \mu \mathrm{m})$, $\mathrm{Fe}_{2} \mathrm{O}_{3}(7 \mu \mathrm{m})$, or $\mathrm{TiO}_{2}(3 \mu \mathrm{m})$ into CaSiEBA flame retardant in order to enhanced the LOI value of initial CaSiEBA (35) to 36, 39 and 39.5, respectively [93]. Moreover, Huhtala and Mohta [94], still from Borealis Technology Oy, disclosed that the partial substitution of calcium carbonates with oMMT nanofillers reduced dripping properties of burned materials. The particles of the nanofiller are dispersed in the polymer matrix so that the maximum thickness in polymer matrix in at least one dimension is below $10 \mathrm{~nm} .12 \mathrm{wt} \%$ of silicone in combination with $34 \mathrm{wt} \%$ of calcium carbonate was also used as a flame retardant agent of other acrylate-based polymers enhanced by PDMS addition in ethylene butyl acrylate (EBA) for wire and cable TG measurements (Fig. 18), which show that

Table 7

Result of the cone calorimeter tests of CaSiEBA compositions studied by Hermansson et al. [44] and Krämer et al. [89] groups ${ }^{\mathrm{a}}$.

\begin{tabular}{lll}
\hline Material & Hermansson & Kramer \\
\hline Chalk (wt\%) & 30 & $30-40$ \\
Silicone (wt\%) & 12.5 & $5-7$ \\
EBA (wt\%) & 57.3 & $\mathrm{NC}^{\mathrm{b}}$ \\
Additives (wt\%) & 0.2 (antioxidant Irganox 1010) & - \\
Peak HRR (kW m & -2 & $284 \pm 32$ \\
Ignition time (s) & 326 & $197 \pm 4$ \\
Mass loss (\%) & 148 & $62 \pm 2$ \\
\hline
\end{tabular}

a Cone calorimeter with $35 \mathrm{~kW} \mathrm{~m}^{-2}$ external heat flux.

b Not communicated. applications. Substitution with 4 wt\% of alkyl quarternary ammonium montmorillonite decreased HRR average of EBA composite from 257 to $215 \mathrm{~kW} \mathrm{~m}^{-2}$. Silicone and chalk not only improve flame retardancy of EBA, but combination of these compounds has also been used as flame retardant in other polymers. A commercial flame retardant with silicone, calcium carbonate in the form of chalk and EBA is currently available under the trend name Casico $^{\mathrm{TM}}$ [44]. The flame retardant mechanism of Casico is complex and is related to a number of reactions, e.g. ester pyrolysis, formation of carbon dioxide, ionomer formation and formation of an intumescent structure stabilized by a protecting char. Later studies by Krämer et al. [89] have confirmed the role of chalk and silicone in an ethylene-acrylate based copolymer by using these materials as flame retardant agent in PP. Formulations were based on an ethylene-butyl acrylate copolymer blended with polypropylene with a ratio 4:3 (CaSiEBA-PP), and an ethylene-methacrylic acid copolymer (CaSiEMAA, see also next part). In all formulations, the acrylate content is $8 \mathrm{wt} \%$ in the EBA copolymer, the chalk filling level $30-40$ wt\% and the silicone amount $5-7$ wt\%. Fig. 18 shows the TGA of these blends. The mass loss in a nitrogen atmosphere was very similar for all three formulations, proceeding principally in a single step which led to significant mass losses above $400^{\circ} \mathrm{C}$ with a maximum rate at $460-470^{\circ} \mathrm{C}$. The more pronounced mass loss for CaSiEBA compared to CaSiEBA-PP is consistent with the higher butyl acrylate content in the former material (Fig. 18(a)) [89]. Under thermo-oxidative degradation, CaSiEBA-PP and CaSiEBA polymers displayed degradation in the three temperature regions, with

Table 8

Effect of chalk and silicone additions to flame retardancy of EBA copolymers [44].

\begin{tabular}{lllcl}
\hline Material & LOI $(\%)$ & Peak HRR $\left(\mathrm{kW} \mathrm{m}^{-2}\right)$ & Ignition time $(\mathrm{s})$ & Mass loss (\%) \\
\hline EBA & 18 & 1304 & 77 & 98.1 \\
SiEBA & 19 & 1044 & 84 & 98.7 \\
CaEBA & 20 & 656 & 102 & 71.7 \\
CaSiEBA & 30.5 & 326 & 148 & 65.9 \\
\hline
\end{tabular}


Table 9

Cone calorimetry results and LOI data for different mixing times of CaSiEBA composite $^{\mathrm{a}}[92]$.

\begin{tabular}{llllll}
\hline Material $^{\mathrm{b}}$ & $\begin{array}{l}\text { Mixing time } \\
(\mathrm{min})\end{array}$ & $\begin{array}{l}\text { Max HRR } \\
\left(\mathrm{kW} \mathrm{m}^{-2}\right)\end{array}$ & $\begin{array}{l}\text { Average HRR } \\
\left(\mathrm{kW} \mathrm{m}^{-2}\right)\end{array}$ & $\begin{array}{l}\text { Average ignition } \\
\text { time }(\mathrm{s})\end{array}$ & $\begin{array}{l}\text { LOI } \\
(\%)\end{array}$ \\
\hline TRM-4 min & 4 & - & - & - & 31.5 \\
TRM-10 min & 10 & 384 & 264 & 109 & 32.0 \\
TRM-20 min & 20 & 326 & 194 & 148 & 34.0 \\
TRM-30 min & 30 & - & - & - & 32.5 \\
FSE & - & 364 & 226 & 139 & 38.0 \\
\hline
\end{tabular}

a Formulation: $30 \mathrm{wt} \%$ of chalk, $12.5 \mathrm{wt} \%$ of silicone and $57.3 \mathrm{wt} \%$ of EBA; cone calorimetry with incident heat flux of $35 \mathrm{~kW} \mathrm{~m}^{-2}$.

b TRM: two roll mill, FSE: full scale extruder.

a minor mass loss at $250{ }^{\circ} \mathrm{C}$, followed by two major steps at $355^{\circ} \mathrm{C}$ and $430{ }^{\circ} \mathrm{C}$. The subsequent mass loss above $600^{\circ} \mathrm{C}$ was due to degradation of the chalk filler. Acrylic acid and butyl acrylate polymers are known to show a significant decomposition at $360^{\circ} \mathrm{C}$ (Fig. 18(b)). The higher initial mass loss of CaSiEBA-PP at $250^{\circ} \mathrm{C}$ as compared to CaSiEBA, indicates the earlier decomposition of PP. Ignition of CaSiEBA-PP occurred as the surface layer reached temperatures between 350 and $400^{\circ} \mathrm{C}$, as was seen in Fig. 18(b). At these temperatures, CaSiEBA-PP has a significant mass loss, yielding the volatiles necessary for the ignitable gas. IR spectroscopy analysis confirmed that the decomposition of PP preceded the decomposition of EBA and provided a significant contribution to the ignitable gases. Therefore, the combustion of CaSiEBA-PP selfaccelerates and leads to a rapid pyrolysis on the polymer surface.
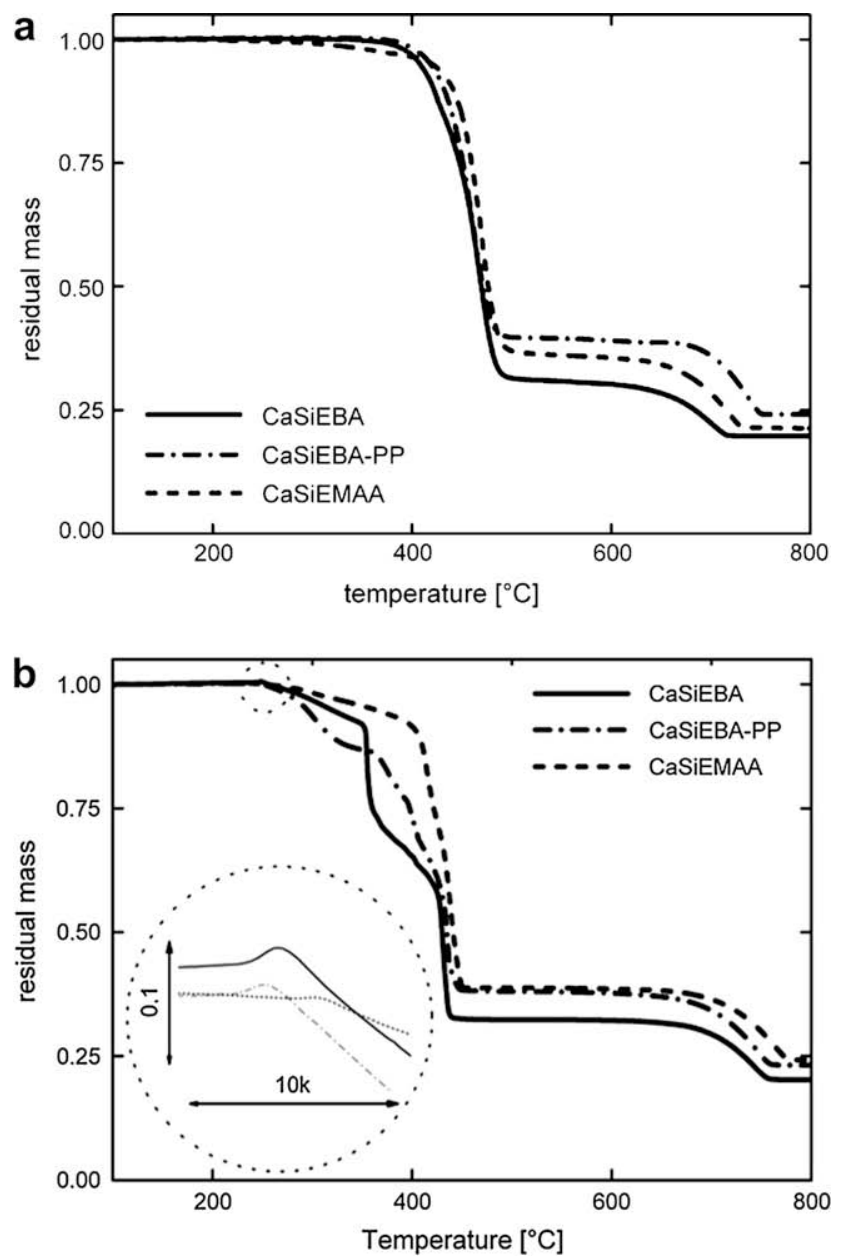

Fig. 18. TG data of several ethylene acrylate-based polymers containing flame retardant chalk and silicone at a heating rate of $10{ }^{\circ} \mathrm{C} \mathrm{min}^{-1}$ : (a) in nitrogen, (b) in air [89].
Moreover, the inner part of the composite did not have much time to undergo the beneficial calcium salt formation, which might lead to char expansion. This explained why the melt viscosity of CaSiEBA-PP was much lower than that for CaSiEBA [89].

\subsection{Ethylene-methacrylic acid (EMAA), ethylene-methyl acrylate (EMA), and ethylene-ethyl acrylate (EEA) copolymers}

Silicone as flame retardant in EMAA was studied by Krämer et al. [89]. EMAA copolymers were blended with chalk and silicone to form an ethylene-methacrylic acid copolymer (CaSiEMAA). The acrylate content of EMAA is $9 \mathrm{wt} \%$, the chalk filling level amounted to $30-40 \mathrm{wt} \%$ and the silicone amounted to $5-7 \mathrm{wt} \%$ of the blends. The TGA showed the enhancement of thermal stability of EMAA by addition of chalk and silicone (Fig. 18). Thermo-oxidative degradation of CaSiEMAA displayed degradation in three temperature regions, with a minor mass loss at $250{ }^{\circ} \mathrm{C}$, followed by major step at above $415^{\circ} \mathrm{C}$, and increasing further at $430{ }^{\circ} \mathrm{C}$, while the mass loss at $600{ }^{\circ} \mathrm{C}$ was due to degradation of chalk (Fig. 18(b)). In their previous work, Krämer et al. [95] demonstrated the significant effect of coated and uncoated precipitated calcium carbonate nanoparticles with an average size of $70 \mathrm{~nm}$ on the thermal and thermo-oxidative stabilities of EMAA with a low filler content ( $5 \mathrm{wt} \%$ ). Here, the high thermal stability of the EMAA formulation does not rely strongly on the silicone glass layer, but may rather be due to an interaction between calcium ions and carboxylate ions (Scheme 11). The char of the highly crosslinked samples was more stable but dissected by a myriad of small cracks. These observations agree with the assumption that the formation of calcium salt stabilises the polymer chains of EMAA and prevents a reduction in molar mass, rather than inducing a strong inter-chain cross-linking in the polymer. The increased melt viscosity shortens the time to ignition but significantly reduces heat release rate as measured by cone calorimetry. Two factors contributed to the melt viscosity of the polymer [89]: (i) Surface cross-linking on the particle surface between polymer and chalk. Calcium salt formation in polymer surface stabilizes the polymer chains and prevents a reduction in molar mass. Low viscosity suggests that inter-chain crosslinking by the calcium ion bonds is weak. (ii) Oxygen contributes to the increase in "complex viscosity". Char formation is stronger in an oxidative environment, whereas the materials melt and form a pool in nitrogen. Oxygen may lead to cross-linking of the polymer chains to form a silicon oxide network on the sample surface through reactions with the silicone in the formulation. Note that studying the char stability and melt viscosity in detail is important, since it can be related to melt dripping which presents a major hazard in a fire: indeed, it increases the burning surface area which can lead to more intense fire and faster fire spread. Thermal improvement of other acrylate polymers thanks to PDMS was extensively studied by several authors. Santra et al. [96] reported that blends of ethylene methyl acrylate (EMA)-PDMS have different thermal stabilities depending on the composition of PDMS. Lower content of PDMS i.e. $30 \mathrm{wt} \%$ showed lower thermal stability compared to higher contents, i.e. above $50 \mathrm{wt} \%$. The authors explained this result by formation of new $\mathrm{C}-\mathrm{C}$ bond between EMA and PDMS as the result of crosslinking between radicals from EMA degradation and vinyl groups in PDMS. Later on, PDMS blended with ethylene ethyl acrylate (EEA) was reported to give the same beneficial effect as in EMA-PDMS blend [97].

\subsection{Low density polyethylene (LDPE)}

Silicone elastomer containing chalk was used by Hermansson et al. [44] to improve flame retardancy of LDPE. LOI and cone calorimeter tests were performed on a composition containing 


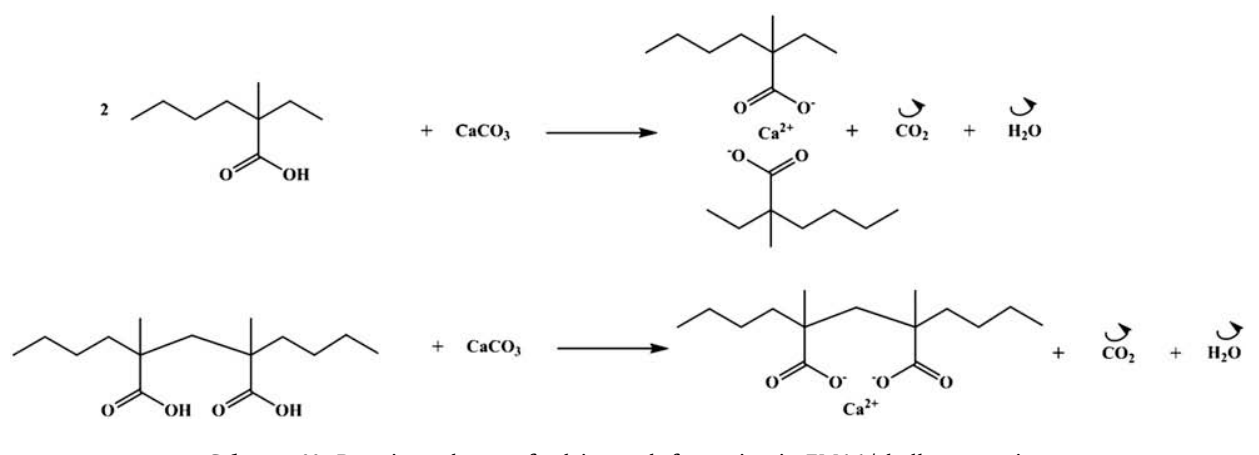

Scheme 11. Reaction scheme of calcium salt formation in EMAA/chalk composite.

about $12.5 \mathrm{wt} \%$ of silicone elastomer, $30 \mathrm{wt} \%$ of chalk and $57.3 \mathrm{wt} \%$ of LDPE, a halogen-free flame-retardant material with intumescent behaviour. The LOI value increased from 18 to 24.5, while cone calorimeter test at heat flux of $35 \mathrm{~kW} \mathrm{~m}^{-2}$ also showed a remarkable improvement in term of HRR, TTI, and mass loss (Table 10). According to Hermansson et al. [44], the flame retardancy in LDPE was exerted through synergetic formation from silicone and chalk of stable intumescent structure covered by chars as heat barrier, thus preventing combustible gases to maintain the flame. Addition of silicone only to LDPE could not lead to the formation of this heat barrier. TGA showed that there was no more residue of SiLDPE at a temperature of $500{ }^{\circ} \mathrm{C}$, whereas in CaSiLDPE they found $29.8 \mathrm{wt} \%$ of residue at $500{ }^{\circ} \mathrm{C}$ and $17.2 \mathrm{wt} \%$ of residue at $1000^{\circ} \mathrm{C}$ respectively. Silicone alone has also been studied to enhance thermal stability of LDPE. Increasing thermal stability of LDPE by PDMS was explained by crosslinking formation between radicals from degradation product of LDPE and vinyl groups in PDMS backbone [97]. Degradation of LDPE, which is the source of radicals in the melt of the components, begins before the degradation of PDMS ceases, to favour crosslinking together with formation of new alkyl groups on the silicon atoms. Since blends of LDPE-PDMS are immiscible, ethylene-methyl acrylate copolymer was introduced as a chemical compatibiliser in the 50:50 blend of LDPE and PDMS rubber previously studied by Santra et al. [98]. EMA reacted with PDMS rubber during melt-mixing at $180^{\circ} \mathrm{C}$ to form EMA-grafted PDMS rubber (EMA-g-PDMS) in situ. An optimum proportion of the compatibiliser (EMA) was found to be $6 \mathrm{wt} \%$. Later on, Jana and Nando [99] confirmed this result after investigating the thermal stability of blends of LDPE and PDMS (50:50) compatibilised with various proportions of EMA as polymeric compatibiliser. In addition to $\mathrm{C}-\mathrm{C}$ crosslinks in the blend system, EMA-g-PDMS acts as virtual bridges between the two components holding the continuous (LDPE) and dispersed (PDMS) phases together. Therefore, formation of intra- as well as inter-molecular crosslinking between LDPE and PDMS matrix enhances the mechanical strength and stability of the blend. At higher proportions of EMA (beyond $6 \mathrm{wt} \%$ ), most likely EMA-g-PDMS tends to form a separate phase with respect to LDPE and PDMS. In another study of EMA incorporation as compatibiliser in 75:25 LDPE-PDMS rubber blends, Jana et al. [100] found that the addition of $2 \mathrm{wt} \%$ EMA showed the optimum thermal stability compared to other compositions with 0 and $6 \mathrm{wt} \%$ EMA. Thus the quantity of compatibiliser (EMA) required for the different compositions of LDPE-PDMS needs to be systematically optimized.

\section{Table 10}

TGA, LOI and cone calorimeter results of CaSiLDPE [44].

\begin{tabular}{llllc}
\hline Material & Peak HRR $\left(\mathrm{kW} \mathrm{m}^{-2}\right)$ & Ignition time $(\mathrm{s})$ & Mass loss $(\%)$ & LOI (\%) \\
\hline LDPE & 1420 & 76 & 99.4 & 18 \\
SiLDPE & & & & 0 \\
CaLDPE & & 95 & 69.4 & 17.2 \\
CaSiLDPE & 320 & 95 & 24.5 \\
\hline
\end{tabular}

\subsection{Polypropylene (PP)}

Modified silicone-based flame retardant containing phosphorus, nitrogen and silicon called PSiN has been synthesized and used in polypropylene (PP) [101]. PSiN was prepared with various ratios of $\alpha, \omega$-dihydroxy-polydimethylsiloxane (PDMS), $N$ - $\beta$-(aminoethyl)- $\gamma$-aminopropyl methyl dimethoxy silane (HD-103) in SiN synthesis by the route showed in Scheme 9(b) and neopentyl glycol phosphonyl chloride (PCII) (Scheme 12). Li et al. [102] reported that PSiN application in PP provided flame retardant performance as well as thermal stability for PP. At $30 \mathrm{wt} \%$ loading of PSiN, LOI value of PP/PSiN was enhanced from 17 to 26 , and the char yield at $800{ }^{\circ} \mathrm{C}$ was improved from 0 to $27 \mathrm{wt} \%$ with $4.4 \mathrm{wt} \%$ of $\mathrm{P}, 2 \mathrm{wt} \%$ of $\mathrm{Si}$, and $1 \mathrm{wt} \%$ of $\mathrm{N}$. The phosphorus in PSiN provides possibility for the PP blends to form char, and the silicon improves the thermal stability of char because when temperatures of PP/PSiN increased, siliconcontaining compounds melt and migrate to the surface of the materials due to their low surface energy. Phosphorus-containing compounds degrade at relatively low temperature to form protective phosphorus-carbon layer with weak phosphorate bonds. The nitrogen-containing compounds in the sample decompose to generate ammonia or other molecules. The high heat-insulating, heat-resistant generation and incombustible ammonia gas plays a role in reducing the flammability of materials. It is not flammable and can dilute the concentration of the oxygen near the surface of materials as well as swell the carbon layer during a fire. The silicon containing compounds degrade to generate silicon dioxide that could not be oxidized further and be left in the carbon layer, therefore it improves the thermal stability of the char layer. The foamed and thermally stable carbon layer shows good insulation properties in heat and mass transfer, which results in the improvement of fire performance of the polymer. A filler such as wollastonite was also added into PDMS to enhance flame retardancy of polypropylene. In a patent of Dow Corning, Romenesco and Shephard [103] proposed to disperse wollastonite in conjunction with a silicone gum or silicone base in a thermoplastic polyolefin (mainly polypropylene and polyethylene) resin. These materials were prepared with a view to improve insulation and jacketing materials for transmission media cable applications. They mentioned that the wollastonite used should have a particle size of 2-30 $\mu \mathrm{m}$, a needle-like shape, an aspect ratio (length:diameter) of $3: 1$ or greater. When burned, these thermoplastic silicone vulcanisates develop char structures with good integrity, and exhibit extremely low flame spread and smoke and heat generation properties. They showed that a better char structure is formed on burning when the calcium silicate is added at a ratio above $25 \mathrm{wt} \%$, based on the total formulation. The upper limit of calcium silicate that is useful will depend on the properties desired in the uncured and cured compositions. Generally, calcium silicate present at greater than about $60 \mathrm{wt} \%$ of the total formulation results in uncured compositions too stiff and therefore difficult to process. 
$\mathrm{Cl}-\prod_{\mathrm{Cl}}^{\mathrm{O}}-\mathrm{Cl}$<smiles>CC(C)(CO)CO</smiles><smiles>CC1(C)COP(=O)(Cl)OC1</smiles>

(PCII)

$\mathrm{PC}$ II $+\mathrm{SiN} \longrightarrow \mathrm{PSiN}$

Scheme 12. The synthesis route of PSiN flame retardant.

\subsection{Poly(vinyl acetate) (PVAc)}

Zulfiqar and Ahmad [104] studied the thermal stability of PVAc blended with several types of siloxane such as PDMS, polydiphenylsiloxane (PDPS) and poly(dimethyl/diphenylsiloxane) (PDMDPS). The thermal stability of PVAc-PDMS blends of different compositions is shown in Fig. 19. Polysiloxanes are substantially more stable than PVAc, so that increasing the quantity of polysiloxane in the blends, gradually increases the stability. Blends of PVAc and PDMS also led to slightly larger residue contents than the pure siloxane. This behaviour was explained by authors on the basis of crosslinking induced by the presence of catalysing agents such as $\mathrm{CH}_{3} \mathrm{COOH}$ or acetate radicals which are released by PVAc. The free radicals diffusing from the PVAc phase are responsible for abstraction of hydrogen atoms from methyl groups in PDMS.

\subsection{Ethylene vinyl acetate (EVA)}

In EVA copolymer for wire and cable applications, Davidson and Wilkinson [88] reported that the addition of $5 \mathrm{wt} \%$ of trimethylsilyl chain-ended PDMS gum and a stearate coated calcium carbonate (average particle size of $1.5 \mu \mathrm{m}$ ) remarkably improved flame retardancy of EVA copolymer (Table 11). Andreasson et al. [105] reported that, silicone together with calcium carbonate and MDH improved flame retardancy of EVA composites for cable and wire applications in terms of LOI. LOI of 40.8 was obtained when EVA composites contain $6.25 \mathrm{wt} \%$ of silicone, $29 \mathrm{wt} \%$ of calcium carbonate and $29 \mathrm{wt} \%$ of precipitated $\mathrm{MDH}$. Addition of $2 \mathrm{wt} \%$ of $\mathrm{TiO}_{2}$ having average particle size of $2.5 \mu \mathrm{m}$ into EVA composites filled with MDH remarkably improved flame retardancy compared to EVA alone by LOI enhancement of about 36 to 37 .

\subsection{Polystyrene (PS)}

A composition containing 80:20 of PS-PDMS blend was synthesized and the thermal degradation and pyrolysis mechanisms were studied in detail by Lomakin et al. [106]. According to these authors, the flame retardation mechanism of PS by PDMS occurs both from thermal stabilization of PS in one hand and thermal destabilization of PDMS on the other hand, via crosslinking reactions of styrene and dimethylsiloxane fragments (Scheme 13). This mechanism has been proven by analyses of pyrolysis products formed from the PS-PDMS blend. At $600{ }^{\circ} \mathrm{C}$ they observed two new compounds. The first compound, apparently formed by the cross-reaction (termination) of two macroradical fragments of the PS and PDMS chains, was identified as 3-phenyl-1-(3', $3^{\prime}, 5^{\prime}, 5^{\prime}, 7^{\prime}, 7^{\prime}, 9^{\prime}, 9^{\prime}$-octamethylcyclopentasiloxy)butane (I in Scheme 13) and the second compound is a radical fragment of PS. Then at $800^{\circ} \mathrm{C}$, they found a new product identified as phe$\operatorname{nyl}\left(3^{\prime}, 3^{\prime}, 5^{\prime}, 5^{\prime}, 7^{\prime}, 7^{\prime}\right.$-hexamethylcyclotetrasiloxy)propane, and formed by the cross-reaction of radical fragments of PS and PDMS degraded chains.

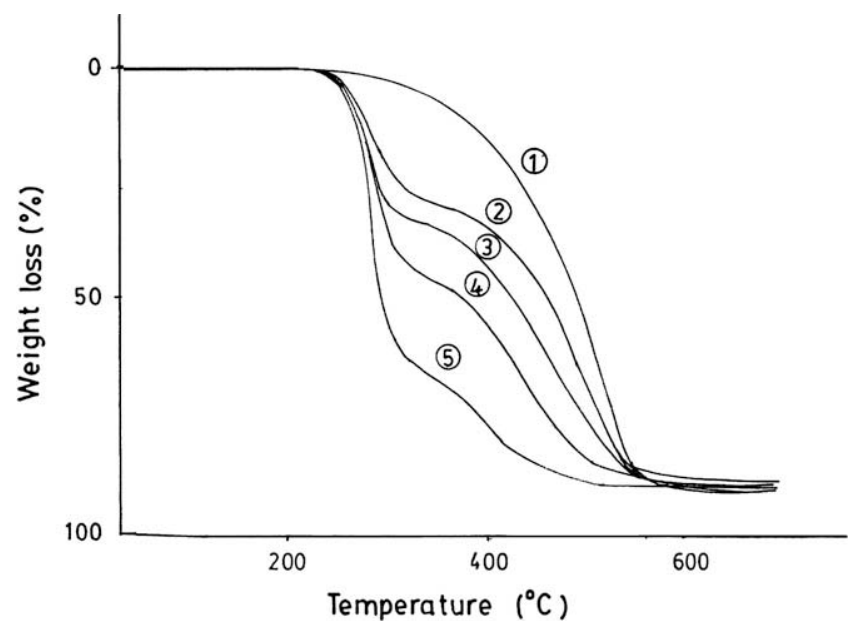

Fig. 19. TG curves (dynamic nitrogen, heating rate $10{ }^{\circ} \mathrm{C} / \mathrm{min}$ ) for PDMS:PVAc blends: 100\% PDMS (1), 75\% PDMS (2), 50\% PDMS (3), 25\% PDMS (4) and 0\% PDMS (5).

\subsection{Poly(vinyl chloride) (PVC)}

McNeill and Basan [107] reported the thermal degradation of blends of PVC with PDMS by thermogravimetry over the whole composition range. The results show destabilization at low loadings of PDMS, but for compositions with $50 \%$ or more PDMS, both polymers are stabilized. Similar effects were reported in the case of PVC blending with other polysiloxane polymers such as PDPS and PDMDPS [108] blends. Blends of higher siloxane contents show stability throughout the decomposition range, which increases with the siloxane concentrations due to delay in the release of chloride radicals.

\subsection{Polyurethane (PU)}

Belva et al. [109] reported that PDMS could not enhance the heat stability of polyurethane (PU) in thermo-oxidative conditions, but the amount of high temperature residue increased and depended on the amount of PDMS incorporated in PU chains due to formation and accumulation of silica (Fig. 20). PU/PDMS hybrid formed a protective layer limiting heat transfer between the flame and the substrate. In order to improve miscibility of PDMS in PU-PDMS blend, Santra et al. [110] proposed the addition of ethylene-methyl acrylate (EMA). The effect of EMA copolymer as a reactive polymeric compatibiliser in the blend was proven by mechanical property measurements and phase morphology studies. Similar to its compatibilising properties in LDPE-PDMS blend [98], EMA reacted with PDMS rubber during melt mixing to produce EMA- $g$ PDMS rubber in situ, which acted as the compatibiliser for the binary system of TPU and PDMS rubbers. EMA-g-PDMS rubber is believed to undergo specific interaction via hydrogen bonding with the TPU matrix through the ketone $(\mathrm{C}=0)$ group of EMA and the unassociated amine (-NH-) group of TPU, whereas the PDMS

\section{Table 11}

LOI value enhancement of different types of EVA copolymers by addition of silicone and stearate coated $\mathrm{CaCO}_{3}[88]$.

\begin{tabular}{lllll}
\hline $\begin{array}{l}\text { Vinyl acetate content } \\
\text { in EVA copolymer (\%) }\end{array}$ & $\begin{array}{l}\text { EVA content } \\
(\mathrm{wt} \%)\end{array}$ & $\begin{array}{l}\text { Silicone } \\
(\mathrm{wt} \%)\end{array}$ & $\begin{array}{l}\mathrm{CaCO}_{3} \\
(\mathrm{wt} \%)\end{array}$ & $\begin{array}{l}\text { LOI } \\
(\%)\end{array}$ \\
\hline 28 & 65 & 5 & 30 & 27 \\
28 & 60 & 5 & 35 & 28 \\
28 & 55 & 5 & 40 & 29 \\
28 & 50 & 5 & 45 & 34 \\
18 & 50 & 5 & 45 & 29 \\
40 & 50 & 5 & 45 & 30 \\
\hline
\end{tabular}




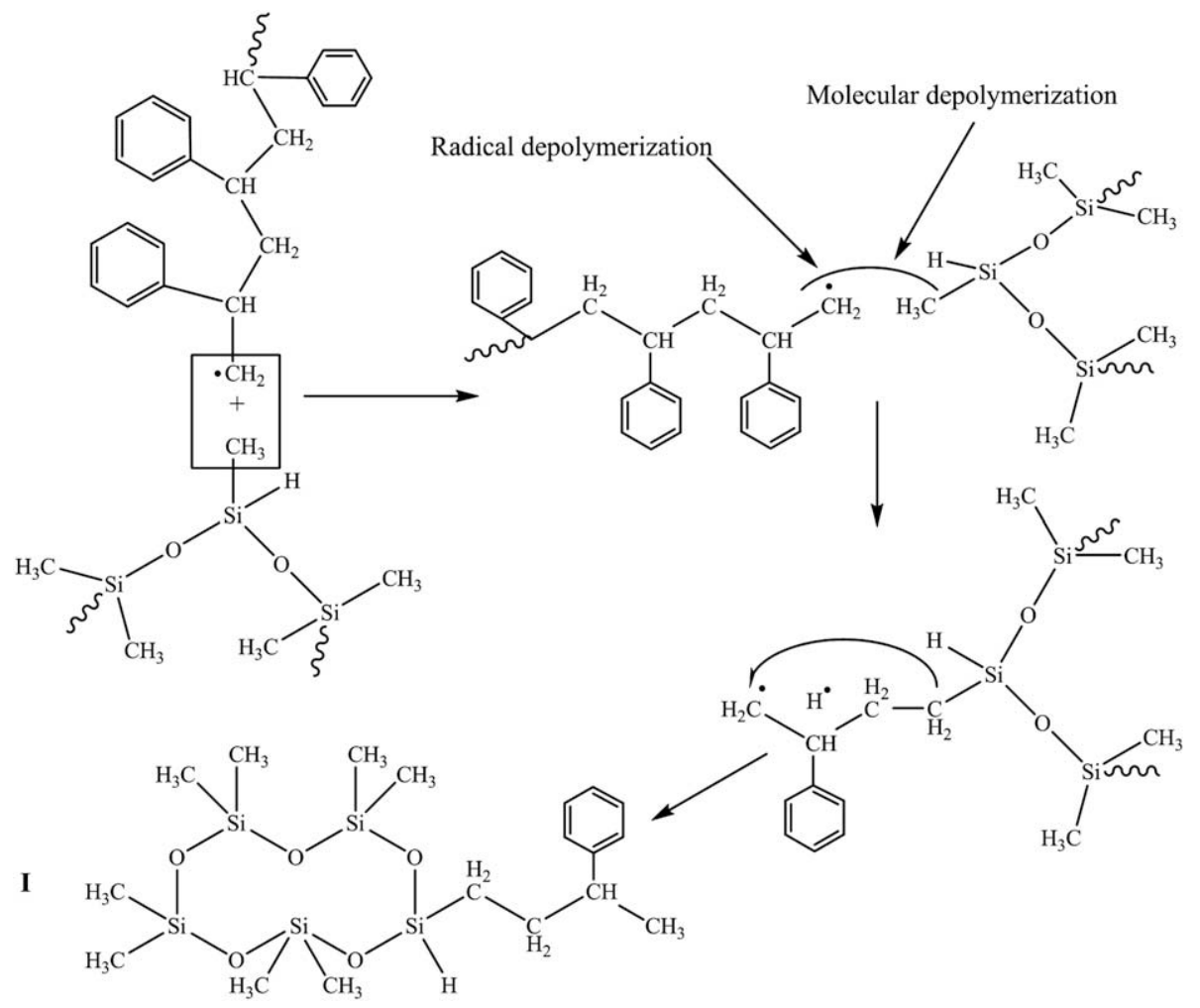

Scheme 13. Pyrolysis mechanism of polystyrene-polydimethylsiloxane blend.

rubber in the EMA-g-PDMS disperses well with the bulk PDMS matrix.

\subsection{Polyamide-6 (PA-6)}

Dong et al. [111] have developed two elastomeric flame retardants to improve flame retardancy of polyamide 6. S-ENP is made of resin silicone nanoparticles with $T_{\mathrm{g}}$ of $-120^{\circ} \mathrm{C}$ and particle size of $\sim 100 \mathrm{~nm}$, and S-ENPC is S-ENP where unmodified clay with a dry weight ratio of $4 / 1$ has been added. It has been found that S-ENP not only increases the toughness and improves the flame retardancy of polyamide-6, but also helps, in S-ENPC, unmodified clay exfoliate in polyamide- 6 matrix (Fig. 21 ). The flammability properties of polyamide- 6 composites characterized by cone calorimetry showed that nanocomposite containing $10 \mathrm{phr}$ of S-ENP decreased the lower peak heat release rate (PHRR) down to 60\% compared to pure polyamide- 6 , compared to $68 \%$ lower for composites containing $10 \mathrm{phr}$ of S-ENPC. In S-ENPC, S-ENP and clay were found to have a synergistic flame retardant effect on polyamide- 6 resulting from the formation of two barriers, coat-like layer and island-like flocculates, on the surface of the nanocomposite residue at the end of combustion.

\subsection{Epoxy resin}

Liu and Chou [112] compared nano-scale silica, diglycidylether terminated-polydimethylsiloxane (PDMS-DG) and TEOS as siliconsource additive in phosphorus epoxy resin. Nano-scale silica could not migrate to surface of degraded residues during thermal degradation of epoxy resin, so it failed to show synergism with phosphorus on flame retardation. PDMS-DG and TEOS showed significant performance in silicon migration and could form a protective layer for preventing/retarding further degradation of char, but self-degradation of PDMS-DG during the heating period resulted in some silicon loss in the condensed phase. Thus, formation of epoxy-silica hybrid structure through sol-gel reactions by using TEOS was a good approach for achieving phosphorus-silicon synergism of flame retardation in epoxy resins. Hsiue et al. [113] found that synergistic effect of phosphorus-silicon on epoxy resin fire resistance can be further levelled up by using modified siloxane reagents to replace silanes. They mixed $44.3 \mathrm{wt} \%$ of bis(3-glycidyloxy)phenylphosphine oxide (BGPPO) with $34.6 \mathrm{wt} \%$ of diamine aminopropyl-terminated polydimethylsiloxane (PDMS- $\mathrm{NH}_{2}$ ) in place of the triglycidyloxy phenyl (TGPS). They obtained a high LOI value of 45 for the resin with

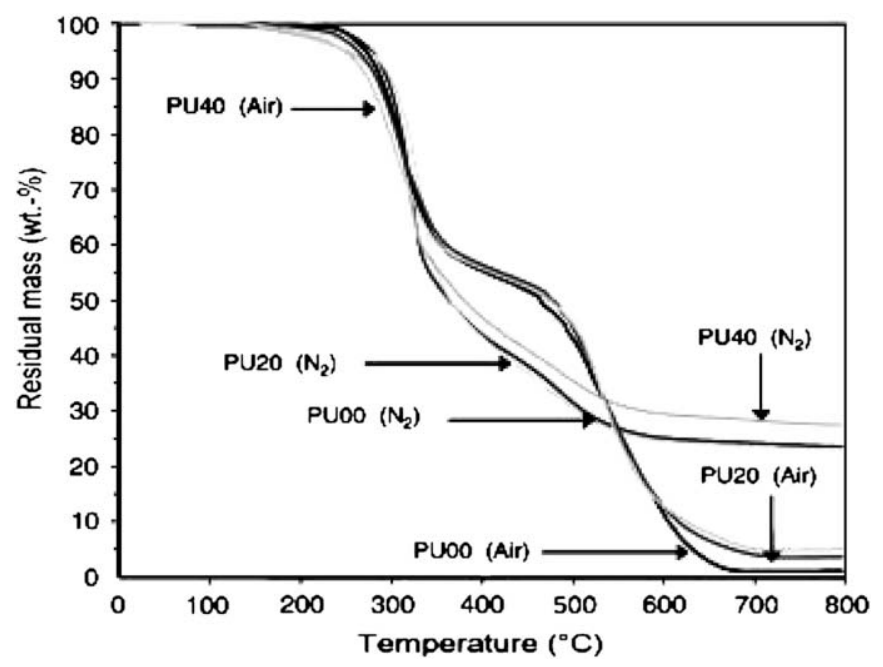

Fig. 20. TG curves of neat PU (PU00) and PU/PDMS hybrid (PU20: PU containing 20 wt\% of PDMS and PU40: PU containing 40 wt\% of PDMS) in nitrogen and air fluxes [109]. 


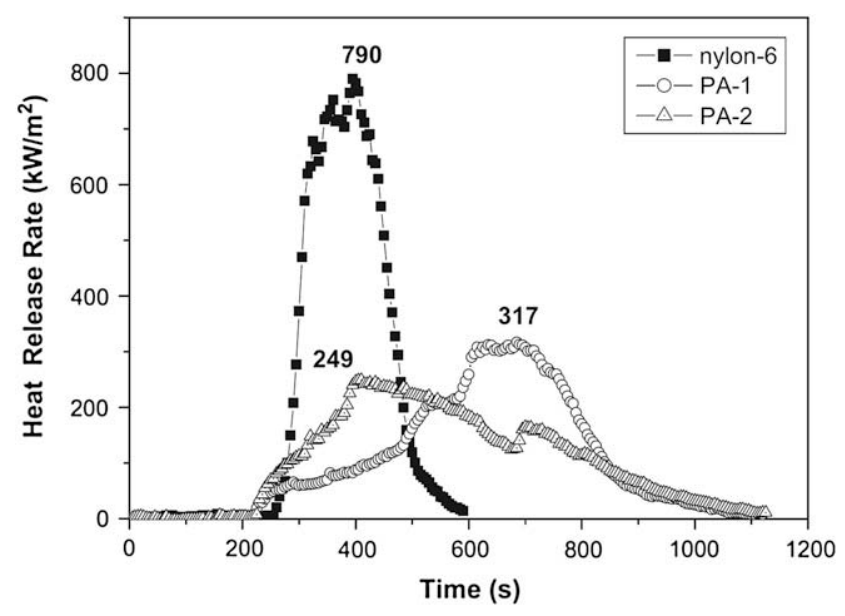

Fig. 21. Heat release rate (HRR) plots for pure polyamide-6, composite polyamide-6-SENP (PA-1) and composite polyamide-6-S-ENPC (PA-2) at a heat flux of $35 \mathrm{~kW} \mathrm{~m}^{-2}$ [111].

a phosphorus content of $4.8 \mathrm{wt} \%$ and a silicon content of $12.7 \mathrm{wt} \%$. Furthermore, the LOI values increased with the increase in silicon content. This highly synergistic flame retardation efficiency of siloxane with phosphorus mainly comes from the formation of a continuous silica layer, which reduces thermal oxidation of the phosphorus char.

\subsection{Poly(bisphenol fluorenone carbonate) (BPFPC)}

Only 5-10 wt\% of silicone in multi-sequenced copolymers of bisphenol fluorenone carbonate and PDMS could enhance the LOI values of BPFPC from 38 to 51 [114]. Above $15 \mathrm{wt} \%$ of silicone blocks, LOI started to decrease. The residue changed from a fine, black, friable char formed with the homopolymer, to a more voluminous, very strong and large black char at moderate amounts of silicone, and to a gray, coarse, weak residue at high silicone contents. It was noticed that the mechanical properties of the formed char depended on the silicone content and represented an important requirement for obtaining higher LOI values.

\section{Conclusions}

Silicones are greatly acknowledged for their better thermal and thermo-oxidative stabilities compared to most carbon-based polymers. This acute resistance against flame has put PDMS in the top list of polymers for applications at high temperature where flame retarding behaviour is required. As a flame retardant, PDMS offers outstanding advantages such as halogen-free flame retardant with very low or almost zero emission of toxic smokes, thus considered to be among the "environmentally friendly" category of additives. Silicones can be used as flame retardant agents through direct blending within the polymer matrix, incorporation into porous filler, or by synthesizing block/graft copolymers including silicone segments. Silicone acts as a flame retardant through condensed phase by favouring the formation of a silica layer as a heat and mass transfer barrier. Therefore, the basic strategy of the flame retardation of silicone is to avoid ring formation and to increase the formation of silica as the pyrolysis product. Flame retardancy of silicone can be improved by filler addition. Several types of fillers have been used to improve flame retardancy of silicone, such as silica, calcium carbonate, wollastonite, mica, talc, kaolin, montmorillonite, carbon black, aluminium trihydrate, and magnesium dihydrate. Generally, calcium carbonate, wollastonite and mica improve flame retardancy of silicone by ceramization phenomena. Talc, kaolin, and montmorillonite improve flame retardancy of silicone by catalytic effect which accelerates silica layer formation. Fillers such as calcium carbonate, wollastonite, mica, kaolin, and montmorillonite also improve the mechanical properties of the silica layer, an important issue when one knows that the fragile ash of silica residue formed by firing silicone may not be strong enough to function as a barrier in flame retardation for certain applications. Metal hydrate (ATH or MDH) favours heat absorption but ATH is less ideal for use as flame retardant agent in PDMS formulations applied in wire and cable applications because of its relatively low decomposition temperature and crack generation which is of inconvenience in terms of residue cohesion. For this reason, probably boehmite would be a better choice to avoid crack generation in the residue of firing silicone. The technology of fire-resistant silicones passes through the addition of low contents of additives such as stabilizers, synergistic agents, etc. depending on final product application. For instance, platinum, $\mathrm{ZnO}, \mathrm{TiO}_{2}, \mathrm{ZrO}_{2}, \mathrm{CeO}, \mathrm{FeO}$, and $\mathrm{Fe}_{2} \mathrm{O}_{3}$ are additives that were commonly used to improve flame retardancy of silicone. Carbon nanotubes have hardly been tested as flame retardant fillers in PDMS, despite their known ability to dissipate heat. Finally, some works have shown that PDMS alone can enhance thermal stability of polycarbonate (PC), bisphenol fluorenone carbonate (BPFPC), nylon, and polyurethane. PDMS filled with flame retardants are used in some polymers such as PC-PDMS block copolymer, ethylene butyl acrylate (EBA), ethylene-methacrylic acid copolymer, polypropylene, low density polyethylene (LDPE), and ethylene vinyl acetate (EVA). Structure modification of silicone by incorporating some flame-retardant elements such as phosphorus and/or nitrogen has showed improved flame retardancy and intumescent char formation by synergistic effects. This type of siliconebased flame retardant has been widely used as additives in other polymer matrixes than silicone, such as polyurethane, PC/ABS alloy, polypropylene and epoxy resin.

\section{Appendix}

Main techniques of fire retardancy evaluation quoted in this review are summarized below.

\section{Cone calorimeter test}

The cone calorimeter test is at present the most advanced method for assessing materials' reaction to fire. Indeed, this test gives a possibility to evaluate: (i) the ignitability; (ii) the combustibility; (iii) the smoke production and (iv) the production of toxic gases. Fig. 22 shows the principle of the cone calorimeter, based on the principle of oxygen consumption calorimetry. Generally, the heat of combustion of any organic material is directly related to the amount of oxygen required for combustion in which $13.1 \mathrm{MJ}$ of heat is released per $\mathrm{kg}$ of oxygen consumed. The cone calorimeter brings quantitative analysis to materials flammability research by investigating parameters such as heat release rate (HRR), time to ignition (TTI), total heat release (THR) and mass loss rate (MLR). The HRR measurements can be further interpreted by looking at average HRR, peak HRR and time to peak HRR. Heat release rate is the key measurement required to assess the fire hazard of materials and products as it quantifies fire size, rate of fire growth and consequently the release of associated smoke and toxic gases. The cone calorimeter, if so configured, can also measure and quantify smoke output as well as $\mathrm{CO} / \mathrm{CO}_{2}$ release rates [115]. Cone calorimeter tests can be conducted in accordance with national and international standards including BS 476 (Part 15), ASTM E1354 and ASTM E1474, and ISO 5660-1. An example of cone calorimeter test according to ISO 5660-1:1993 is given hereafter [116]. The surface of the test specimen is exposed to a constant level of heat irradiance, within 


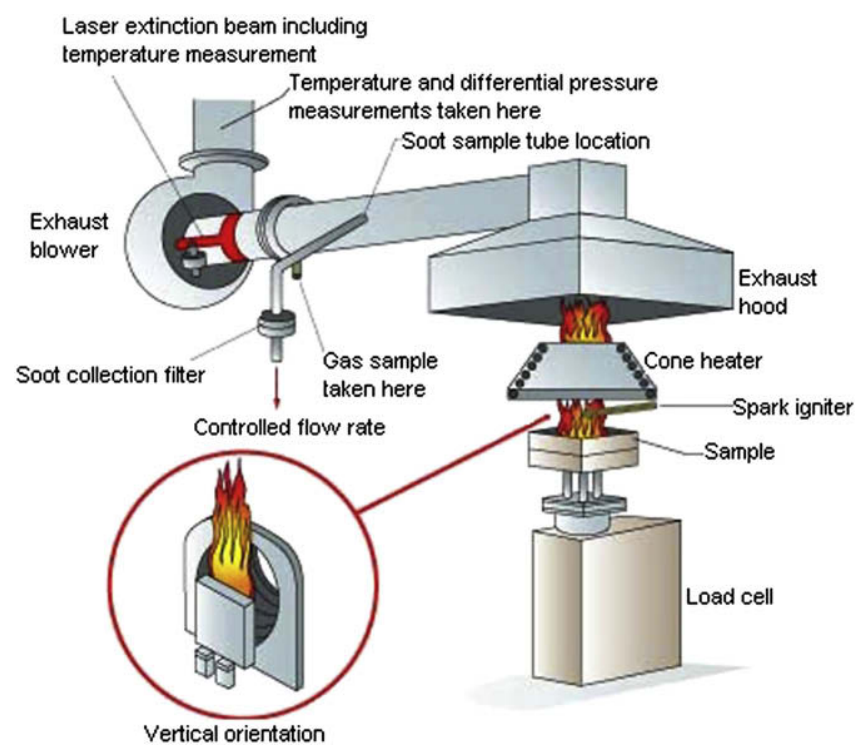

Fig. 22. Schematic principle of cone calorimeter [124].

the range $0-100 \mathrm{~kW} \mathrm{~m}^{-2}$, from a conical heater. Volatile gases from the heated specimen are ignited by an electrical spark igniter. Combustion gases are collected by an exhaust hood for further analysis. This gas analysis makes it possible to calculate heat release rate and to assess production of toxic gases from the specimen. Smoke production is assessed by measuring attenuation of a laser beam by smoke in the exhaust duct. The attenuation is related to volume flow, resulting in a measure of smoke density called smoke extinction area $\left[\mathrm{m}^{2} \mathrm{~s}^{-1}\right]$. The specimen is mounted on a load cell which records the mass loss rate of the specimen during combustion. A thorough analysis requires testing at several irradiance levels. Typical levels of irradiance are $25,35,50$ and $75 \mathrm{~kW} \mathrm{~m}^{-2}$. According to ISO 5660-1:1993(E), three specimens shall be tested at each heat flux level. The test result contains information about dimensions, pre-treatment and conditioning of the test specimens, and information about the test conditions. The following test results are tabulated: (i) time to ignition [TTI, s]; (ii) total heat released [THR, $\mathrm{MJ} \mathrm{m}^{-2}$ ], (iii) maximum heat release rate [MHR, $\mathrm{kW} \mathrm{m}^{-2}$ ], (iv) average heat release rate after $180 \mathrm{~s}$ and after $300 \mathrm{~s}$ [average $\mathrm{HRR}_{180}$, or average $\mathrm{HRR}_{300}, \mathrm{~kW} \mathrm{~m}^{-2}$ ], (v) effective heat of combustion [EHC, $\mathrm{MJ} \mathrm{kg}^{-1}$ ]; (vi) average smoke production $\left[\mathrm{m}^{2} \mathrm{~s}^{-1}\right]$, (vii) production of carbon monoxide (CO) [g]. It is also possible to measure production of other gas components, like cyanhydric acid (HCN). The following results are given graphically for each of the applied irradiation levels: (i) heat release rate [HRR, $\left.\mathrm{kW} \mathrm{m}{ }^{-2}\right]$; (ii) rate of smoke production $\left[\mathrm{m}^{2} \mathrm{~s}^{-1}\right]$; (iii) rate of production of $\mathrm{CO}$ and $\mathrm{HCN}\left[\mathrm{g} \mathrm{s}^{-1}\right]$; (iv) specimen mass as a function of time $\left[\mathrm{g} \mathrm{s}^{-1}\right.$ ]. The unit $\mathrm{m}^{2}$ is related to specimen area. The surface of the specimens shall be essentially flat. The specimens shall be representative of the product, and as far as possible be similar to the final product. A complete test requires that at least 12 specimens with dimensions of $100 \mathrm{~mm} \times 100 \mathrm{~mm}$ and of maximum thickness of $50 \mathrm{~mm}$ be tested. Different types of typical burning behaviour give rise to characteristic curves of HRR vs. time. Some are illustrated in Fig. 23 [117].

\section{Limiting oxygen index (LOI) test}

The limiting oxygen index (LOI) or oxygen index (OI) is a method for evaluation of the flammability of materials. LOI is defined as the minimum concentration of oxygen in an oxygen-nitrogen mixture, required to sustain combustion of a vertically mounted test specimen. Hence, higher LOI values represent better flame retardancy [118]. Preliminary tests are first carried out in order to ascertain the approximate $\mathrm{O}_{2} / \mathrm{N}_{2}$ ratio required for the material under investigation. This is reached when the materials burns at a uniform slow rate after ignition. The oxygen content of the $\mathrm{O}_{2} / \mathrm{N}_{2}$ mixture is then lowered until the test specimen just continues to burn. After the next lower $\mathrm{O}_{2}$ concentration (a reduction of $0.2 \%$ in the oxygen content) the test specimen must be extinguished. Table 12 reports the oxygen index test specifications [118]. The oxygen index is determined by the US standard ASTM D 2863-77 [119] procedure which has been introduced as Nordtest method NT Fire 013. Fig. 24 shows the principle of the measurement and a figure of LOI test equipment.

\section{UL-94 test}

UL-94 is the standard applied by the American Underwriters Laboratories for testing the flammability and fire safety of plastic materials used in devices and appliances [120]. The standard classifies plastics according to the way they burn in various orientations and thicknesses. UL-94 applies not only to the electrical industry but also to all areas of applications except the use of plastics in building. UL-94 is particularly significant for plastics used in electrical products since a UL listing of the product frequently requires

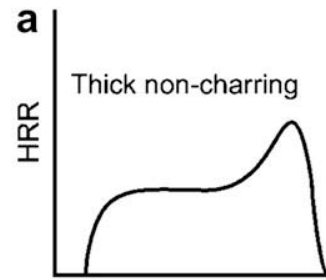

Time

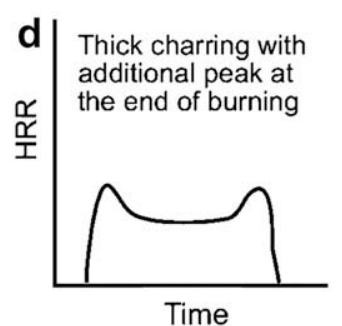

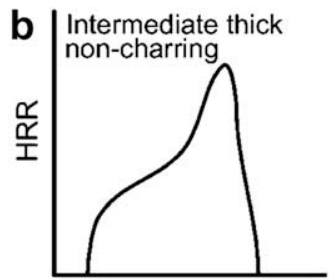

Time

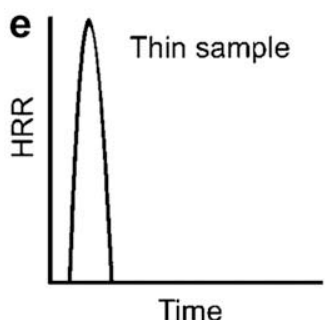

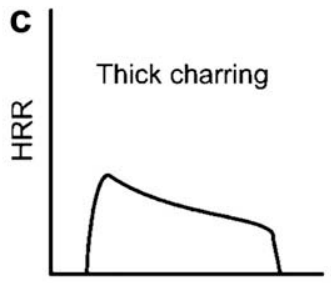

Time

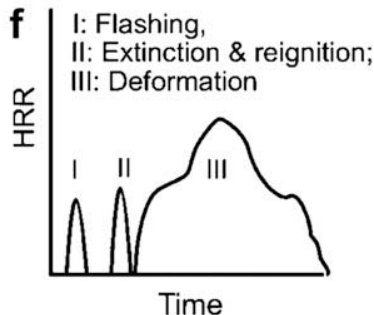

Fig. 23. Typical HRR curves for different characteristic burning behaviors [117]. 
Table 12

Oxygen index test specifications.

\begin{tabular}{ll}
\hline Specimens & 10 specimens $150 \mathrm{~mm} \times 6 \mathrm{~mm} \times 3 \mathrm{~mm}$ \\
Specimen position & Clamped vertically \\
Ignition source & Gas pilot flame \\
Test duration & $\begin{array}{l}\text { Until the minimum oxygen concentration } \\
\text { of an } \mathrm{O}_{2} / \mathrm{N}_{2} \text { mixture required to sustain } \\
\text { combustion is reached }\end{array}$ \\
& Expressed as $=100 \times \mathrm{O}_{2} / \mathrm{O}_{2}+\mathrm{N}_{2}$ (\%) \\
\hline
\end{tabular}

a favourable flammability classification of the materials used [121]. UL-94 contains test procedures for both horizontally and vertically positioned test specimens in the form of rods. In the UL-94 HB (Horizontal Burning) test, the burning of a horizontal plastic specimen is tested, and in the most demanding $\mathrm{HB}$, specifications are: slow burning on a horizontal specimen; burning rate $<76 \mathrm{~mm} /$ min for thickness $<3 \mathrm{~mm}$. In UL-94 V (Vertical Burning) tests, the test specimen is vertical and ignited by a Bunsen burner to be classified according to their burning times as V-0, V-1, V-2. These tests are more rigorous than the HB test since the vertical specimens are burned by their lower ends, thus preheating material above it, and the samples must extinguish themselves. The test layout is illustrated in Fig. 25. A flame is applied twice to the lower end of the vertically suspended test specimen for $10 \mathrm{~s}$. The top class, i.e. $\mathrm{V}-0$ is achieved if the mean inter-flame time of five samples after 10 applications of the flame does not exceed $5 \mathrm{~s}$. The material is placed in class V-1 if the mean after-flame time is less than $25 \mathrm{~s}$. If flaming drippings occur, the material is classified in V-2; the ignition of surgical cotton placed below the specimen serves as a criterion for this phenomenon.

\section{Relation between LOI, cone calorimeter and UL-94 tests}

Since cone calorimeter measures flammability in different manner than LOI and UL-94 fire tests, one should not be surprised by the poor correlation between them. Morgan and Bundy [116] tried to explain differences among LOI, cone calorimeter and UL-94 test. LOI is a small-scale test that uses a variable percentage oxygen atmosphere to maintain a candle-like burn, and UL-94 V applies a small calibrated flame twice under the sample (configured vertically) for $10 \mathrm{~s}$ followed by measuring time to extinguishment after each flame application. Cone calorimetry, on the other hand, uses a forced combustion in which radiant heat is projected onto a sample before ignition and during burning of the sample. The sample is usually in a horizontal configuration, thus eliminating any physical effects of polymer burning (dripping away from the flame, for example) that are sometimes used to pass the UL-94 V test, especially under the V-2 rating. Further, the sample in the cone calorimeter exposed to continuous heat during the test is well ventilated, whereas UL-94 is not. In effect, cone calorimeter measures the material response to constant fire threat with time, whereas UL-94 measures the material response to remove a fire threat and its time to self-extinction. Therefore, some studies have been conducted to show correlations between UL-94, LOI and cone calorimeter tests.

LOI and UL-94 relationship: there have been many efforts to correlate LOI and UL-94 tests systematically. Generally, the LOI values of UL-94 V-1, V-0 rated materials were higher than those of HB materials. However, it does not mean that higher LOI gives better UL-94 V ratings [122]. Weil et al. [123] reported that the LOI value might be levelled with UL-94 or cone calorimeter data to some degree in certain conditions but it was hard to show close relations between LOI and UL-94 or cone calorimeter data because of the downward burning test condition of LOI.

Cone calorimeter and UL-94 relationship: studies about the quantitative relationship between UL-94 V and cone calorimeter remain elusive, even if the cone calorimeter can be used to understand why a material passes or fails a particular UL-94 $\mathrm{V}$ rating [116]. In particular, a $\mathrm{HRR}_{0}>100 \mathrm{~kW} \mathrm{~m}^{-2}$ for materials showed sustained ignition (HB) in the UL-94 test, while a $\mathrm{HRR}_{0}<100 \mathrm{~kW} \mathrm{~m}^{-2}$ correlated well with self-extinguishing behaviour [124].
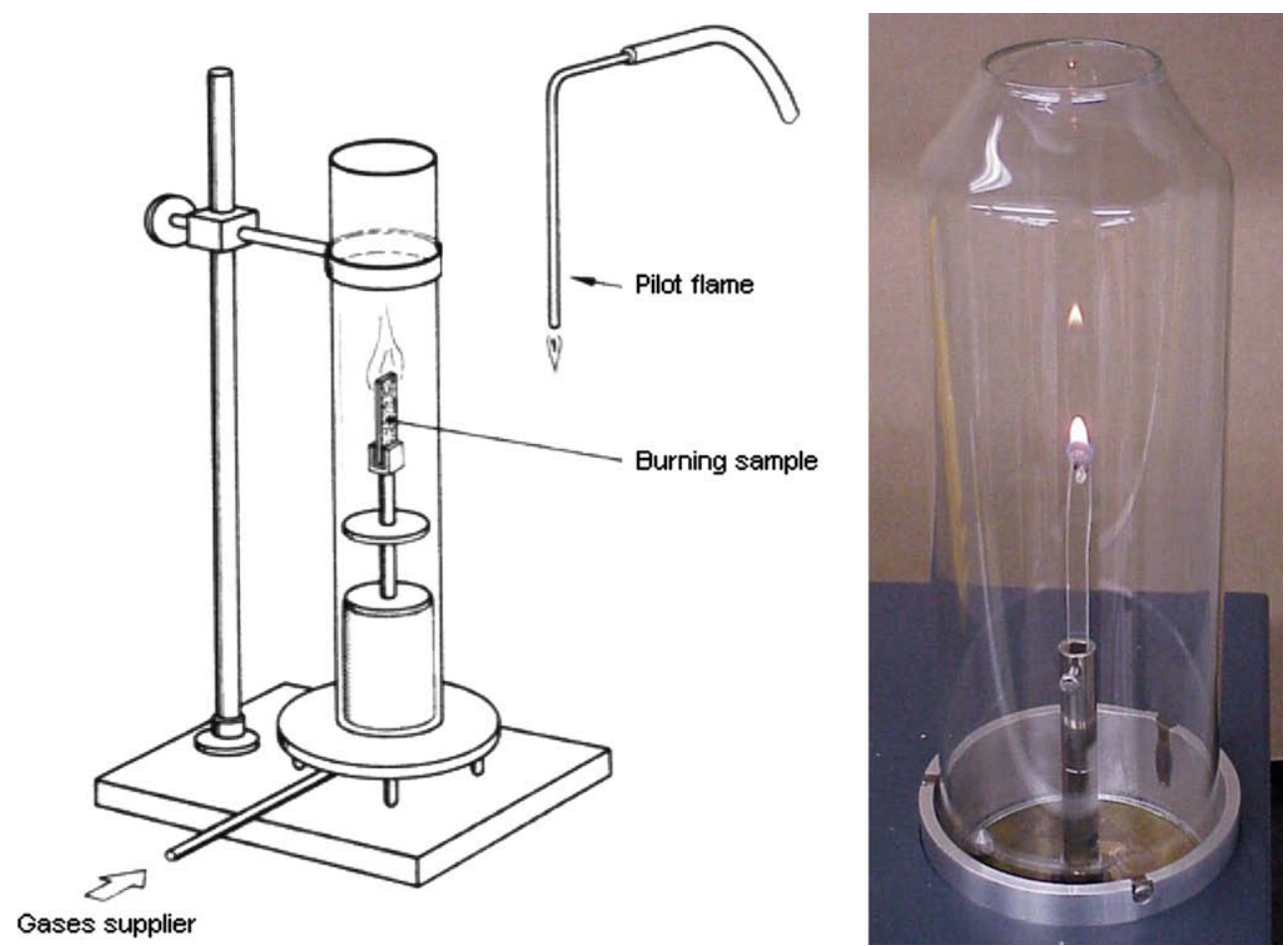

Fig. 24. Installation scheme and a photo of LOI test equipment [118]. 


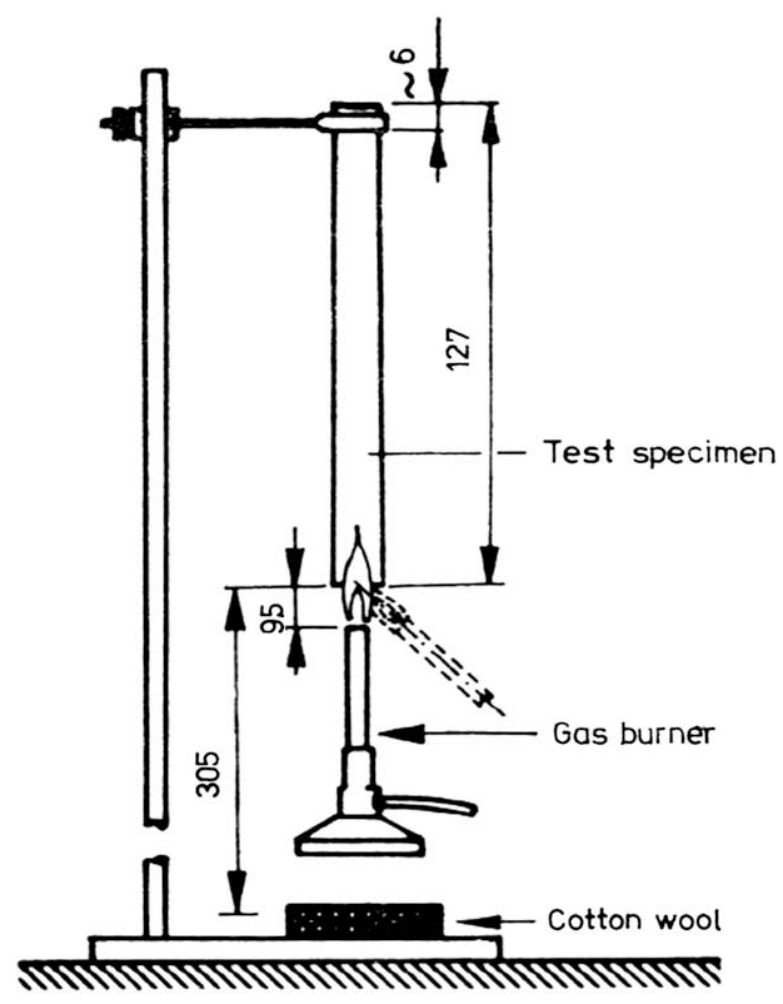

Fig. 25. Installation scheme of UL-94 equipment [121].

LOI, UL-94 and HRR (cone calorimeter) relationship: Hong et al. [122] showed that HRR obtained from the cone calorimeter was more related to UL-94 ratings than LOI. The lower the HRR, the better the UL-94 rating obtained. Still, it seems that more studies are required to clarify the correlation between HRR and UL-94.

\section{References}

[1] Biron M. Silicones or siloxanes applications. Techniques de l'Ingénieur Oct 2007:N2882 (in French).

[2] Dvornic PR. In: Jones RG, Ando W, Chojnowski J, editors. Thermal stability of polysiloxanes: silicone-containing polymers. Dordrecht, the Netherlands: Kluwer Academic Publisher; 2000. p. 185-212.

[3] Buch RR. Rates of heat release and related fire parameters for silicones. Fire Safety 1991;17:1-12.

[4] Hshieh F-Y. Shielding effects of silica-ash layer on the combustion of silicones and their possible applications on the fire retardancy of organic polymers. Fire Mater 1998;22:69-76.

[5] Marosi G, Màrton A, Anna P, Bertalan G, Marosfoi B, Szép A. Ceramic precursor in flame retardant systems. Polym Degrad Stab 2002;77:259-65.

[6] Wen J, Mark J. Mechanical properties and structural characterization of poly(dimethylsiloxane) elastomers reinforced with zeolite fillers. J Mater Sci 1994;29(2):499-503.

[7] Mansouri J, Burford RP, Cheng YB, Hanu L. Formation of strong ceramified ash from silicone-based compositions. J Mater Sci 2005;40:5741-9.

[8] Camino G, Lomakin S, Lazzari M. Polydimethylsiloxane thermal degradation. Part 1. Kinetic aspects. Polymer 2001;42(6):2395-402.

[9] Radhakrishnan TS. New method for evaluation of kinetic parameters and mechanism of degradation from pyrolysis-GC studies: thermal degradation of polydimethylsiloxanes. J Appl Polym Sci 1999;73:441-50.

[10] Grassie N, Macfarlane IG. The thermal degradation of polysiloxane-I poly (dimethylsiloxane). Eur Polym J 1978;14:875-84.

[11] Camino G, Lomakin S, Lageard M. Thermal polydimethylsiloxane degradation. Part 2. The degradation mechanisms. Polymer 2002;43(7):2011-5.

[12] Deshpande G, Rezac ME. The effect of phenyl content on the degradation of poly(dimethyl/diphenylsiloxane) copolymers. Polym Degrad Stab 2001;74:363-70.

[13] Jovanovic JD, Govedarica MN, Dvornic PR, Popovic IG. The thermogravimetric analysis of some polysiloxanes. Polym Degrad Stab 1998;61:87-93.

[14] Grassie N, Francey K. The thermal degradation of polysiloxanes. Part 3. Poly(dimethyl/methyl phenyl siloxane). Polym Degrad Stab 1980;2(1):53-66.

[15] Grassie N, Francey KF, Macfarlane IG. The thermal degradation of PDMS. Part 4: poly(dimethyl/diphenyl siloxane). Polym Degrad Stab 1980;2(1):67-83.
[16] Connell JE, Metcalfe E, Thomas MJK. Silicate-siloxane fire retardant composites. Polym Int 2000;49:1092-4.

[17] Hayashida K, Tsuge S, Ohtani H. Flame retardant mechanism of polydimethylsiloxane material containing platinum compound studied by analytical pyrolysis techniques and alkaline hydrolysis gas chromatography. Polymer 2003;44:5611-6.

[18] Lagarde R, Lahaye J, Bargain M. Mecanisme d'ignifugation d'élastomères organosiliciques par le platine. Eur Polym J 1977;13:769.

[19] Smith SB. Method of preparing fire retardant siloxane foams and foams prepared therefrom, US Patent 3,923,705; 1975.

[20] Fujiki H, Tanaka M. Silicone coated base material and air bag base material, European Patent 0,669,419; 1995.

[21] Hatanaka M, Mahekawa R, Maruyama H. Flame retardant silicone rubber compositions, US Patent 3,862,082; 1975.

[22] Schroeder RM, Tselepis AJ, Wolf ATF. Sprayable silicone emulsions which form elastomers having smoke and fire resistant properties, European Patent $0,839,853 ; 1998$.

[23] Ota K, Hirai K. Flame retardant silicone rubber composition for coating electrical wire and cable, US Patent 6,011,105; 1998.

[24] Gun'ko VM, Borysenko MV, Pissis P, Spanoudaki A, Shinyashiki N, Sulim IY, et al. Polydimethylsiloxane at the interfaces of fumed silica and zirconia/ fumed silica. Appl Surf Sci 2007;253:7143-56.

[25] Anon, Composition organopolysiloxaniques, French Patent 2,166,313; 1972.

[26] Dubois R, Pouchelon A, Pusineri C. Utilisation de mélanges à base de Pt et de composé de métaux de transition autres que le Pt pour améliorer les propriétés de résistance à l'arc des élastomères silicones, World Patent 98,029,488; 1998.

[27] Alexandre M, Dubois P, Devalckenaere M, Claes M. Fireproof composition. World Patent 2007,048,208; 2007.

[28] Hancock M. In: Rothon R, editor. Filled thermoplastic: particulate-filled polymer composites. New York, USA: Longman Scientific and Technical; 2003. p. 279-316

[29] Harper CA. Modern plastics handbook. Maryland, USA: McGraw Hill; 1999. pp. $4.26-4.36$

[30] Hornsby PR, Rothon RN. In: Le Bras M, Wilkie CA, Bourbigot S, Duquesne S, Jama $C$, editors. Fire retardant fillers for polymers: fire retardancy of polymers: new applications of mineral fillers. Cambridge, United Kingdom: RSC; 2005. p. 19-41.

[31] Osman MA, Atallah A, Kahr G, Suter UW. Reinforcement of poly(dimethylsiloxane) networks by montmorillonite platelets. J Appl Polym Sci 2002;83:2175-83.

[32] Clerc L, Ferry L, Leroy E, Lopez-Cuesta J-M. Influence of talc physical properties on the fire retarding behaviour of (ethylene-vinyl acetate copolymer/ magnesium hydroxide/talc) composites. Polym Degrad Stab 2005;88:504-11.

[33] Szép A, Szabo A, Tòth N N, Anna P, Marosi G. Role of montmorillonite in flame retardancy of ethylene-vinyl acetate copolymer. Polym Degrad Stab 2006;91:593-9.

[34] Demir MM, Menceloglu YZ, Erman B. Effect of filler amount on thermoelastic properties of poly(dimethylsiloxane) networks. Polymer 2005:46:4127-34.

[35] Arrighi V, Higgins JS, Burgess AN, Floudas G. Local dynamics of poly(dimethyl siloxane) in the presence of reinforcing filler particles. Polymer 1998;39:6369-76.

[36] Yuan QW, Mark JE. Reinforcement of PDMS networks by blended and in-situ generated silica fillers having various sizes, size distributions, and modified surfaces. Macromol Chem Phys 1999;200:206-20.

[37] Kozakiewicz J, Huang SJ. The effects of filler surface modifications on the properties of poly(dimethyl siloxane) elastomers. Org Coat Plast Chem 1981;44:343-6.

[38] Kashiwagi T, Gilman JW, Butler KM, Harris RH, Shields JR, Asano A. Flame retardant mechanism of silica gel/silicas. Fire Mater 2000;24:277-89.

[39] Tanahashi M, Hirose M, Lee J-C, Takeda K. Organic-inorganic nanocomposites prepared by mechanical smashing of agglomerated silica ultrafine particles in molten thermoplastic resin. Polym Adv Technol 2006;17:981-90.

[40] Liu Y-L, Li S-H. Poly(dimethylsiloxane) star polymers having nanosized silica cores. Macromol Rapid Commun 2004;25:1392-5.

[41] Briggs CC. In: Pritchard G, editor. Calcium carbonate: plastics additives: an A$Z$ reference. London: Chapman \& Hall; 1998. p. 148-52.

[42] Deodhar S, Shanmuganathan K, Patra P, Fan Q, Calvert P, Warner S, et-al, Polypropylene based novel flame retardant nanocomposite compositions. In: Technical Papers in Composites 2006 Convention and Trade Show American Composite Manufacturers Association. St Louis, MO USA; October 18-20, 2006.

[43] Xu X, Tao X, Gao C, Zheng Q. Studies on the steady and dynamic rheological properties of poly(dimethyl-siloxane) filled with calcium carbonate based on superposition of its relative functions. J Appl Polym Sci 2008;107:1590-7.

[44] Hermansson A, Hjertberg T, Sultan B-A. The flame retardant mechanism of polyolefins modified with chalk and silicone elastomer. Fire Mater 2003:27:51-70.

[45] Pritchard G. Fillers. In: Pritchard G, editor. Plastics additives: an A-Z reference. United Kingdom: Chaall; 1998. p. 241-51.

[46] Park ES. Mechanical properties and processibilty of glass-fiber, wollastonite, and fluoro rubber reinforced silicone rubber composites. J Appl Polym Sci 2007; 105:460-8.

[47] Nicholson WR, Rapson L, Shephard K. Flame retardant silicone foams, US Patent 6,084,002; 2000

[48] Shephard KL. Flame resistant silicone rubber wire and cable coating composition, US Patent 6,239,378; 2001. 
[49] George C, Pouchelon A, Thiria R. Composition polyorganosiloxanes vulcanisables à chaud utilisable notamment pour la fabrication de fils ou câbles électriques, French Patent 2,899,905; 2006.

[50] Briggs CC. In: Pritchard G, editor. Mica: plastics additives: an A-Z reference. London: Chapman \& Hall; 1998. p. 459-63.

[51] Osman MA, Atallah A, Müller M, Suter UW. Reinforcement of poly (dimethylsiloxane) networks by mica flakes. Polymer 2001;42:6545-56.

[52] Hanu LG, Simon GP, Mansouri J, Burford RP, Cheng YB. Development of polymer-ceramic composites for improved fire resistance. J Mater Process Technol 2004;153-154:401-7.

[53] Hanu LG, Simon GP, Cheng YB. Preferential orientation of muscovite in ceramifiable silicone composites. Mater Sci Eng A 2005;398:180-7.

[54] Mansouri J, Burford RP, Cheng YB. Pyrolysis behaviour of silicone-based ceramifying composites. Mater Sci Eng A 2006;425:7-14.

[55] Ariagno D, Barruel P, Viale A. Heat-vulcanisable organopolysiloxanes, intended for coating of electrical cables, European Patent 0,467,800; 1992.

[56] Branlard P, George C, Leuci C. Polyorganosiloxane compositions vulcanisable by hot process useful in particular for making electric wires or cables, European Patent 1,238,007; 2003.

[57] Alexander G, Cheng Y, Burford R, Shanks R, Mansouri J, Hodzic A, et al. Fire resistant silicone polymer compositions, World Patent 2004,013,255; 2004.

[58] Hanu LG, Simon GP, Cheng YB. Thermal stability and flammability of silicone polymer composites. Polym Degrad Stab 2006;91:1373-9.

[59] Mansouri J, Wood A, Roberts K, Cheng Y-B, Burford RP. Investigation of the ceramifying process of modified silicone-silicate compositions. J Mater Sci 2007;42:6046-55.

[60] Henrist C, Rulmont A, Cloots R, Gilbert B, Bernard A, Beyer G. Toward the understanding of the thermal degradation of commercially available fireresistant cable. Mater Lett 2000;46:160-8.

[61] Genovese A, Shanks RA. Fire performance of poly(dimethyl siloxane) composites evaluated by cone calorimetry. Compos Part A Appl Sci Manuf 2008;39(2):398-405.

[62] Lynch TJ, Chen T, Riley D. Advances in ATH benefit composite products. Reinforc Plast 2003;9:44-6.

[63] Troitzsch HJ. In: Gachter R, Muller H, editors. Flame retardants: plastics additives. Cincinnati: Hanser Publisher; 1993. p. 709-48.

[64] Horn WE. In: Grand DAF, Wilkie CA, editors. Inorganic hydroxycarbonates: their function and use as flame retardant additives: fire retardancy of polymeric materials. USA: CRC Press; 2000. p. 285-352.

[65] Lewin M. In: Le Bras M, Camino G, Bourbigot S, Delobel R, editors. Fire retardancy of polymeric materials: strategies: fire retardancy of polymeric materials: the use of intumescence. London: The Royal Society of Chemistry; 1999. p.1-32.

[66] Hiremath S, Roy S. Aluminium trihydrate (ATH)-a versatile material. Bhel J 2007:28:12-9.

[67] Miyata S. Composite metal hydroxide and its use, US Patent 5,401,442; 1995

[68] Toporcer LH, Dibling MR. Flame retardant elastomeric composition, US Patent 5,260,372; 1993

[69] Tkaczyk JE, Klug FJ, Amarasekera J, Sumpter CA. Silicone composition with improved high temperature tolerance, US Patent 6,051,642; 2000.

[70] Sweet R, Gallmeyer JH. A silicone composition useful in flame retardant applications, World Patent 2004,063,280; 2004.

[71] Gilman JW, Jackson CL, Morgan AB, Richard Jr H. Flammability properties of polymer-layered-silicate nanocomposites: polypropylene and polystyrene nanocomposites. Chem Mater 2000;12(7):1866-73.

[72] Leszczyńska A, Njuguna J, Pielichowski K, Banerjee JR. Polymer/montmorillonite nanocomposites with improved thermal properties. Part I: factors influencing thermal stability and mechanisms of thermal stability improvement. Thermochim Acta 2007:453:75-96.

[73] Burnside SD, Giannelis EP. Synthesis and properties of new poly (dimethylsiloxane) nanocomposites. Chem Mater 1995;7(9):1597-600.

[74] Burnside SD, Giannelis EP. Nanostructure and properties of polysiloxane-layered silicate nanocomposites. Polym Sci Part B: Polym Phys 2000;38:1595-604.

[75] Ma J, Xu J, Ren J-H, Yu Z-Z, Mai Y-W. A new approach to polymer/montmorillonite nanocomposites. Polymer 2003;44:4619-24.

[76] Wang SJ, Long C, Wang X, Li O, Oi Z. Synthesis and properties of silicone rubber/organomontmorillonite hybrid nanocomposites. J Appl Polym Sci 1998;69:1557-61.

[77] Yang L, Hu Y, Lu H, Song L. Morphology, thermal, and mechanical properties of flame-retardant silicone rubber/montmorillonite nanocomposites. J Appl Polym Sci 2006;99:3275-80.

[78] Pape PG, Romenesko DJ. The role of silicone powders in reducing the heat release rate and evolution of smoke in flame retardant thermoplastics. J Vinyl Addit Technol 1997;3:225-32.

[79] Iji M, Serizawa S. Silicone derivatives as new flame retardants for aromatic thermoplastics used in electronic devices. Polym Adv Technol 1998;9:593-600.

[80] Nodera A, Kanai T. Flame retardancy of a polycarbonate-polydimethylsiloxane block copolymer: the effect of the dimethylsiloxane block size. J Appl Polym Sci 2006;100:565-75.

[81] Nodera A, Kanai T. Flame retardancy of polycarbonate-polydimethylsiloxane block copolymer/silica nanocomposites. J Appl Polym Sci 2006;101:3862-8.

[82] Yasuhiro H, Kazuhiko I. Polycarbonate resin composition and its molded articles, US Patent 6,664,313; 2003

[83] Barren JP, Chen FF-S, Osborn AJ. Polycarbonate resin blends containing titanium dioxide, US Patent 6,133,360; 2000.
[84] Lupinski JH, Howkins CM. Flame retardant polycarbonate compositions, US Patent 5,153,251; 1992

[85] Zhong H, Wu D, Wei P, Jiang P, Li Q, Hao J. Synthesis, characteristic of a nove additive-type flame retardant containing silicon and its application in PC/ABS alloy. J Mater Sci 2007;42(24):10106-12.

[86] Zhong H, Wei P, Jiang P, Wang G. Thermal degradation behaviors and flame retardancy of PC/ABS with novel silicon-containing flame retardant. Fire Mater 2007;31:411-23.

[87] Zhong H, Wei P, Jiang P, Wu D, Wang G. Synthesis and characteristics of a novel silicon-containing flame retardant and its application in poly[2,2 propane-(bisphenol) carbonate]/acrylonitrile butadiene styrene. J Polym Sci Part B Polym Phys 2007;45:1542-51.

[88] Davidson NS, Wilkinson K. Flame retardant polymer composition, European Patent 0,393,959; 1990

[89] Krämer RH, Blomqvist P, Hees PV, Gedde UW. On the intumescence of ethylene-acrylate copolymers blended with chalk and silicone. Polym Degrad Stab 2007:92:1899-910.

[90] Hermansson A, Hjertberg T, Sultan B-A. Linking the flame-retardant mechanisms of an ethylene-acrylate copolymer, chalk and silicone elastomer system with its intumescent behaviour. Fire Mater 2005;29:407-23.

[91] Lipatov YS. Polymer reinforcement. Canada: ChemTech Publishing; 1995. pp. 361-389.

[92] Hermansson A, Hjertberg T, Sultan B-A. Distribution of calcium carbonate and silicone elastomer in a flame retardant system based on ethyleneacrylate copolymer, chalk and silicone elastomer and its effect on flame retardant properties. J Appl Polym Sci 2006;100:2085-95

[93] Sultan B-A, Hermansson A, Hjertberg T. Flame retardant polymer composition, European Patent 1,316,581; 2003.

[94] Huhtala J, Motha K. Flame retardant polymer composition comprising nanofillers, European Patent 1,512,718; 2005.

[95] Krämer RH, Raza MA, Gedde UW. Degradation of poly(ethylene-co-methacrylic acid)-calcium carbonate nanocomposites. Polym Degrad Stab 2007;92 (10):1795-802.

[96] Santra RN, Mukunda PG, Nando GB, Chaki TK. Thermogravimetric studies on miscible blends of ethylene-methyl acrylate copolymer (EMA) and polydimethylsiloxane rubber (PDMS). Thermochim Acta 1993;219:283-92.

[97] McNeill IC, Mohammed MH. Thermal analysis of blends of low density polyethylene, poly(ethyl acrylate) and ethylene ethyl acrylate copolymer with polydimethylsiloxane. Polym Degrad Stab 1995;50(3):285-95.

[98] Santra RN, Samantaray BK, Bhowmick AK, Nando GB. In situ compatibilization of low-density polyethylene and polydimethylsiloxane rubber blends using ethylene-methyl acrylate copolymer as a chemical compatibilizer. J Appl Polym Sci 1993;49(7):1145-58.

[99] Jana RN, Nando GB. Thermogravimetric analysis of blends of low-density polyethylene and poly(dimethyl siloxane) rubber: the effects of compatibilizers. J Appl Polym Sci 2003;90(3):635-42.

[100] Jana RN, Mukunda PG, Nando GB. Thermogravimetric analysis of compatibilized blends of low density polyethylene and poly(dimethyl siloxane) rubber. Polym Degrad Stab 2003;80(1):75-82.

[101] Li Q Jiang P, Wei P. Synthesis, characteristic, and application of new flame retardant containing phosphorus, nitrogen, and silicon. Polym Eng Sci 2006; 46:344-50.

[102] Li Q Jiang P, Su Z, Wei P, Wang G, Tang X. Synergistic effect of phosphorus, nitrogen, and silicon on flame-retardant properties and char yield in polypropylene. J Appl Polym Sci 2005;96:854-60.

103] Romenesco DJ, Shepard KL. Fire resistant thermoplastic silicone vulcanizates, World Patent 2000,046,291; 2000.

[104] Zulfiqar S, Ahmad S. Thermal degradation of blends of PVAC with polysiloxane - II. Polym Degrad Stab 2001;71(2):299-304.

[105] Andreasson U, Fagrell O, Sultan BA. Flame retardant polymer composition, European Patent 1,396,865; 2004

[106] Lomakin SM, Koverzanova EV, Shilkina NG, Usachev SV, Zaikov GE. Therma degradation of polystyrene-polydimethylsiloxane blends. Russ J Appl Chem 2003;76(3):472-82.

[107] McNeill IC, Basan S. Thermal degradation of blends of PVC with polydimethylsiloxane. Polym Degrad Stab 1993;39(2):139-44.

[108] Zulfiqar S, Ahmad S. Thermal degradation of blends of PVC with polysiloxane - I. Polym Degrad Stab 1999;65:243-7.

[109] Belva F, Bourbigot S, Duquesne S, Jama C, Le Bras M, Pelegris C, et al. Heat and fire resistance of polyurethane-polydimethylsiloxane hybrid material. Polym Adv Technol 2006;17:304-11.

110] Santra RN, Roy S, Tikku VK, Nando GB. In situ compatibilization of thermoplastic polyurethane and polydimethyl siloxane rubber by using ethylene methyl acrylate copolymer as a reactive polymeric compatibilizer. Adv Polym Technol 1995;14(1):59-66.

111] Dong W, Zhang X, Liu Y, Wang $\mathrm{Q}$ Gui $\mathrm{H}$, Gao J, et al. Flame retardant nanocomposites of polyamide 6/clay/silicone rubber with high toughness and good flowability. Polymer 2006;47:6874-9.

112] Liu YL, Chou C-I. The effect of silicon sources on the mechanism of phos phorus-silicon synergism of flame retardation of epoxy resins. Polym Degrad Stab 2005;90:515-22.

[113] Hsiue GH, Liu Y-L, Tsiao J. Phosphorus-containing epoxy resins for flame retardancy V: synergistic effect of phosphorus-silicon on flame retardancy. J Appl Polym Sci 2000;78:1-7. 
[114] Kashiwagi T, Gilman JW. Silicon based flame retardants. In: Grand AF, Wilkie CA, editors. Fire retardancy of polymeric materials, vol. 10. New York: Marcel Dekker Inc.; 2000. p. 353-89.

[115] Morgan AB, Bundy M. Cone calorimeter analysis of UL-94 V-rated plastics. Fire Mater 2007;31:257-83.

[116] International Organization for Standardization. Fire tests. Reaction to fire. Part 1: rate of heat release from building products (cone calorimeter method), vol. 5660-1. Geneva: ISO; 1993(E).

[117] Schartel1 B, Hull TR. Development of fire-retarded materials - interpretation of cone calorimeter data. Fire Mater 2007;31:327-54.

[118] Becker W, Rupprecht H, Troitzsch J. In: Troitzsch J, editor. Building: international plastics flammability handbook. Munich: Hanser Publishers; 1990. p. 93-284.
[119] Limiting Oxygen Index (LOI): ASTM D2863-97. Standard test method for measuring the minimum oxygen concentration to support candle-like combustion of plastics (Oxygen Index).

[120] http://www.ul.com/plastics/flame.html

[121] Kaufmann W, Prager FH, Schiffer HW. In: Troitzsch J, editor. Electrical engineering: international plastics flammability Handbook. Munich: Hanser Publishers; 1990. p. 344-78.

[122] Hong S, Yang J, Ahn S, Mun Y, Lee G. Flame retardancy performance of various UL94 classified materials exposed to external ignition sources. Fire Mater 2004;28:25-31.

[123] Weil ED, Hirschler MM, Patel NG, Said MM, Shakir S. Oxygen index: correlations to other fire tests. Fire Mater 1992;16:159-67.

[124] Lyon R. Fire and Flammability. Personal communication in symposium on Fire Safe Electronics, 2003. 